\title{
A Review of Stored Energy Release of Irradiated Graphite
}

\section{September 2011}

Prepared by

N. C. Gallego

T. D. Burchell

Approved for public release; distribution is unlimited.

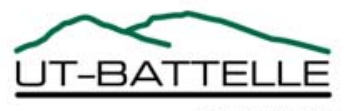




\section{DOCUMENT AVAILABILITY}

Reports produced after January 1, 1996, are generally available free via the U.S. Department of Energy (DOE) Information Bridge.

Web site http://www.osti.gov/bridge

Reports produced before January 1, 1996, may be purchased by members of the public from the following source.

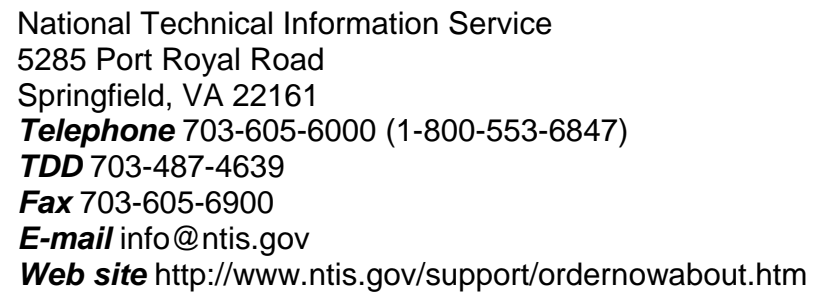

Reports are available to DOE employees, DOE contractors, Energy Technology Data Exchange (ETDE) representatives, and International Nuclear Information System (INIS) representatives from the following source.

Office of Scientific and Technical Information

P.O. Box 62

Oak Ridge, TN 37831

Telephone 865-576-8401

Fax 865-576-5728

E-mail reports@osti.gov

Web site http://www.osti.gov/contact.html

This report was prepared as an account of work sponsored by an agency of the United States Government. Neither the United States Government nor any agency thereof, nor any of their employees, makes any warranty, express or implied, or assumes any legal liability or responsibility for the accuracy, completeness, or usefulness of any information, apparatus, product, or process disclosed, or represents that its use would not infringe privately owned rights. Reference herein to any specific commercial product, process, or service by trade name, trademark, manufacturer, or otherwise, does not necessarily constitute or imply its endorsement, recommendation, or favoring by the United States Government or any agency thereof. The views and opinions of authors expressed herein do not necessarily state or reflect those of the United States Government or any agency thereof. 


\title{
A Review of Stored Energy Release of Irradiated Graphite
}

\author{
N. C. Gallego \\ T. D. Burchell
}

Manuscript Completed: April 2011

Date Published: September 2011

\author{
Prepared for \\ Division of Engineering \\ Office of Nuclear Regulatory Research \\ U.S. NUCLEAR REGULATORY COMMISSION \\ Washington, DC 20555 \\ NRC Job Code V6210 \\ Prepared by \\ OAK RIDGE NATIONAL LABORATORY \\ Oak Ridge, Tennessee 37831-6283 \\ managed by \\ UT-BATTELLE, LLC \\ for the \\ U.S. DEPARTMENT OF ENERGY \\ under contract DE-AC05-00OR22725
}


This page is intentionally left blank. 


\section{Contents}

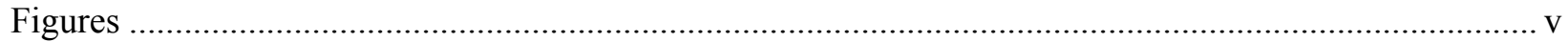

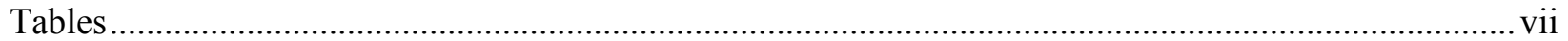

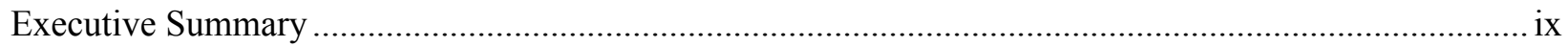

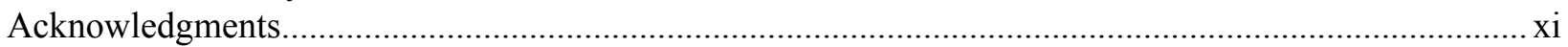

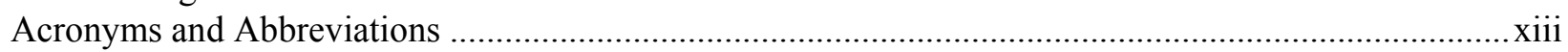

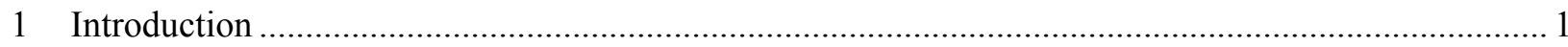

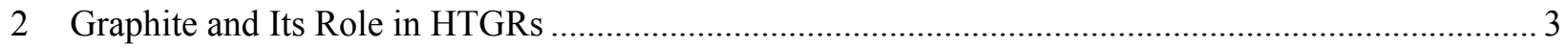

3 Irradiation-Induced Damage in Graphite

3.1 Effect of neutron irradiation on graphite properties ........................................................... 6

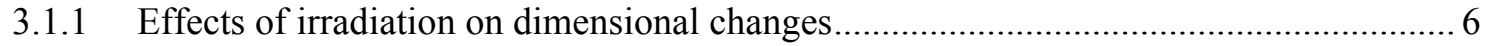

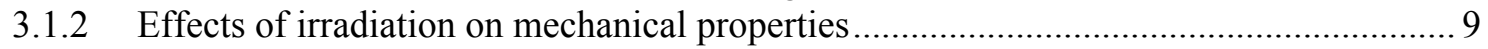

3.1.3 Effects of irradiation on thermal conductivity ........................................................ 10

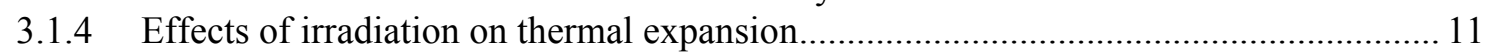

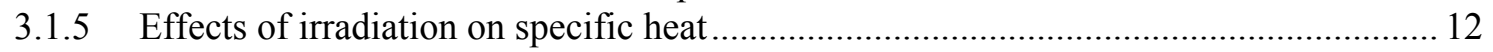

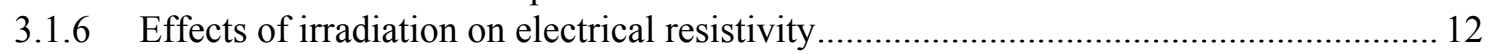

3.2 Theory of displacement damage due to neutron irradiation ................................................. 12

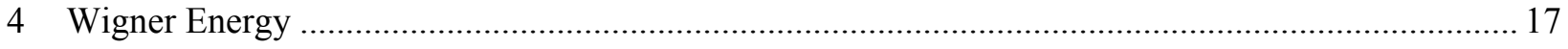

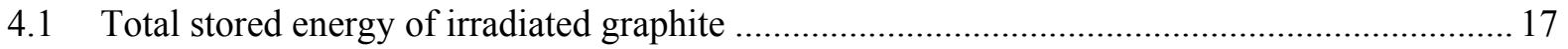

4.2 Rate of release of stored energy of irradiated graphite ......................................................... 19

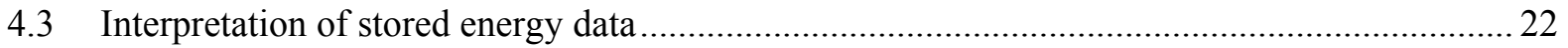

4.3.1 Effects of irradiation dose at low irradiation temperatures........................................... 22

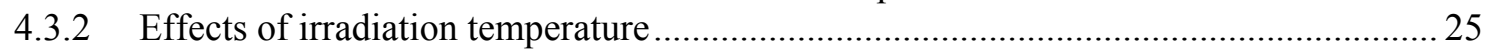

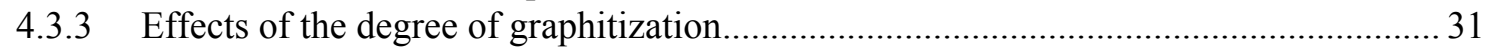

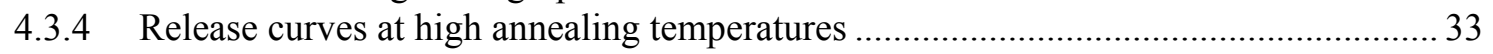

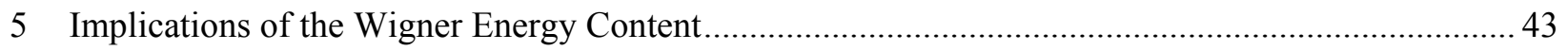

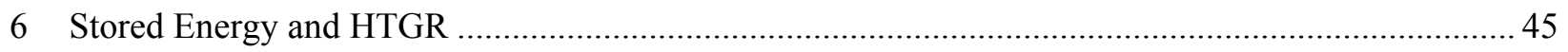

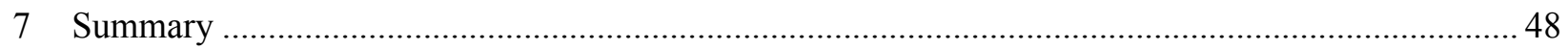

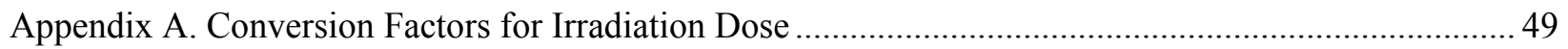

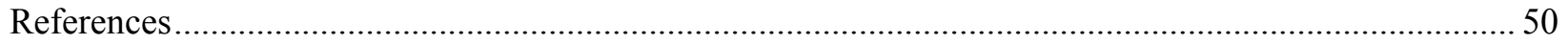


This page is intentionally left blank. 


\section{Figures}

1. SC-MHR reactor system cutaway showing graphite core components .......................................... 4

2. Schematic of lattice defects introduced by radiation in graphite ................................................... 7

3. Neutron irradiation-induced a-axis shrinkage behavior of pyrolytic graphite showing the effects of graphitization temperature on the magnitude of the dimensional changes ......................... 8

4. Irradiation-induced volume changes for H-451 graphite at two irradiation temperatures ................... 9

5. Dimensional change behavior of $\mathrm{H}-451$ graphite at an irradiation temperature of $600{ }^{\circ} \mathrm{C}$ and $900{ }^{\circ} \mathrm{C}$

6. Neutron irradiation-induced Young's modulus changes for GraphNOL N3M at irradiation temperatures 600 and $875^{\circ} \mathrm{C}$

7. Temperature dependence of thermal conductivity in the irradiated and unirradiated condition for typical nuclear grade graphite

8. The irradiation-induced changes in CTE $\left(25-500^{\circ} \mathrm{C}\right)$ for GraphNOL N3M graphite at two irradiation temperatures

9. Sequential HRTEM images illustrating the formation rates of interlayer defects at different temperatures with the same time scale ( 0 to 220 seconds).

10. Normalized formation rate of the clusters of I-V pair defects per unit area of bilayer estimated in HRTEM images recorded at different temperatures

11. Accumulation of total stored energy as a function of dose in graphite at various irradiation temperatures

12. Adiabatic rise curves for a typical high energy sample A, and a typical low energy sample C..........20

13. Rate of release of stored energy, by linear rise of temperature $\left(20^{\circ} \mathrm{C} / \mathrm{min}\right)$; irradiation $\sim 2 \times 10^{20} \mathrm{n} / \mathrm{cm}^{2},(0.04 \mathrm{dpa})$ at $50{ }^{\circ} \mathrm{C}$

14. Stored energy annealing spectra in irradiated graphite; irradiation temperature $30^{\circ} \mathrm{C}$

15. Stored energy release curves for CSF graphite irradiated at $\sim 30^{\circ} \mathrm{C}$ in the Hanford $\mathrm{K}$ reactor cooled test hole.

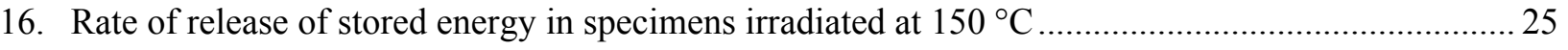

17. Stored energy release curves of CSF graphite exposed to $193 \mathrm{MWd} / \mathrm{AT}(\sim 0.03 \mathrm{dpa})$...................... 26

18. Rates of release of stored energy (measured by linear rise method) for graphites irradiated at 80 and $180^{\circ} \mathrm{C}$.

19. Rates of release of stored energy (measured by linear rise method) for graphites irradiated at temperatures from 30 to $145^{\circ} \mathrm{C}$

20. The effect of irradiation temperature (from 135 to $269^{\circ} \mathrm{C}$ ) on the rate of release of stored energy at equivalent irradiation dose

21. The effect of irradiation temperature on stored energy release curves for exposures around $0.66 \mathrm{dpa}$

22. The effect of irradiation temperature on release of stored energy for graphites irradiated in the G1 reactor

23. Release rate curves for graphite irradiated at $350{ }^{\circ} \mathrm{C}$ (top) and $390{ }^{\circ} \mathrm{C}$ (bottom) 
24. Effect of the irradiation temperature on the stored energy of graphite irradiated at a dose of $\sim 0.04 \mathrm{dpa}$ 30

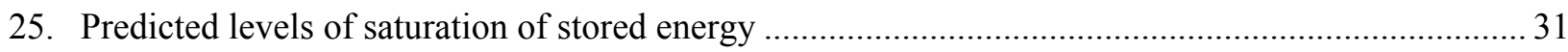

26. Stored energy in special carbons (exposure, $530 \mathrm{MWd}$ /AT or $0.05 \mathrm{dpa}$ ) .......................................... 32

27. Total stored energy and energy release below about $400{ }^{\circ} \mathrm{C}$; irradiation temperature $30{ }^{\circ} \mathrm{C}$

28. Buildup of total stored energy in graphite irradiated at $30^{\circ} \mathrm{C}$ and residual stored energy after annealing at $1000^{\circ} \mathrm{C}$

29. Release curves measured by complete combustion (calorimetry) showing residual stored energy even after annealing at $1000^{\circ} \mathrm{C}$

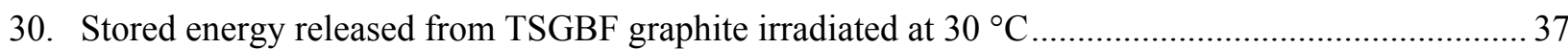

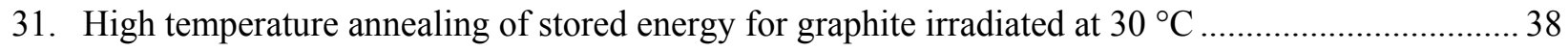

32. Stored energy release behavior for graphite irradiated at $30{ }^{\circ} \mathrm{C}$ and a dose of $3200 \mathrm{MWd} / \mathrm{AT}$ (0.27 dpa), compared with unirradiated graphite $\mathrm{C}_{\mathrm{p}}$ behavior 39

33. Energy release curves for samples irradiated at the BR.2 reactor................................................... 40

34. Release curves for samples irradiated in the G. 1 reactor ..

35. Release curves for graphite samples of various degrees of graphitization, irradiated in the G. 2 reactor

36. Irradiation conditions, dose and temperature, of graphites for which stored energy behavior has been characterized (circles: measurements of total stored energy; diamonds: measurements of release rate); shaded rectangles envelop the operating conditions for both prismatic and pebble-bed type reactors, being considered for the NGNP.... 


\section{Tables}

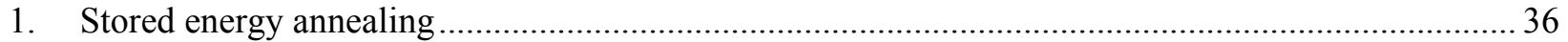

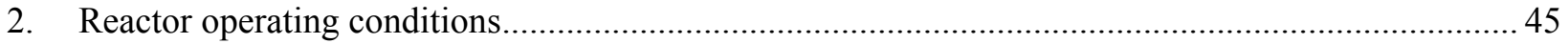


This page is intentionally left blank. 


\section{Executive Summary}

This report summarizes the results from Task 1 of the HTGR Graphite Stored Energy Release Research program. The primary objectives of Task 1 are to conduct a literature review of current knowledge on the subject of the stored energy release of irradiated graphites and to assess such information for relevance to high temperature gas-cooled reactor (HTGR) operations from regulatory safety evaluations.

Background information on graphite and its role in HTGRs, as well as on the effects of neutron irradiation on the properties of graphite along with some theory of displacement damage in graphite, is provided. The concept of stored (Wigner) energy and the various techniques available to measure either the total stored energy in irradiated graphite or the rate of release of stored energy are described, and the available literature on the subject of stored energy of irradiated graphite is reviewed. The literature review found that the bulk of the work on this area was done in the 1950s and 1960s, with very little attention afterwards. Only a few papers and reviews on the subject can be found from the 1980s and 2000s.

The published data indicates that, for a given irradiation temperature, the total stored energy increases with irradiation dose and appears to reach a saturation limit after long exposures; similarly, the rate of accumulation of stored energy and the saturation value decrease with increasing irradiation temperature. These trends, however, are only supported experimentally with data for irradiation temperatures of up to $450{ }^{\circ} \mathrm{C}$ and doses of $<2 \mathrm{dpa}$.

A characteristic release peak at around $200{ }^{\circ} \mathrm{C}$ was found for graphites irradiated a low temperature. This peak shifts to higher temperatures and diminishes in magnitude (to almost undetectable levels), as the irradiation temperature increases. A significant level of uncertainty associated with data from energy release studies (due either to differences in technique or methodology, or to the inherent difficulty of the measurements) makes a direct comparison of the results very difficult and challenging.

Evidence was found to indicate that not all of the stored energy is released even after anneals at temperatures around $1000{ }^{\circ} \mathrm{C}$, and that stored energy remains in the graphite, requiring higher temperatures for annealing. Moreover, there is some indication that a second release peak is possible at temperatures in the range of $1200-1500^{\circ} \mathrm{C}$. However, all of these indications are for graphites irradiated at low temperature, which contains large amounts of stored energy.

In summary, the data discussed in this report suggests that only small amounts of stored energy should accumulate at HTGR-relevant operating temperatures and that if this energy were released at higher annealing temperatures, the rate of release probably would be small. However, there is no experimental data for stored energy release rate at high temperatures from graphite irradiated at HTGR-relevant temperatures $\left(T_{\text {irr }} \sim 250\right.$ $1100^{\circ} \mathrm{C}$ ). Thus acquiring a series of experimental measurements appears prudent. 
This page is intentionally left blank. 


\section{Acknowledgments}

This work is sponsored by the Office of Nuclear Regulatory Research, U.S. Nuclear Regulatory Commission, under Job Code V6210; Program Manager: Dr. Makuteswara Srinivasan. 
This page is intentionally left blank. 


\section{Acronyms and Abbreviations}

ACRS Advisory Committee on Reactor Safeguards

BEPO British Experimental Pile Operation

BNL Brookhaven National Laboratory

CTE coefficient of thermal expansion

DOE U.S. Department of Energy

dpa displacement per atom

DSC differential scanning calorimeter

DTA differential thermal analysis

DWNT double-walled nanotube

FPY full power year

SC-MHR steam cycle modular helium reactor

HOPG highly ordered pyrolytic graphite

HRTEM high resolution transmission electron microscopy

HTGR high temperature gas-cooled reactor

HTR high temperature reactor

HTTR High-Temperature Engineering Test Reactor

I-V interstitial-vacancy

MWd/AT megawatt day per adjacent ton

$\mathrm{MWd} / \mathrm{ATe}$ megawatt day per adjacent ton (equivalent Calder dose)

NGNP Next Generation Nuclear Plant

NRC Nuclear Regulatory Commission

nvt number, volume, temperature

ORNL Oak Ridge National Laboratory

PBMR pebble bed modular reactor

PBR pebble bed reactor

PKA primary knock-on atom

PMR prismatic modular reactor

PRA probabilistic risk assessment

SERS stored energy release study

SKA secondary knock-on atom

STM scanning tunneling microscopy

TEM transmission electron microscopy

UKAEA United Kingdom Atomic Energy Authority

VHTR very high temperature reactor 
This page is intentionally left blank. 


\section{Introduction}

In 2009, Oak Ridge National Laboratory (ORNL) conducted a Nuclear Graphite Workshop, ${ }^{1}$ sponsored by the Nuclear Regulatory Commission (NRC), whose representatives participated along with other invited nuclear graphite specialists to (1) assess our knowledge of graphite behavior in the high temperature gascooled reactor (HTGR) environment, (2) identify technical gaps between the NRC advanced reactor research plan and Department of Energy (DOE) research on the Next Generation Nuclear Plant (NGNP) relevant to graphite core component performance, and (3) recommend research areas that NRC may pursue to provide information and data for establishing technical bases for regulatory decisions. The nuclear graphite expert panel identified research on potential release of stored energy when graphite is heated to higher than its previously irradiated temperature, as might occur in a loss-of-coolant accident, as one of the research topics that NRC should pursue for developing technical bases for regulatory staff positions on potential reheating of graphite core components due to accident conditions.

Prior to the 2009 workshop, Dr. D. A. Powers of the Advisory Committee on Reactor Safeguards (ACRS) had noted in a trip report ${ }^{2}$ that from a regulatory perspective, potentially more dramatic effects of the temperature dependence of radiation damage to graphite need to be further studied for the HTGR. A reasonably good technical background and knowledgebase of the low temperature radiation damage that afflicted the Windscale reactor (the so-called Wigner energy effect) exist. However, there could be modal changes in the type and extent of damage that may not be annealed at the operating temperatures of the HTGR. Like the Wigner energy, these high temperature radiation damage effects could store energy in the graphite. This energy could potentially be released when the graphite component in HTGR is chemically reacted or heated to a sufficiently high temperature. The prevailing consensus is that this is not an issue for high temperature reactors because of possible annealing of the defect energy during operation; thus, as far as we know, this effect is currently ignored in the analyses of plant responses to accidents.

The panel ${ }^{1}$ recommended that NRC should conduct a literature review and develop a white paper corroborating the above. It was also further recommended that NRC should support the experimental verification by conducting differential scanning calorimeter (DSC) experiments up to $1500{ }^{\circ} \mathrm{C}$ on graphite samples irradiated at temperatures relevant to the NGNP designs in order to confirm this understanding.

The regulatory staff needs adequate information on this phenomenon because of the propensity for irradiated graphite to release its energy stored during irradiation after any subsequent heat-up above its previous irradiation temperature-for example, in a loss-of-coolant accident. Even though graphite, by itself, does not burn or promote burning, ${ }^{3}$ it nevertheless undergoes loss of weight due to oxidation, especially at very high temperatures in an oxidative environment. In an accident event that could precipitate the release of stored energy, the temperature of the graphite could potentially increase rapidly and promote additional oxidation. Graphite particles may be transported as dust and provide potential pathways for radionuclides to be transported throughout the reactor coolant system. This is a regulatory safety issue that needs reliable data for safety evaluation and regulatory decision.

The design and licensing approaches for modular HTGRs and the DOE NGNP very high temperature reactor(VHTR) will rely extensively on the results of plant-specific probabilistic risk assessment (PRA). The risk contribution from potential heat release and runaway oxidation reaction during a loss-of-coolant accident

to the overall plant risk is difficult to evaluate because of yet unknown information on potential release of stored energy at very high temperatures for current nuclear-grade NGNP graphite. 
In 2010, NRC sponsored ORNL to conduct the research necessary to establish an improved understanding on one specific safety concern-namely, the potential release of stored energy due to the irradiation of graphite core components of the HTGR envisioned for the NGNP. The objectives of the research are to (1) evaluate current knowledge of the effects on potential accidents of energy stored in previously irradiated nuclear graphite; (2) assess this knowledge with regard to the operational conditions expected for the NGNP HTGR; (3) develop an experimental plan to study the stored energy, including an examination of available options with previously irradiated graphite, such as $\mathrm{H}-451$, which may be available at ORNL; (4) conduct experiments identified in (3); and (5) analyze the data and provide conclusions on whether or not the potential for stored energy release could be a safety issue for the NGNP HTGR. This report is the outcome of objective (1).

The results of this stored energy release study (SERS) will enable NRC staff to determine whether or not potential stored energy release of HTGR graphite after high temperature irradiation is a safety issue for NGNP and, if so, determine to what extent and what type of data and information would be required from a potential design certification applicant. An independent capability to understand the importance of stored energy release and the potential for rapid oxidation and dust release, which can act as a carrier of radionuclides, provides the staff the needed technical expertise to conduct a safety evaluation.

In this report, the role of graphite in HTGRs is summarized, followed by a review of the irradiationinduced damage to graphite. The techniques available to measure either the total stored energy or the release rate of stored energy are then summarized, providing a historical account of the available published data on the subject. These results are put into context for the NGNP, comparing operating conditions. Finally, conclusions are drawn from this survey and analysis. 


\section{Graphite and Its Role in HTGRs}

The Next Generation Nuclear Plant, ${ }^{4}$ NGNP, will be a helium-cooled HTGR with a large graphite core. ${ }^{5,6}$ Graphite physically contains the fuel, acts as the neutron moderator for this thermal reactor, provides a heat sink and passive safety during off-normal (accident) conditions, and comprises the majority of the core volume. The basic technology for inert gas-cooled HTGR design is well established from the early graphite piles of the 1940s to the fully commercial reactor designs operating in the 1980s, such as Fort St. Vrain and Peach Bottom reactors in the United States.

The renewed interest in HTGRs is based primarily on modular design concepts that utilize the unique properties of the technology to ensure retention of radioactive fission products by inherent and passive means. This characteristic offers the promise of an economically competitive electricity generation option at modest unit size, suitable for construction and operation in both industrialized and developing countries. The high temperature capability and smaller unit size also offer the prospect for nonelectrical applications for high temperature process heat.

While increasing interest in modular HTGR designs is a recent development, the concept is not new. Smaller, modular designs have been under development for over 30 years, beginning with a design originating in Germany in 1979. The supporting HTGR technology has been under development for over 50 years, with major programs in the United Kingdom, the United States, and Germany from the 1950s through the early 1990s. Important milestones were achieved in the design and successful operation of HTGRs during the 1960s and 1970s, and in the production and demonstration of robust, high quality fuel and other key elements of the technology.

Two designs of modular HTGR power plants are currently under active development: (1) the Pebble Bed Modular Reactor (PBMR) and (2) the Steam Cycle Modular Helium Reactor (SC-MHR).

The PBMR design comprises a pebble bed core (pebble fuel spheres $6 \mathrm{~cm}$ diameter) and a closed-cycle gas turbine or steam turbine with a thermal power of approximately $260 \mathrm{MWt}$ and net electrical output of approximately $110 \mathrm{MWe}$. The PBMR was under development as a commercial project, advanced by an international design team led by the South African electric utility Eskom (the project unfortunately was cancelled in late $2009^{7}$ ); AREVA is currently performing a PBMR technology readiness assessment. ${ }^{8}$

The SC-MHR design comprises a prismatic core (prismatic hexagonal fuel blocks $\sim 35 \mathrm{~cm}$ wide by $75 \mathrm{~cm}$ high) and a steam cycle design with a thermal power of approximately $350 \mathrm{MWt}$ and net electrical output of approximately $56 \mathrm{MWe}$. The SC-MHR is under development as a combined private/public sector project, and in the United States it is being advanced by an international consortium led by General Atomics. ${ }^{9}$

All HTGR designs utilize keyed (interlocked) graphite blocks to form the core configuration (Figure 1 is a cutaway view of a SC-MHR, which has an annular core). Other than the actual graphite fuel elements, the inner graphite reflector structure is expected to receive the highest operating temperature and dose rate in the reactor core. The primary material issue for these inner and outer reflector blocks is one of long-term irradiation stability, since the expected temperature ranges and applied stress levels are well within the capability limits for graphite. 


\begin{tabular}{|c|c|}
\hline Core Components & Composition \\
\hline Fuel elements & $\begin{array}{l}\text { PCEA reactor-grade } \\
\text { graphite (GrafTech) }\end{array}$ \\
\hline Reflector elements & PCEA graphite \\
\hline $\begin{array}{l}\text { Lower reflector support } \\
\text { structure }\end{array}$ & PCEA graphite \\
\hline Permanent side reflector & $\begin{array}{l}\text { PCEA graphite with } \mathrm{B}_{4} \mathrm{C} \\
\text { steel pins }\end{array}$ \\
\hline Reactivity control material & $\mathrm{B}_{4} \mathrm{C}$ \\
\hline Metallic reactor internals & Alloy $800 \mathrm{H}$ or Alloy X \\
\hline
\end{tabular}

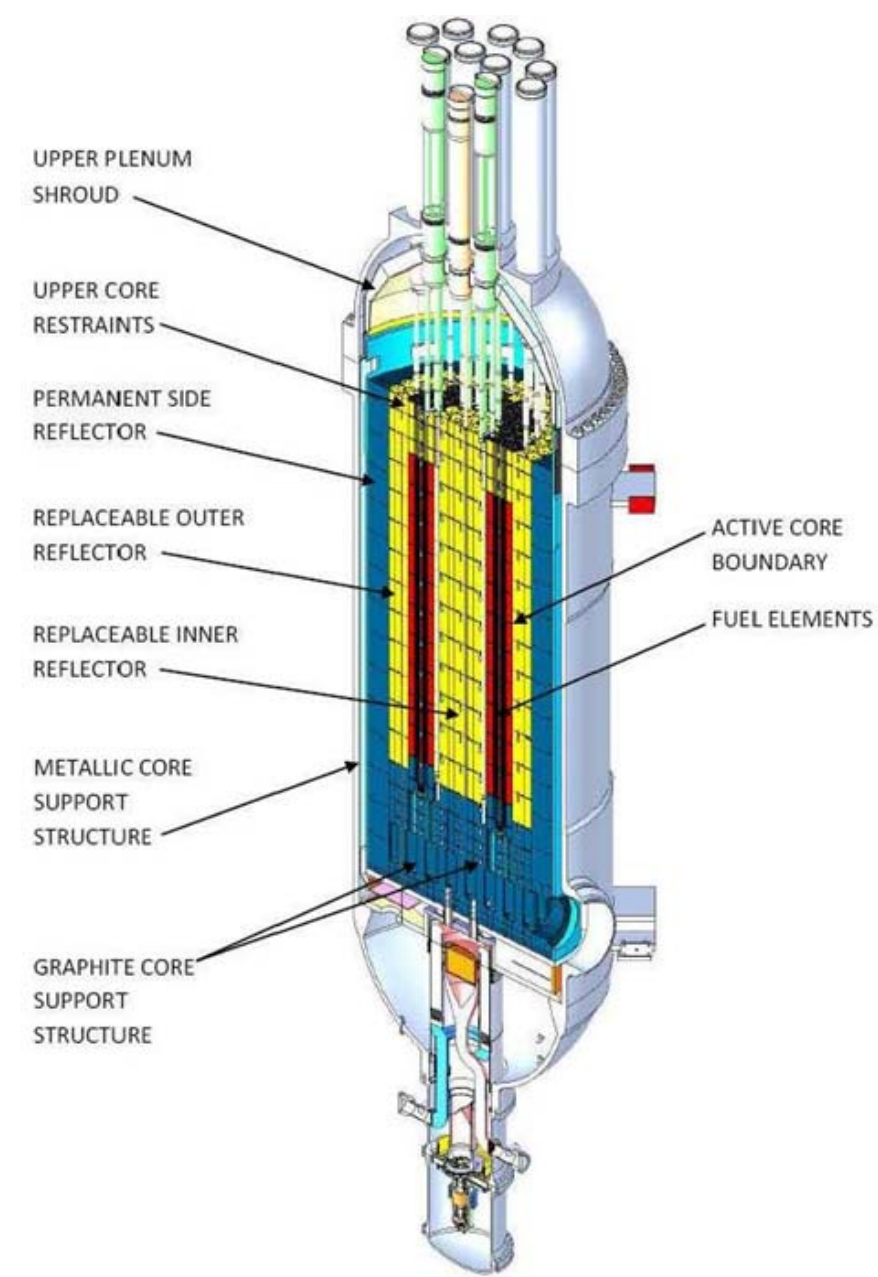

Figure 1. SC-MHR reactor system cutaway showing graphite core components. ${ }^{9}$

The long-term behavior of graphite under the temperature and irradiation conditions representative of the two designs is a complex function of the initial material properties and service conditions, with the pebble bed core experiencing higher cumulative doses and the prismatic core experiencing higher temperatures.

The reflector blocks are the primary structural component of the active core and for the pebble bed design are expected to be replaced at intervals determined by degradation models and inspection results. Over a period of long reactor operation and large cumulative damage dose ( $>5 \mathrm{dpa})$, the physical dimensions of the graphite blocks are expected to change as a result of irradiation-induced dimensional changes (new basal plane formation between existing crystal planes arising from free interstitials created during irradiation) and in-plane shrinkage due to accumulation of basal plane vacancies.

Extensive experience with graphite behavior under irradiation has been obtained through experimental testing as well as from the operation of HTGR plants. In addition, a large body of experience is available from the operation of the carbon dioxide-cooled reactors (Magnox and advanced gas-cooled reactors) developed in the United Kingdom. Important aspects of this experience are documented in the proceedings of International Atomic Energy Agency meetings on the status of graphite development for gas-cooled reactors ${ }^{10}$ and on graphite moderator life-cycle behavior. ${ }^{11}$ The report Irradiation Damage in Graphite due to Fast Neutrons in 
Fission and Fusion Systems ${ }^{12}$ summarizes the vast amount of information that has been accumulated and the understanding that has been gained for the use of those concerned with graphite materials in the future.

No commercial graphite-moderated reactor has been constructed since the 1980s. The last graphite reactors constructed in the United States were the HTGRs Peach Bottom (Pennsylvania) and Fort St. Vrain (Colorado), built in the 1960s and 1970s. Japan ${ }^{13}$ and China ${ }^{14}$ have both constructed experimental (small scale) graphite-moderated high temperature reactors (HTRs). New commercial HTGR designs are being developed in the United States and China. The design and construction of a commercial graphite-moderated HTR, one that can be licensed by the NRC, requires the reestablishment of the nuclear graphite supply chain, including reliable coke sources, experienced graphite manufacturers, and the generation of sufficient graphite properties and environmental effects data to facilitate graphite core design and licensing. The acquisition of these quantitative data is the primary goal of the $\mathrm{NGNP}^{4}$ graphite research and development program. The individual research and development activities ongoing with the NGNP graphite program are described in ORNL/TM-2008/129, ${ }^{5}$ INL/EXT-07-13165, ${ }^{6}$ and PLN-2497. ${ }^{15}$ The activities include the thermal, physical, and mechanical testing programs for the selected graphite types, an irradiated material property (irradiation creep) testing program, microstructural as well as whole-core modeling efforts, and the development of new ASTM test standards deemed necessary for evaluation of properties of graphite components in nuclear applications. 


\section{Irradiation-Induced Damage in Graphite}

Radiation damage to a solid graphite with crystalline microstructure occurs from either ballistic (atomic or subatomic kinetic) collisions or radiological (conversion of radiation-induced electronic excitations to kinetic energy) phenomena. These events can result in significant disruptions to the atomic lattice. Single vacancies and vacancy loops/clusters are left within the basal planes of the crystalline structure, causing the basal planes to collapse or shrink (plane destruction) as further damage accumulates and vacancy clusters grow. The magnitude of the atomic bonding energy governs such disruptions, and the resulting damage is cumulative over time. Generally, ballistic events have higher damage efficiencies per event and provide a limiting case for materials exposed to such an environment (i.e., a high neutron flux in the HTGR core).

The effects of neutron irradiation on graphite are manifested in three areas: physical dimensional changes, thermal properties changes, and mechanical properties changes. ${ }^{15}$ The physical dimensional changes to the graphite microstructure resulting from irradiation are the underlying mechanism for many of the physical and mechanical performance limitations in the graphite reactor core components. Specifically, the phenomenon of irradiation-induced dimensional change creating large internal stresses that can compromise the integrity of the graphite components (the generation of large through-component cracks) is generally considered the life-limiting issue for graphite. The generally excellent thermal conductivity of graphite is critical for protecting the fuel particles during off-normal events as well as for accommodating the thermally induced stress within (reflector blocks). Degradation in thermal properties - conductivity, specific heat, emissivity, and coefficient of thermal expansion-will significantly impact the ability of the graphite to both absorb energy and transfer the heat load out of the core region during an off-normal event. Without adequate removal of the heat, fuel particle centerline temperatures will exceed the design limits, resulting in unacceptable numbers of particle failures and radiation release levels. In addition, thermally induced stresses can be exacerbated between and within graphite blocks with significantly altered thermal properties. Accurate characterization of the mechanical properties is fundamental to determining the induced and applied stresses to the graphite components - specifically, properties such as elastic modulus; compressive and tensile strength; shear strength to predict fracture probability; and multiaxial failure criteria because of the complex stress states, both internal and external, on the components. Reliable measurements of the mechanical properties, along with calculated estimates of the induced internal and external stresses from irradiationinduced physical changes to the graphite, are needed to determine the ability of the graphite component to withstand the imposed loads and service conditions during operation.

\subsection{Effect of neutron irradiation on graphite properties}

Irradiation damage is influenced by a number of factors, including the irradiation temperature and dose, the degree of crystallinity within the microstructure, the distribution of crystallite orientation, and the microdamage within the graphitic microstructure formed during fabrication processes. Of these factors, irradiation temperature is considered to play the most dominant role. Below we summarize these effects on a variety of graphite properties

\subsubsection{Effects of irradiation on dimensional changes}

Because of the anisotropic crystal structure of graphite, the interstitial atoms preferentially diffuse and accumulate in lower energy areas between the basal planes (van der Waals bonds between the covalently bonded basal plane atoms). These mobile groups of interstitial atoms aggregate into larger clusters, physically forcing the basal layer planes apart. The atoms within the clusters eventually rearrange themselves into new basal planes, resulting in the expansion of the graphite crystal in the $c$-axis direction. The concurrent 
contraction in the $a$-axis direction (parallel to the basal planes) occurs from vacancy collapse and plane destruction (Figure 2).

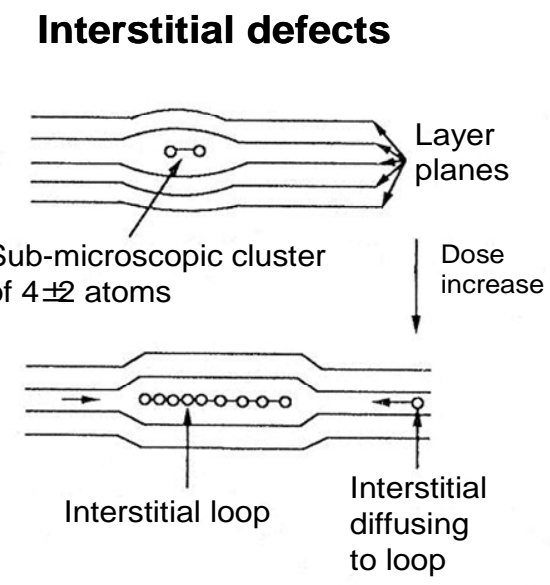

\section{vacancy defects}

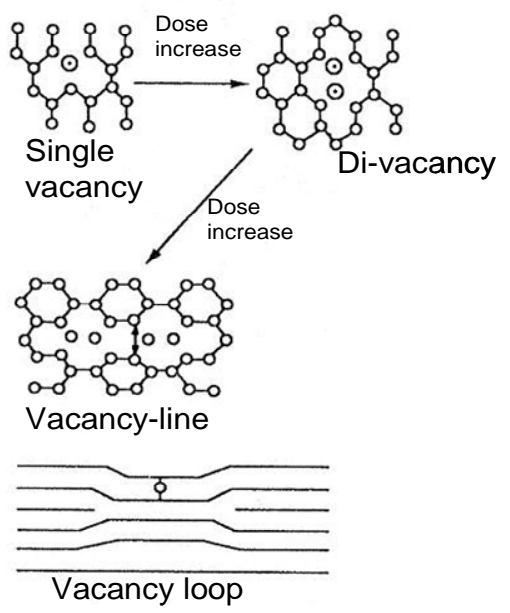

Figure 2. Schematic of lattice defects introduced by radiation in graphite. ${ }^{16}$

Dimensional changes can be very large, as demonstrated in studies on well-ordered graphite materials, such as highly oriented pyrolytic graphite (HOPG), which has frequently been used to study neutron irradiation-induced dimensional changes of graphite crystallite. ${ }^{17,18}$ Price ${ }^{19}$ conducted such a study in pyrolytic graphite. Figure 3 shows the crystallite shrinkage in the $a$-direction for neutron doses up to 12 dpa for samples that were graphitized at a temperature of $2200-3300{ }^{\circ} \mathrm{C}$ prior to being irradiated at 1300 $1500{ }^{\circ} \mathrm{C}$. The $<a>$-axis shrinkage increases linearly with dose for all of the samples, but the magnitude of the shrinkage at any given dose decreases with increasing graphitization temperature. Similar trends were noted for the $<_{c}>$-axis expansion. The significant effect of graphitization temperature on irradiation-induced dimensional change accumulation can be attributed to thermally induced improvements in crystal perfection, thereby reducing the number of defect trapping sites in the lattice. 


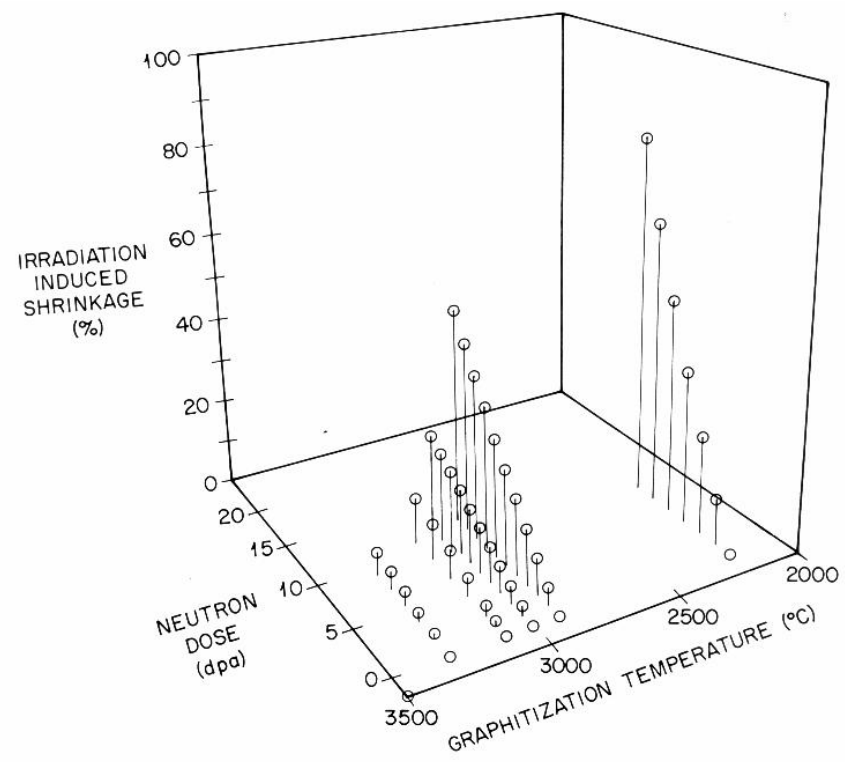

Figure 3. Neutron irradiation-induced a-axis shrinkage behavior of pyrolytic graphite showing the effects of graphitization temperature on the magnitude of the dimensional changes.

Nuclear graphites possess a polycrystalline structure, usually with significant texture resulting from the method of forming during manufacture. Consequently, structural and dimensional changes in polycrystalline graphites are a function of the crystallite dimensional changes and the graphite's texture. In polycrystalline graphite, thermal shrinkage cracks that occur during manufacture and that are preferentially aligned in the crystallographic $\left\langle a>\right.$-direction will initially accommodate the $<_{c}>$-direction expansion, so mainly $<a>$-direction contraction will be observed. The graphite thus undergoes net volume shrinkage. With increasing neutron dose (displacements) the incompatibility of crystallite dimensional changes leads to the generation of new porosity, and the volume shrinkage rate falls, eventually reaching zero. The graphite now begins to swell at an increasing rate with increasing neutron dose. The graphite thus undergoes a volume change "turnaround" into net growth that continues until the generation of cracks and pores in the graphite, due to differential crystal strain, eventually causing total disintegration of the graphite.

Irradiation-induced volume change data for $\mathrm{H}-451$ at two irradiation temperatures are $\operatorname{shown}^{20}$ in Figure 4. It is observed that at a higher irradiation temperature, the turnaround from volume shrinkage to growth occurs at a lower fluence and the magnitude of the volume shrinkage is smaller. This effect is attributed to the thermal closure of aligned microcracks in the graphite which accommodates the $\langle c>$-axis growth. Hence there is less accommodating volume available at the higher temperatures, and the $<c>$-axis growth dominates the $<a>$-axis shrinkage at lower doses. 


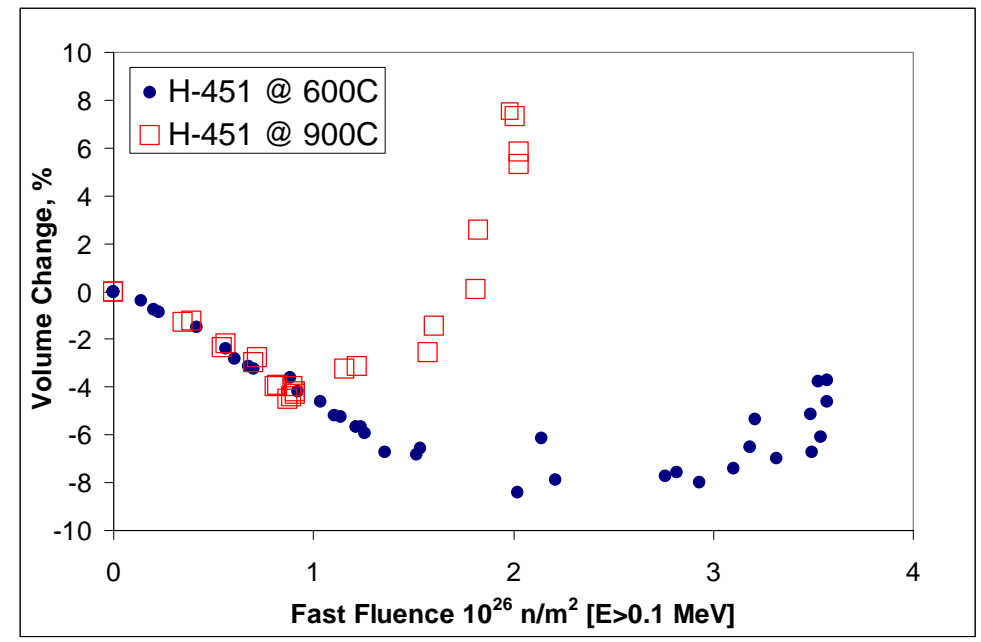

Figure 4. Irradiation-induced volume changes for H-451 graphite at two irradiation temperatures. ${ }^{20}$

The irradiation-induced dimensional changes of H-451 at 600 and $900{ }^{\circ} \mathrm{C}$ are shown in Figure 5. H-451 graphite is an extruded material and thus the filler coke particles, and the crystallographic $<a>$-direction, are preferentially aligned in the extrusion axis (parallel direction); therefore, the $<a>$-direction shrinkage is more apparent in the parallel (to extrusion) direction (Figure 5). The dimensional changes are greater at an irradiation temperature of $600{ }^{\circ} \mathrm{C}$ than at $900{ }^{\circ} \mathrm{C}$ - that is, both the maximum shrinkage and the turnaround dose are greater at an irradiation temperature of $600{ }^{\circ} \mathrm{C}$. This temperature effect can be attributed to the thermal closure of internal porosity aligned parallel to the $a$-direction that accommodates the $\langle c>$-direction swelling. At higher irradiation temperatures a greater fraction of this accommodating porosity is closed, and thus the shrinkage is less at the point of turnaround. A general theory of dimensional change in polygranular graphite due to Simmons ${ }^{21}$ has been extended by Brocklehurst and Kelly, ${ }^{22}$ and reviewed by Kelly and Burchell. ${ }^{23}$
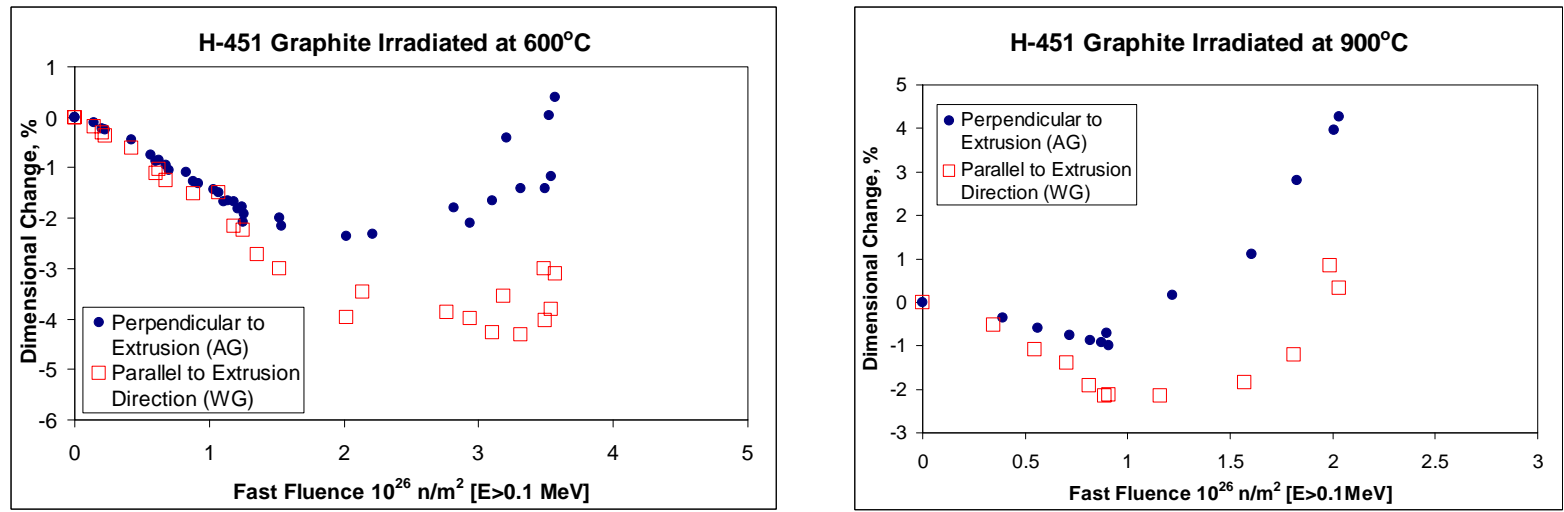

Figure 5. Dimensional change behavior of $H-451$ graphite at an irradiation temperature of $600{ }^{\circ} \mathrm{C}$ and $900{ }^{\circ} C^{20}$

\subsubsection{Effects of irradiation on mechanical properties}

The mechanical properties of nuclear graphites are substantially altered by radiation damage. In the unirradiated condition, nuclear graphites behave in a brittle fashion and fail at relatively low strains. The stress-strain curve is nonlinear, and the fracture process occurs through the formation of subcritical cracks that 
coalesce to produce a critical flaw. ${ }^{24,25}$ When graphite is irradiated the stress-strain curve becomes more linear, the strain to failure is reduced, and the strength and elastic modulus are increased. On irradiation there is a rapid rise in strength, typically $\sim 50 \%$, that is attributed to dislocation pinning at irradiation-induced lattice defect sites. This effect has largely saturated at doses $>1 \mathrm{dpa}$. Above $\sim 1$ dpa a more gradual increase in strength occurs due to structural changes within the graphite. For nuclear graphites the dose at which the maximum strength is attained loosely corresponds with the volume change turnaround dose, indicating the importance of pore closure and generation in controlling the high-dose strength behavior, and may be as much as a factor two higher than the unirradiated value. The irradiation-induced elastic modulus changes for GraphNOL N3M graphite ${ }^{26}$ are shown in Figure 6. The low-dose change due to dislocation pinning (dashed line) saturates at a dose $<1 \mathrm{dpa}$.

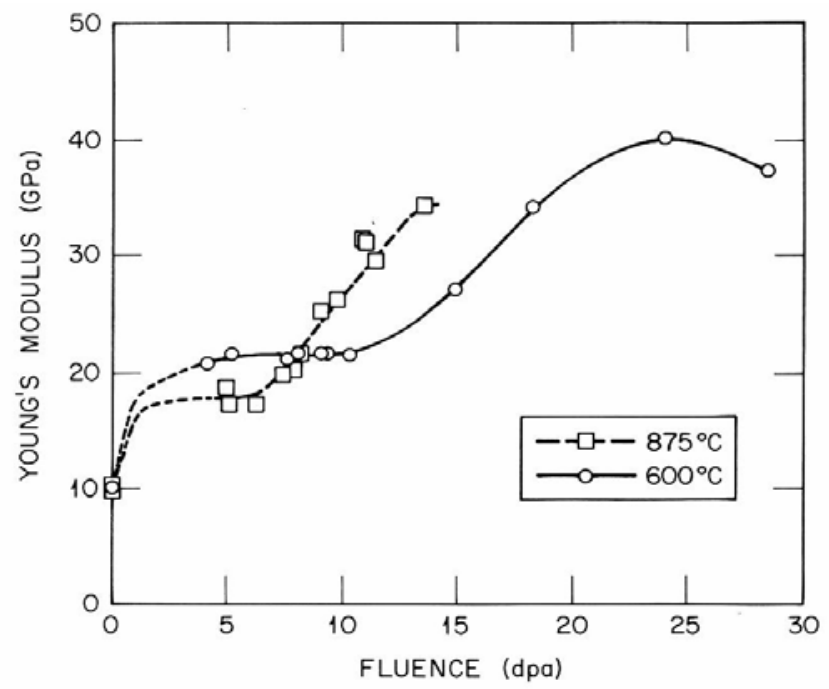

Figure 6. Neutron irradiation-induced Young's modulus changes for GraphNOL N3M at irradiation temperatures 600 and $875{ }^{\circ} C^{26}$

\subsubsection{Effects of irradiation on thermal conductivity}

Graphite is a phonon conductor of heat. Thus any reduction in the intrinsic defect population causes a reduction in the degree of phonon-defect scattering, an increase in the phonon mean free path, and an increase in the thermal conductivity. In graphite such thermally induced improvements are attributable to increases in crystal perfection and a concomitant increase in the size of the regions of coherent ordering upon graphitization. With increasing temperature the dominant phonon interaction becomes phonon-phonon scattering (Umklapp processes). Therefore, there is a reduction of thermal conductivity with increasing temperature. $^{27}$

The mechanism of thermal conductivity and the degradation of thermal conductivity have been reviewed extensively. ${ }^{17,18,28,29}$ The increase of thermal resistance due to irradiation damage has been ascribed by Taylor et al. ${ }^{30}$ to the formation of (1) submicroscopic interstitial clusters, containing $4 \pm 2$ carbon atoms; (2) vacant lattice sites, existing as singles, pairs, or small groups; and (3) vacancy loops, which exist in the graphite crystal basal plane and are too small to have collapsed parallel to the hexagonal axis. The contribution of collapsed lines of vacant lattice sites and interstitial loops to the increased thermal resistance is negligible. 
The reduction in thermal conductivity due to irradiation damage is temperature and dose sensitive. At any irradiation temperature, the decreasing thermal conductivity will reach a "saturation limit." This limit is not exceeded until the graphite undergoes gross structural changes at very high doses. The "saturated" value of conductivity will be attained more rapidly and will be lower, at lower irradiation temperatures. ${ }^{31}$ In graphite, the neutron irradiation-induced degradation of thermal conductivity can be very large, as illustrated in Figure 7. This reduction is particularly large at low temperatures. Bell et al. ${ }^{32}$ have reported that the roomtemperature thermal conductivity of PGA graphite is reduced by more than a factor of 70 when irradiated at $155^{\circ} \mathrm{C}$ to a dose of $\sim 0.6 \mathrm{dpa}$. At an irradiation temperature of $355^{\circ} \mathrm{C}$ the room-temperature thermal conductivity of PGA was reduced by less than a factor of 10 at doses twice that obtained at $155^{\circ} \mathrm{C}$. Above $600{ }^{\circ} \mathrm{C}$ the reduction of thermal conductivity is less significant. For example, Kelly ${ }^{33}$ reported the degradation of PGA at higher temperatures: At an irradiation temperature of $600^{\circ} \mathrm{C}$ and a dose of $\sim 13 \mathrm{dpa}$, the thermal conductivity was degraded by only a factor of $\sim 6$; at irradiation temperatures of $920{ }^{\circ} \mathrm{C}$ and $1150{ }^{\circ} \mathrm{C}$, the degradation was minimal (less than a factor of 4 at $\sim 7 \mathrm{dpa}$ ). For the fine-grained, isomolded graphite shown in Figure 7, the degradation of thermal conductivity at the irradiation temperature $\left(600^{\circ} \mathrm{C}\right)$ was only a factor of $\sim 3$ but was a factor $\sim 6$ at a measurement temperature of $100^{\circ} \mathrm{C}$.

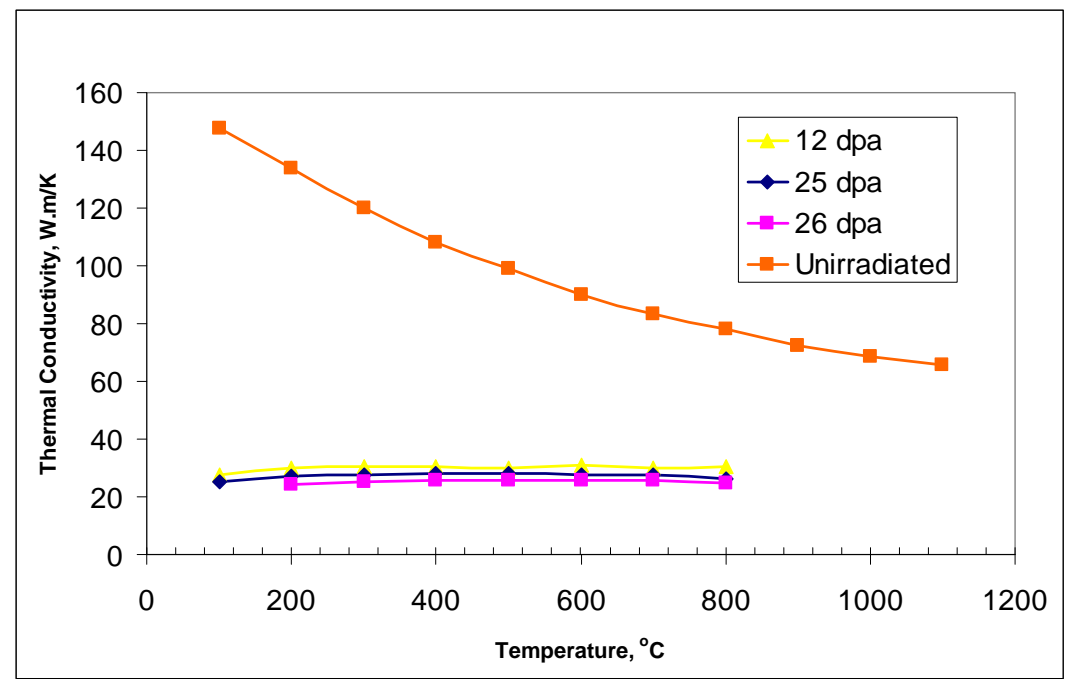

Figure 7. Temperature dependence of thermal conductivity in the irradiated and unirradiated condition for typical nuclear grade graphite. Irradiation temperature $=600{ }^{\circ} \mathrm{C}^{34}$

\subsubsection{Effects of irradiation on thermal expansion}

Graphite exhibits large anisotropy in the coefficients of thermal expansion (CTEs) of the crystals as a direct consequence of the bond anisotropy and the resultant anisotropy in the crystal lattice compliances. The thermal expansion of polycrystalline graphites is controlled by the thermal closure of aligned internal porosity that forms due to thermal shrinkage strains on cooling from graphitization. Thus the $\langle c\rangle$-axis expansion of the graphite crystals is initially partially accommodated by this internal porosity, and a much lower bulk CTE value is observed. On further heating the graphite crystals fill more of the available internal porosity, and more of the $\langle c>$-axis expansion is observed. The bulk CTE thus increases with temperature.

Since the CTE of polycrystalline graphite is dependent on the pore structure, irradiation-induced changes in the pore structure can be expected to modify the thermal expansion behavior of carbon materials. Burchell and Eatherly ${ }^{26}$ report the behavior of GraphNOL N3M (which is typical of many fine-textured graphites); it undergoes an initial increase in the coefficient of thermal expansion followed by a steady 
reduction to a value less than half the unirradiated value of $5 \times 10^{-6}{ }^{\circ} \mathrm{C}^{-1}$ (Figure 8). Similar behavior is reported by Kelly ${ }^{33}$ for grade IM1-24 graphite.

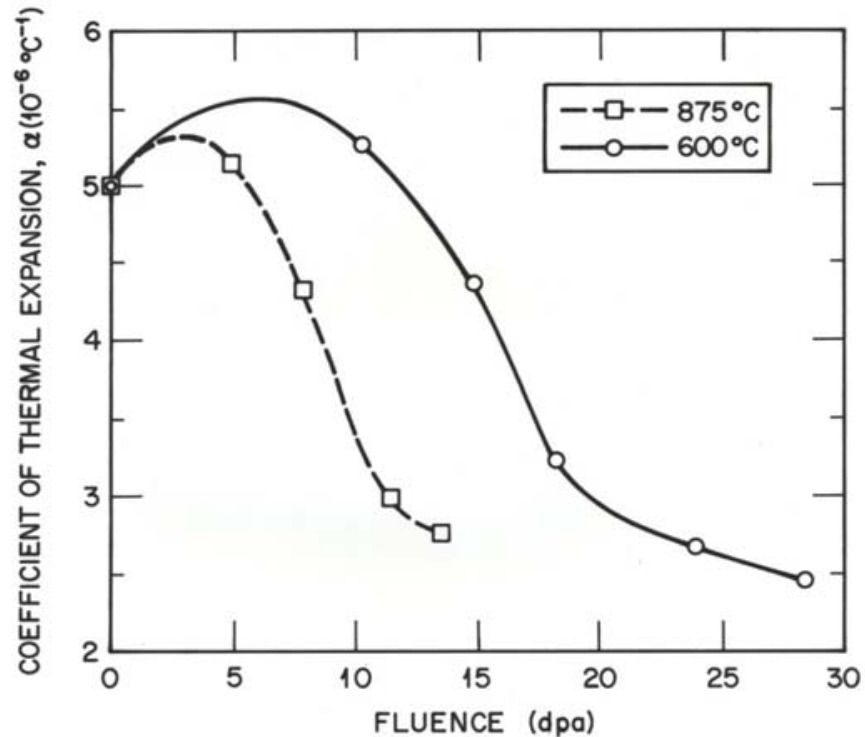

Figure 8. The irradiation-induced changes in CTE $\left(25-500^{\circ} \mathrm{C}\right)$ for GraphNOL N3M graphite at two irradiation temperatures. ${ }^{26}$

\subsubsection{Effects of irradiation on specific heat}

Irradiation causes a small increase in the specific heat $\left(\mathrm{C}_{\mathrm{p}}\right)$ of graphite measured at temperatures low enough that no annealing of irradiation damage takes place during measurement (i.e., below irradiation temperature).$^{49}$ However, the release of energy from the thermal annealing of damage accumulated at low irradiation temperature (Wigner energy) will reduce the effective specific heat at higher temperatures (i.e., above irradiation temperature).

\subsubsection{Effects of irradiation on electrical resistivity}

The electrical resistivity of graphite is also affected by radiation damage. The mean free path of the conduction electron in unirradiated graphite is relatively large, being limited only by crystallite boundary scattering. Neutron irradiation introduces (1) scattering centers, which reduce charge carrier mobility; (2) electron traps, which decrease the charge carrier density; and (3) additional spin resonance. The net effect of these changes is to increase the electrical resistivity on irradiation, initially very rapidly, with little or no subsequent change to relatively high fluence. ${ }^{28,26}$ A subsequent decrease at very high neutron doses is attributed to structural degradation.

\subsection{Theory of displacement damage due to neutron irradiation}

The binding energy of a carbon atom in the graphite lattice ${ }^{35}$ is about $7 \mathrm{eV}$. Impinging energetic particles such as fast neutrons, electrons, or ions can displace carbon atoms from their equilibrium positions. There have been many studies of the energy required to displace a carbon atom $\left(E_{d}\right)$, as reviewed by Kelly, ${ }^{17}$ Burchell, ${ }^{28}$ Banhart, ${ }^{36}$ and Telling and Heggie. ${ }^{37}$ The value of $E_{d}$ lies between 24 and $60 \mathrm{eV}$. The latter value has gained wide acceptance and use in displacement damage calculations, but a value of $\sim 30 \mathrm{eV}$ would be more appropriate. Moreover, as discussed by Banhart, ${ }^{36} \mathrm{Hehr},{ }^{38}$ and Telling and Heggie, ${ }^{37}$ an angular 
dependence of the threshold energy for displacement would be expected. The value of $E_{d}$ in the crystallographic $\left\langle c>\right.$-axis is in the range $12-20 \mathrm{eV},{ }^{36,39}$ while the in-plane value is much greater.

The primary atomic displacement, primary knock-on carbon atoms (PKAs), produced by energetic particle collisions produces further carbon atom displacements in a cascade effect. The cascade carbon atoms are referred to as secondary knock-on atoms (SKAs). The displaced SKAs tend to cluster in small groups of 5-10 atoms, and for most purposes it is satisfactory to treat the displacements as if they occur randomly. The total number of displaced carbon atoms will depend upon the energy of the PKA, which is itself a function of the neutron energy spectrum, and the neutron flux. Once displaced, the carbon atoms recoil through the graphite lattice, displacing other carbon atoms and leaving vacant lattice sites. However, not all of the carbon atoms remain displaced, and the temperature of irradiation has a significant influence on the fate of the displaced atoms and lattice vacancies. The displaced carbon atoms easily diffuse between the graphite layer planes in two dimensions, and a high proportion will recombine with lattice vacancies. Others will coalesce to form $\mathrm{C}_{2}, \mathrm{C}_{3}$, or $\mathrm{C}_{4}$ linear molecules. These, in turn, may form the nucleus of a dislocation loop-essentially a new graphite plane. Interstitial clusters may, on further irradiation, be destroyed by a fast neutron or carbon knock-on atom (irradiation annealing). Adjacent lattice vacancies in the same graphitic layer are believed to collapse parallel to the layers, thereby forming sinks for other vacancies that are increasingly mobile above $600{ }^{\circ} \mathrm{C}$, and hence can no longer recombine and annihilate interstitials.

Banhart $^{36}$ observed typical basal plane defects in a graphite nanoparticles using high resolution transmission electron microscopy (HRTEM). These defects can be understood as dislocation loops that form when displaced interstitial atoms cluster and form less mobile agglomerates. Other interstitials condense onto this agglomerate, which grows into a disc and pushes apart the adjacent plane. Further agglomeration leads to the formation of a new lattice plane.

Other deformation mechanisms have been proposed for irradiated graphite. Wallace ${ }^{40}$ proposed a mechanism whereby interstitial atoms could facilitate $s p^{3}$ bonds between the atomic basal planes, this mechanism allowing the stored energy (Wigner energy) to be explained. Jenkins ${ }^{41}$ argued that the magnitude of the increase in shear modulus $\left(\mathrm{C}_{44}\right)$ with low dose irradiation could not be explained by interstitial clusters pinning dislocations, but that a few $s p^{3}$-type covalent bonds between the planes could easily account for the observed changes. More recently, Telling and Heggie, ${ }^{37}$ in their ab initio calculations of the energy of formation of the "spiro-interstitial," advocate this mechanism to explain the stored energy characteristics of displacement-damaged graphite, particularly the large energy release peak seen at $\sim 200^{\circ} \mathrm{C}$. The first experimental evidence of the interlayer interstitial-vacancy pair defect with partial $s p^{3}$ character in between bi-layers of graphite was recently reported by $\mathrm{Urita}^{42}$ in a study of double-walled carbon nanotubes (DWNTs).

Jenkins ${ }^{41}$ invoked the formation of $s p^{3}$ bonding to explain the $<c>$-axis growth observed as a result of displacement damage. If adjacent planes are pinned, one plane must buckle as the adjacent planes shrink due to vacancy shrinkage; buckled planes yield the $\langle c\rangle$-axis expansion that cannot be explained by swelling from interstitial cluster alone. Telling and Heggie ${ }^{37}$ are very much in support of this position based upon their review of the literature and ab initio simulations of the damage mechanisms in graphite. Their simulations showed how the spiro-interstitial (cross-link) essentially locked the planes together. Additionally, di-vacancies could lead to the formation of pentagons and heptagons in the basal planes, causing the observed bending of graphene layers and $<_{c}>$-axis swelling. ${ }^{36,43,44}$ The predicted $<_{c}>$-axis crystal expansion via this mechanism is in closer agreement with the experimentally observed single crystal and HOPG dimensional change data.

The buckling of basal planes as a consequence of irradiation damage has been observed in HRTEM studies of irradiated HOPG by Tanabe ${ }^{43}$ and by Koike and Pedraza. ${ }^{44}$ In their study Koike and Pedraza 
observed 300\% expansion of thin HOPG samples subjected to electron irradiation in an in situ TEM study. Their experimental temperatures ranged from -35 to $660{ }^{\circ} \mathrm{C}$. They noted that the damaged microstructure showed retention of crystalline order up to $1 \mathrm{dpa}$. At higher doses they observed the lattice fringes to break up into segments $0.5-5 \mathrm{~nm}$ in length, with up to $15^{\circ}$ rotation of the segments with respect to the original $\{0001\}$ planes.

The evidence in favor of the formation of bonds between basal planes involving interstitials is considerable; however, such bonds are not stable at high temperature. As reported by numerous authors and reviewers, ${ }^{36,37,41,42}$ the $s p^{3}$-like bond would be expected to break and recombine with lattice vacancies with increasing temperature, such that at $T>225^{\circ} \mathrm{C}$ they no longer exist. Indeed, the irradiated graphite stored energy annealing peak at $\sim 200{ }^{\circ} \mathrm{C}$ and the HRTEM observations of Urita et al. ${ }^{42}$ demonstrate this clearly. Figure 9 shows a sequential series of HRTEM images illustrating the formation rates of interlayer defects at different temperatures with the same time scale (0 to 220 seconds) in DWNTs. The arrows indicate possible interlayer defects. At $T=-180{ }^{\circ} \mathrm{C}$ ( $a$ in Figure 9$)$ the electron irradiation-induced defects are numerous, and the nanotubes inside quickly become damaged due to complex defects. At $27^{\circ} \mathrm{C}(b$ in Figure 9$)$ the nanotubes are more resistive to the damage from electron irradiation, yet defects are still viable. At $300{ }^{\circ} \mathrm{C}(c$ in Figure 9), defect formation is rarely observed and the DWNTs are highly resistant to the electron beam irradiation, presumably because of the ease of defect self-annihilation (annealing).
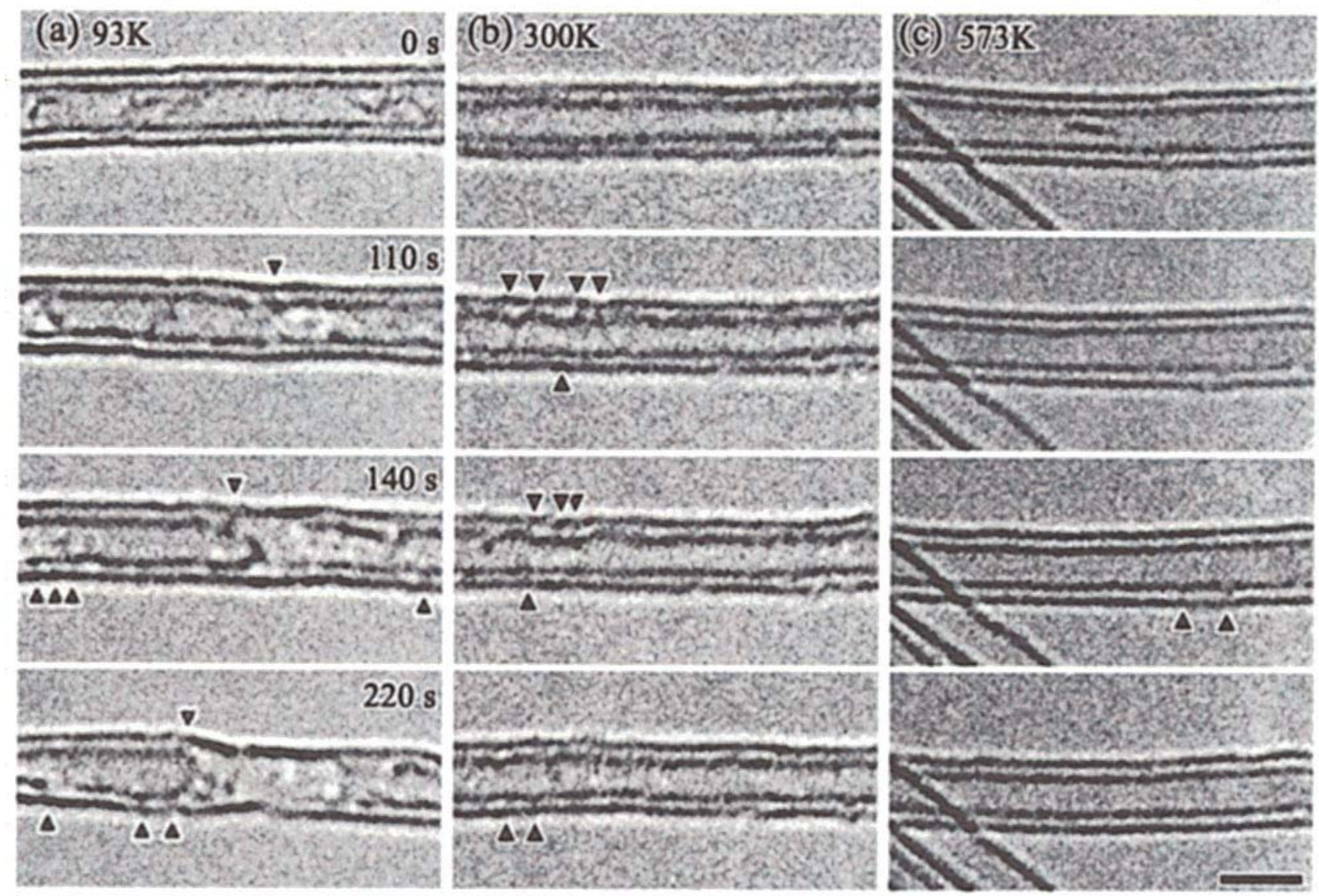

Figure 9. Sequential HRTEM images illustrating the formation rates of interlayer defects at different temperatures with the same time scale (0 to 220 seconds). (a) $93 \mathrm{~K}\left(-180{ }^{\circ} \mathrm{C}\right)$, (b) $300 \mathrm{~K}\left(27^{\circ} \mathrm{C}\right)$, (c) $573 \mathrm{~K}$ $\left(300{ }^{\circ} \mathrm{C}\right)$, in double-walled carbon nanotubes. The arrows indicate possible interlayer defects. Scale bar $=$ $2 \mathrm{~nm}^{42}$

In an attempt to estimate the critical temperature for the annihilation of the interstitial-vacancy $(I-V)$ defect pairs, a systematic HRTEM study was undertaken at elevated temperatures by Urtita et al. ${ }^{42}$ The formation rate of the $I-V$ defects that showed sufficient contrast in HRTEM is plotted in Figure 10. The 
reported numbers were considered to be an underestimate since single $I-V$ pairs may not have given sufficient contrast to be convincingly isolated from the noise level and thus may have been missed. However, the data was considered satisfactory for indicating the formation rate as a function of temperature. The number of clusters of $I-V$ pairs found in a DWNT was averaged for several batches at every $50{ }^{\circ} \mathrm{C}$ and normalized by the unit area. As observed in Figure 10 the defect formation rate displays a constant rate decline, with a threshold appearing at $\sim 450-500 \mathrm{~K}\left(\sim 177-227^{\circ} \mathrm{C}\right)$. This threshold corresponds to the stored energy release peak (discussed in Section 4) as shown by the dotted line in Figure 10. Evidently, the irradiation damage resulting from higher temperature irradiations (above $\sim 200-300^{\circ} \mathrm{C}$ ) is different in nature from that occurring at lower irradiation temperatures.

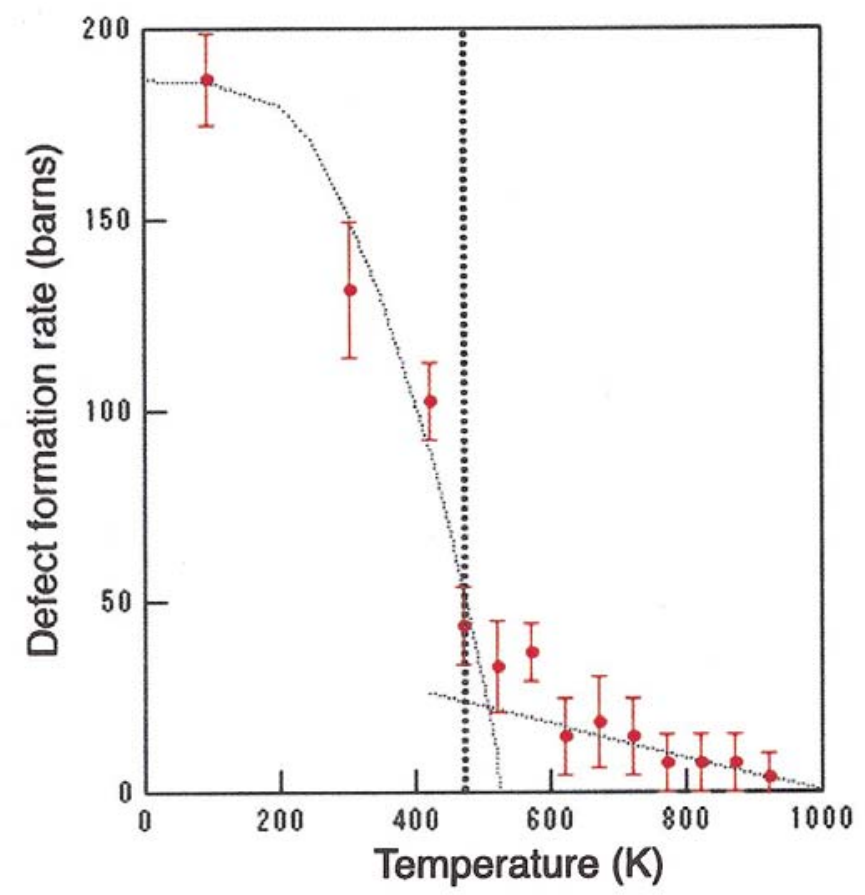

Figure 10. Normalized formation rate of the clusters of I-V pair defects per unit area of bilayer estimated in HRTEM images recorded at different temperatures. The dotted line shows the known temperature for Wigner-energy release $\left(\sim 473 \mathrm{~K}\right.$ or $\left.200{ }^{\circ} \mathrm{C}\right) .{ }^{42}$

Koike and Pedraza ${ }^{44}$ studied the dimensional change in HOPG caused by electron irradiation-induced displacement damage. They observed in situ the growth in $\left\langle_{c}\right\rangle$-axis of the HOPG crystals as a function of irradiation temperature at damage doses up to $\sim 1.3 \mathrm{dpa}$. Increasing $\langle c\rangle$-axis expansion with increasing dose was seen at all temperatures. The expansion rate, however, was significantly greater at temperatures $<\sim 200{ }^{\circ} \mathrm{C}$ (their data was at $25^{\circ} \mathrm{C}$ and $145^{\circ} \mathrm{C}$ ) compared to that at irradiation temperatures $>\sim 200^{\circ} \mathrm{C}$. This observation supports the concept that separate irradiation damage mechanisms may exist at low irradiation temperatures $\left(\sim T<200^{\circ} \mathrm{C}\right)$, that is, buckling due to $s p^{3}$ bonded cross linking of the basal planes via interstitials, than at elevated irradiation temperatures $\left(T>\sim 200{ }^{\circ} \mathrm{C}\right)$, where the buckling of planes is attributed to clustering of interstitials that induces the basal planes to bend, fragment, and then tilt. Koike and Pedraza ${ }^{44}$ also observed crystallographic $<a>$-axis shrinkage upon electron irradiation in situ at several temperatures $(145,280$, and $\left.420{ }^{\circ} \mathrm{C}\right)$. The shrinkage increased with dose at all irradiation temperatures, and the shrinkage rate reduced with increasing irradiation temperature. This behavior is attributed to buckling and breakage of the basal planes, with the amount of tilting and buckling decreasing with increasing temperature due to (1) a switch in mechanism as discussed above and (2) increased mobility of lattice vacancies above $\sim 400{ }^{\circ} \mathrm{C}$. 
Jenkins ${ }^{41,45}$ also discussed the deformation of graphite crystals in terms of a unit $c$-axis dislocation (prismatic dislocation), i.e., one in which the Burgers vector, $\mathbf{b}$, is in the crystallographic $<c>$-direction. The $<_{c}>$-axis migration of interstitials can take place by unit $c$-axis dislocations. The formation and growth of these and other basal plane dislocation loops undoubtedly play a major role in graphite crystal deformation during irradiation.

Ouseph $^{46}$ observed prismatic dislocation loops (both interstitial and vacancy) in unirradiated HOPG using scanning tunneling microscopy (STM). Their study allowed atomic resolution of the defect structures. Such defects had previously been observed as regions of intensity variations in transmission electron microscopy (TEM) studies in the 1960s. ${ }^{47}$

Telling and Heggie's first principle simulations ${ }^{37}$ have indicated a reduced energy of migration for a lattice vacancy compared to the previously established value. Therefore, they argue, the observed limited growth of vacancy clusters at high temperatures $\left(T>626^{\circ} \mathrm{C}\right)$ indicates the presence of a barrier to further coalescence of vacancy clusters (i.e., vacancy traps). Telling and Heggie implicate a cross-planar metastable vacancy cluster in adjacent planes as the possible trap. The disc-like growth of vacancy clusters within a basal plane ultimately leads to a prismatic dislocation loop. TEM observations show that these loops appear to form at the edges of interstitial loops in neighboring planes in the regions of tensile stress.

The role of vacancies needs to be reexamined based on the foregoing discussion. If the energy of migration is considerably lower than previously considered, and the likelihood of vacancy traps exists, the vacancy and prismatic dislocation may well play a larger role in displacement damage-induced in-crystal deformation. The diffusion of vacancy lines to the crystal edge essentially heals the damage, such that crystals can withstand massive vacancy damage and recover completely. 


\section{Wigner Energy}

In 1942 E. P. Wigner suggested that irradiations might affect the graphite moderator of a nuclear reactor. He suggested that fast neutrons would displace atoms from their normal positions and so produce lattice defects in the form of holes in the carbon networks and interstitial atoms intercalated between the layer planes of the graphite. The interstitial atoms would cause an increase in the interlayer spacing and so cause the graphite to grow. Lattice strains produced by the defects would increase the internal energy of the graphite. This increase in internal energy or "stored energy" (known also as the Wigner effect) might, if it were suddenly released, cause a spontaneous rise in temperature of the graphite component. ${ }^{48}$

The topic of stored energy in irradiated graphite and the release of stored energy has been studied extensively, and several excellent reviews have been published on the topic, including Chapter 12 in the book Nuclear Graphite by Nightingale, ${ }^{49}$ Chapter 8 in the book Radiation Damage in Graphite by Simmons, ${ }^{48}$ and a paper by Bell et al. ${ }^{32}$ These documents provide sound introductions to the topic of stored energy in irradiated graphite and contain a comprehensive summary of the studies and data available up to the publishing dates (1962 and 1965). A more recent review of the topic is available in Chapter 4 of International Atomic Energy Agency report TECDOC-1154, published in $2000 .^{12}$

To create a comprehensive information database on this topic, we reviewed the aforementioned publications and consulted the original sources of information whenever possible or available. We are also providing information and data published since the publication of Nightingale's and Simmons' books, some information not covered in TECDOC-1154, and other recent information reported after 2000.

We begin this section with a review of the various methods available to measure either the total stored energy or the rate of release of stored energy of irradiated graphite. We then evaluate the effect of several material-, test-, and irradiation-related variables on the stored energy of graphite. We conclude with a summary of the challenges involved in interpreting earlier results and cautions for conducting DSC tests to provide stored energy information for irradiated graphite.

\subsection{Total stored energy of irradiated graphite}

The total stored energy can be determined as the difference in the heat of combustion of irradiated and unirradiated graphite. The release of the last traces of stored energy requires heating to very high temperatures. The stored energy per unit mass, $S$, can be determined by measuring the increase in the roomtemperature heat of combustion. If $\Delta H_{i}$ and $\Delta H_{u}$ are the heats of combustion of an irradiated and a similar, but unirradiated, graphite sample, respectively, then ${ }^{49}$

$$
S=\Delta H_{i}-\Delta H_{u}
$$

The standard method of measurement of the heat of combustion uses high accuracy bomb calorimetry. However, due to the relatively small contribution of $S$ to the heat of combustion, very precise measurements are necessary, but challenging. An accuracy of better than \pm 1 or $2 \mathrm{cal} / \mathrm{g}$ is required in studying lightly damaged samples. Since the heat of combustion of unirradiated graphite is $3.26 \times 10^{4} \mathrm{~J} / \mathrm{g}(7,800 \mathrm{cal} / \mathrm{g})$, measurement of the heat of combustion to about 0.01 percent is required to attain an accuracy of $\pm 1 \mathrm{cal} / \mathrm{g}$. A precision in the range of \pm 3 to $4 \mathrm{cal} / \mathrm{g}$ is usually sufficient to characterize heavily damaged samples with stored energies $>100 \mathrm{cal} / \mathrm{g}$. Greater precision is required to characterize samples with relatively small amounts of stored energy. 
Most published measurements of $S$ were made during the 1950s by either the Windscale Laboratory of the United Kingdom Atomic Energy Authority (UKAEA) or the U.S. National Bureau of Standards, using an isothermal-jacket bomb calorimeter to measure the heat of combustion from the reaction of a small amount of graphite with oxygen. ${ }^{50,51,52,53,54}$

The accumulation of stored energy as a function of reactor irradiation is shown in Figure 11. It is observed that a relatively large amount of energy, $630 \mathrm{cal} / \mathrm{g}$, is stored when graphite is exposed to $5000 \mathrm{MWd} / \mathrm{AT}\left(\sim 0.43 \mathrm{dpa}\right.$ ) at $30^{\circ} \mathrm{C}$. This is equal to $7.5 \mathrm{kcal} / \mathrm{g}$ atom, several times the estimated interlayer binding energy in unirradiated graphite. This amount of energy also corresponds to the integrated heat capacity of unirradiated graphite between 100 and $1550^{\circ} \mathrm{C}$. However, if the sample is exposed to $4500 \mathrm{MWd} / \mathrm{AT}(\sim 0.39 \mathrm{dpa})$ at $450^{\circ} \mathrm{C}$, the energy stored is reduced significantly to $15 \mathrm{cal} / \mathrm{g}$.

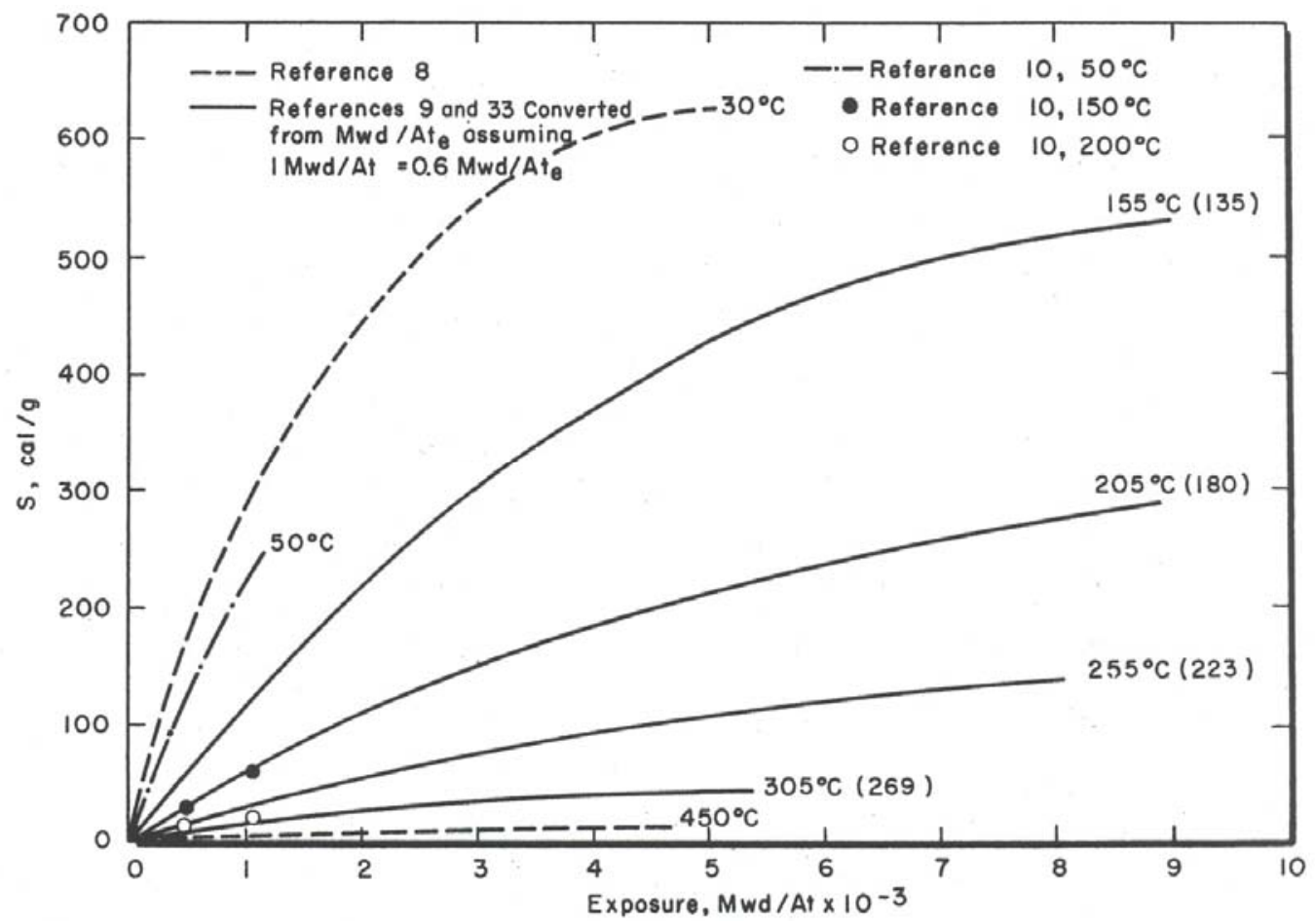

Figure 11. Accumulation of total stored energy as a function of dose in graphite at various irradiation temperatures. ${ }^{49}$

The data from Figure 11 also show that for a given irradiation temperature, $S$ increases with exposure and appears to achieve saturation after very long exposures $\left(S_{\infty}\right)$; it is also observed that the rate of accumulation of stored energy and the saturation value that $S$ approaches after very long exposures $\left(S_{\infty}\right)$ decrease with increasing irradiation temperature. For a low irradiation temperature of $30{ }^{\circ} \mathrm{C}, S_{\infty}$ appears to be in the range 650 to $700 \mathrm{cal} / \mathrm{g}$, while for a higher irradiation temperature, it is in the range of $<100 \mathrm{cal} / \mathrm{g}$. A simple semiempirical model for neutron-induced stored energy in graphite irradiated at low temperature was proposed by Newgard ${ }^{55}$ in the late $1950 \mathrm{~s}$. The model attempted to explain saturation in stored energy as a function of dose; however, the results from the model equations were only in close agreement with data in the region up to $20 \times 1020 \mathrm{nvt}(\sim 0.44 \mathrm{dpa})$ and diverged for greater doses.

Relatively small, perhaps negligible, amounts of stored energy, which is not of concern, have been reported for irradiations above $450{ }^{\circ} \mathrm{C}$. A single CSGBF sample irradiated ${ }^{49}$ to $15,000 \mathrm{MWd} / \mathrm{AT}$ ( $\left.\sim 1.29 \mathrm{dpa}\right)$ 
at about $500{ }^{\circ} \mathrm{C}$ accumulated $40 \mathrm{cal} / \mathrm{g}$. Another measurement ${ }^{56}$ on one sample after an exposure of $1.8 \times 10^{20}$ neutrons $/ \mathrm{cm}^{2}(\mathrm{E}>1 \mathrm{MeV})(\sim 0.26 \mathrm{dpa})$ at $750{ }^{\circ} \mathrm{C}$ gave $9 \mathrm{cal} / \mathrm{g}$. These results and the extrapolation of results obtained at lower temperatures appear to indicate that buildup of stored energy will not be significant at temperatures in the $500-1000{ }^{\circ} \mathrm{C}$ range; however, actual experimental evidence does not exist to confirm this trend beyond the evaluated conditions, particularly for a combination of high temperatures and high accumulated doses, which is typical for an HTGR service.

\subsection{Rate of release of stored energy of irradiated graphite}

The total stored energy of irradiated graphite is an important parameter; however, this measurement alone is inadequate for the prediction of possible temperature excursions of irradiated graphite subjected to heating above the irradiation temperature. A more appropriate measurement is the rate of release (or release rate) of stored energy as a function of annealing temperature.

Early stored energy release curves (rate of release of stored energy vs. annealing temperature) were derived from heat of combustion measurements obtained on several smaller samples sectioned from an irradiated graphite sample. One section is isothermally annealed at $T_{1}$; another section, at a higher temperature, $T_{2}$; etc. The $\Delta H$ is measured on each section, and the stored energy released in each temperature interval $(\Delta T)$ is calculated. A plot of $\Delta S / \Delta T$ as a function of the annealing temperature is a stored energy release curve, the resolution of which is determined by the magnitude of $\Delta T$. This method has the disadvantage of requiring a large number of $\Delta H$ measurements to cover the spectrum with satisfactory resolution. Also, a gradient of stored energy across a sample could be problematic; if the sample were sectioned into several, each would have a different amount of stored energy. As assurance that each sample will have the same amount of stored energy, the original sample can be ground prior to annealing. In this case, only the average stored energy is determined; however, information regarding any gradient in stored energy, potentially existing due to differences in damage within the sample, may not be obtained by this method. An advantage of this method is that the region in which high temperature annealing takes place can be more easily studied.

Several experimental methods for determining rate of release of stored energy have been developed, with variations of each method from laboratory to laboratory, but in general terms, the methods for measuring energy release rates can be classified into isothermal, adiabatic, and linear rise.

Isothermal method. This method consists of rapidly inserting an irradiated graphite sample in a gas or liquid at an elevated temperature for a predetermined time. From an analysis of the heating rate curve, the stored energy released up to the temperature of the heating fluid can be calculated. Variations of the isothermal method were employed at Argonne National Laboratory, the Hanford site, and in England. ${ }^{57}$ The results of these experiments, while providing a measure of stored energy released under the conditions of the experiments, were difficult to apply in a general way. Wechsler et al. ${ }^{58}$ described another type of isothermal method based upon exchange of radiation heat between the sample and the calorimeter. In common with other isothermal methods, this method does not give data on stored energy as a continuous function of the annealing temperature; it gives only the total stored energy released up to the temperature of the calorimeter.

Adiabatic rise method. The adiabatic rise method provides a means of determining the total energy released at a given temperature and is not a method of measuring the release curve. It is applicable only to those regions of the release curve for which

$$
\int \frac{d S}{d T} d T>\int C_{p} d T
$$


In this method the temperature of the sample is raised rapidly to promote a fairly rapid release of stored energy. The sample is then maintained in adiabatic surroundings, and the temperature rise of the sample is measured as a function of time. The adiabatic rise method has been found especially valuable in predicting the spontaneous temperature rise of irradiated graphite under approximately adiabatic conditions. It was refined to a high degree by Simmons and coworkers at the UKAEA Harwell site and was used extensively in predicting the annealing behavior of the graphite during the release of stored energy in the British Experimental Pile Operation (BEPO). ${ }^{59}$

Typical adiabatic rise curves of irradiated graphite samples cored from various positions in the BEPO reactor are shown in Figure 12. The differences in the curves for a high energy sample and a low energy sample ${ }^{\dagger}$ are shown. The starting temperature may be raised in steps until a suitable starting rate is obtained. The curves show that at times the calorimeter must follow a slow drift, during which time precise temperature control is needed to keep the heat transfer small. At other times the rate of temperature rise is rapid, and the calorimeter must be able to follow this without lagging or overshooting.

The stored energy released in an adiabatic rise experiment is well defined only if the starting and finishing conditions are specified. In most Harwell measurements a starting temperature was chosen to produce an initial rate of rise of $1{ }^{\circ} \mathrm{C} / \mathrm{min}$, and the measurement was terminated when the rate decreased to $0.2{ }^{\circ} \mathrm{C} / \mathrm{min}$. The major uncertainty in the adiabatic rise measurements with this type of calorimeter is the uncertainty in the starting conditions, partly because it is not possible to reach the starting temperature instantaneously and partly because some heat is transferred to the sample after the heater current has been switched off. Even so, a reproducibility of $\pm 1.5 \mathrm{cal} / \mathrm{g}$ in the energy released up to $400{ }^{\circ} \mathrm{C}$ was reported for measurements of the energy release for BEPO irradiated samples.

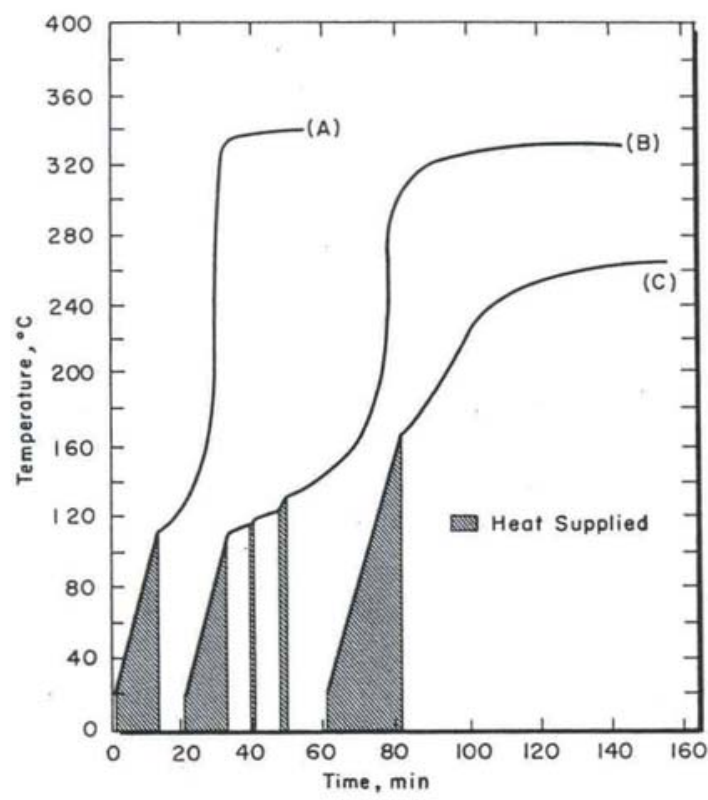

Figure 12. Adiabatic rise curves for a typical high energy sample A, and a typical low energy sample $C$. Curve B illustrates the way in which the starting rate can be changed until a suitable rate is obtained. ${ }^{59}$

\footnotetext{
$\dagger$ Exact irradiation conditions (dose and temperature) were not specified.
} 
Linear rise method. In this method, heat is supplied to the sample at the rate required to raise its temperature at a constant rate. The difference in energy supplied between two experiments gives the energy release rate, usually expressed in terms of unit temperature rise,

$$
\frac{d S}{d T}=\frac{1}{a} \frac{d S}{d t}
$$

where $S$ is the stored energy per unit mass, $a$ is the rate of temperature rise, $t$ is the time, and $T$ is the temperature.

Those methods that can be classified broadly as linear rise include a modification of the Sykes method ${ }^{48,60}$ employed at Argonne ${ }^{61}$ Hanford, and the Chalk River Laboratories in Canada; the twin crucible method; the differential thermal analysis method; and the improved linear rise method reported in England. ${ }^{49,59,57}$ All these variations employed a calorimeter whose temperature rise is only approximately linear, but since the stored energy is determined from the difference in two annealing curves, a small deviation from linearity is not serious if the temperature-time program is the same for the two curves.

In early versions ${ }^{61}$ of the linear rise method, the difference between the temperature of the sample and that of the calorimeter was recorded during the experiment. The procedure normally employed was to record the temperature differential as a function of time or temperature up to 400 to $500{ }^{\circ} \mathrm{C}$. The release of stored energy was indicated by a temperature rise in the sample. The experiment was repeated on the partially annealed sample. Assuming that no stored energy was released during the second run, $d S / d T$ could be calculated as a function of annealing temperature.

Most linear rise calorimeters were limited to temperatures less than $500{ }^{\circ} \mathrm{C}$, where the release peak was observed for samples irradiated at low temperatures. Koyama ${ }^{49 *}$ reported on a linear rise calorimeter to measure $d S / d T$ to $1200{ }^{\circ} \mathrm{C}$, using only one single graphite sample, and instrumentation to maintain a constant temperature rise of $10^{\circ} \mathrm{C} / \mathrm{min}$. Tests with unirradiated graphite showed that the power curves $*$ were reproducible to $\pm 5 \%$; however, Koyama did not provide any data for irradiated samples.

It has been observed that the detailed shapes of the release curves obtained in different laboratories by the linear rise method vary with the operating characteristics of the particular instrument; the operating procedures; treatment of the data (i.e., considering the slight differences in the heating rates causing variation in heat transfer, which were inevitable); the lag voltages (if any), which have not been standardized; and various corrections and approximations that are often applied to the data. For example, significant differences in the shape and maximum position of the " $200{ }^{\circ} \mathrm{C}$ peak" are obtained with heating rates of $2.5^{\circ} \mathrm{C} / \mathrm{min}$ and $13{ }^{\circ} \mathrm{C} / \mathrm{min}$. These variables can be held sufficiently constant so that reproducible results can be obtained on a given instrument. However, some cross-checking and standardization between the laboratories measuring stored energy by linear rise methods are needed. In spite of the experimental difficulties encountered and the careful work required, the linear rise method is probably the most generally useful method to measure the rate of release of stored energy of irradiated graphite.

\footnotetext{
* The reference to Koyama's instrument for measuring release rates at temperatures up to $1200{ }^{\circ} \mathrm{C}$ came from Nightingale's book; no other available reference from Koyama with actual measurements at high temperatures was found.

+ Power curves: heat flow (mW) vs. time or temperature.
} 


\subsection{Interpretation of stored energy data}

\subsubsection{Effects of irradiation dose at low irradiation temperatures}

The early results of a considerable number of studies on the effects of fast neutron irradiation on graphite, and particularly on the stored energy, were presented at the International Conferences on the Peaceful Uses of Atomic Energy. The report by Kinchin, ${ }^{62}$ at the first conference in the mid 1950 s, showed the rate of energy release up to about $400{ }^{\circ} \mathrm{C}$ for a sample of extruded graphite irradiated at $50{ }^{\circ} \mathrm{C}$ and a dose of $2 \times 10^{20} \mathrm{n} / \mathrm{cm}^{2}\left(\sim 0.04 \mathrm{dpa}\right.$ ) (for a heating rate of $\left.20^{\circ} \mathrm{C} / \mathrm{min}\right)$. The results showed a well-defined peak in the rate of release of stored energy around $200{ }^{\circ} \mathrm{C}$ (Figure 13). At the same conference, Woods et al. ${ }^{63}$ also reported on the measurements of the release of stored energy by calorimetric technique for graphites irradiated at about $30^{\circ} \mathrm{C}$, and varying doses, from $1.3 \times 10^{20}$ nvt up to $11.6 \times 10^{20} \mathrm{nvt}(\sim 0.03-0.26 \mathrm{dpa})$. The results (Figure 14) showed a large peak at about $200^{\circ} \mathrm{C}$, which increases in intensity with exposures up to about $4.2 \times 10^{20}$ neutrons $/ \mathrm{cm}^{2}(\sim 0.09 \mathrm{dpa})$. At higher exposures, this release peak is diminished and increasing proportions of the stored energy are released only at higher temperatures. The values of the specific heat of unirradiated graphite were also plotted (dashed line) and are in agreement with those reported by Butland and Maddison. ${ }^{64}$

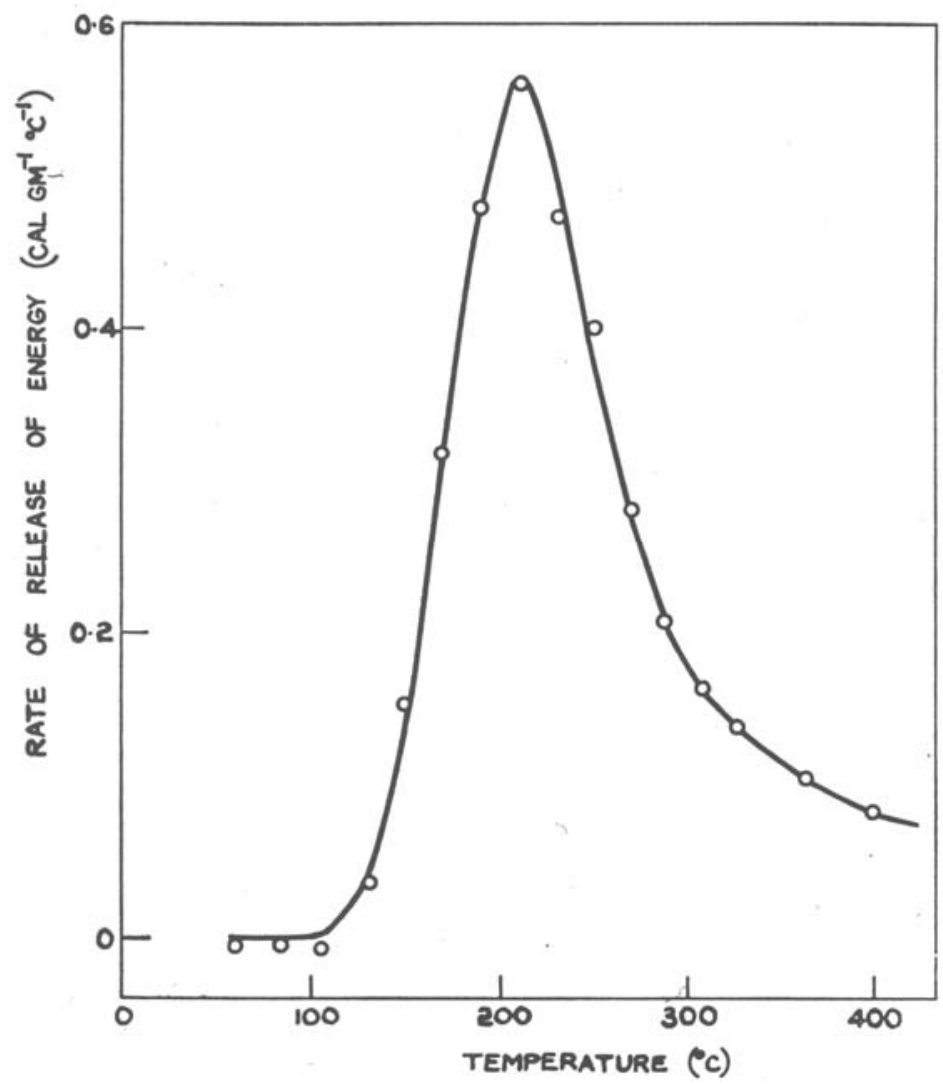

Figure 13. Rate of release of stored energy, by linear rise of temperature $\left(20^{\circ} \mathrm{C} / \mathrm{min}\right)$; irradiation $\sim 2 \times 10^{20} \mathrm{n} / \mathrm{cm}^{2},(0.04 \mathrm{dpa})$ at $50{ }^{\circ} \mathrm{C}^{62}$ 


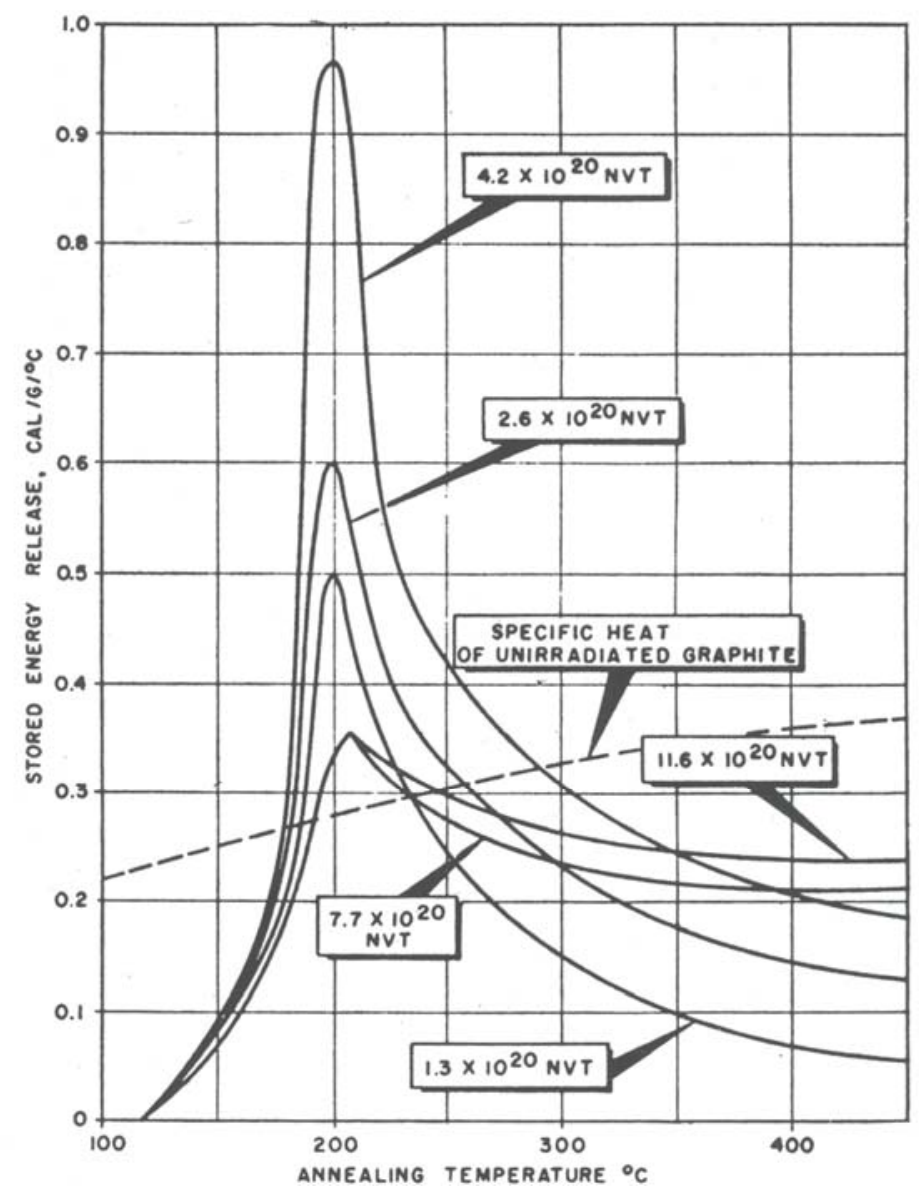

\begin{tabular}{|ll|}
\hline $\begin{array}{l}\text { Dose } \\
\times \mathbf{1 0}^{\mathbf{2 0}} \mathbf{N V T}\end{array}$ & $\begin{array}{l}\text { Dose } \\
\text { dpa }\end{array}$ \\
& \\
1.3 & 0.03 \\
2.6 & 0.06 \\
4.2 & 0.09 \\
7.7 & 0.17 \\
11.6 & 0.26 \\
\hline
\end{tabular}

Figure 14. Stored energy annealing spectra in irradiated graphite; irradiation temperature $30{ }^{\circ} \mathrm{C}^{63}$

Several years later at the Fifth Conference on Carbon (1961), Bridge, Kelly, and Gray ${ }^{65}$ reported additional measurements on the rate of energy release for samples irradiated to a wider range of irradiation doses (varying from $0.01 \mathrm{dpa}$ up to $0.49 \mathrm{dpa}$ ) at an irradiation temperature of $30{ }^{\circ} \mathrm{C}$ (irradiation experiments were conducted in a water-cooled test hole in the Hanford reactor but measured in the United Kingdom; measurements made at $\sim 2{ }^{\circ} \mathrm{C} / \mathrm{min}$ ) (Figure 15). These measurements showed again the well-defined peak at about $200{ }^{\circ} \mathrm{C}$ and a trend similar to that shown by Woods, ${ }^{63}$ although the magnitude of the peak does not agree for similar irradiation conditions. In the 1950s and 1960s, most authors cautioned about comparing results obtained by different workers, with different equipment, at different times, because the experimental techniques for these types of measurements were under development and improvements were continuously being made to improve the resolution of the experiments. 


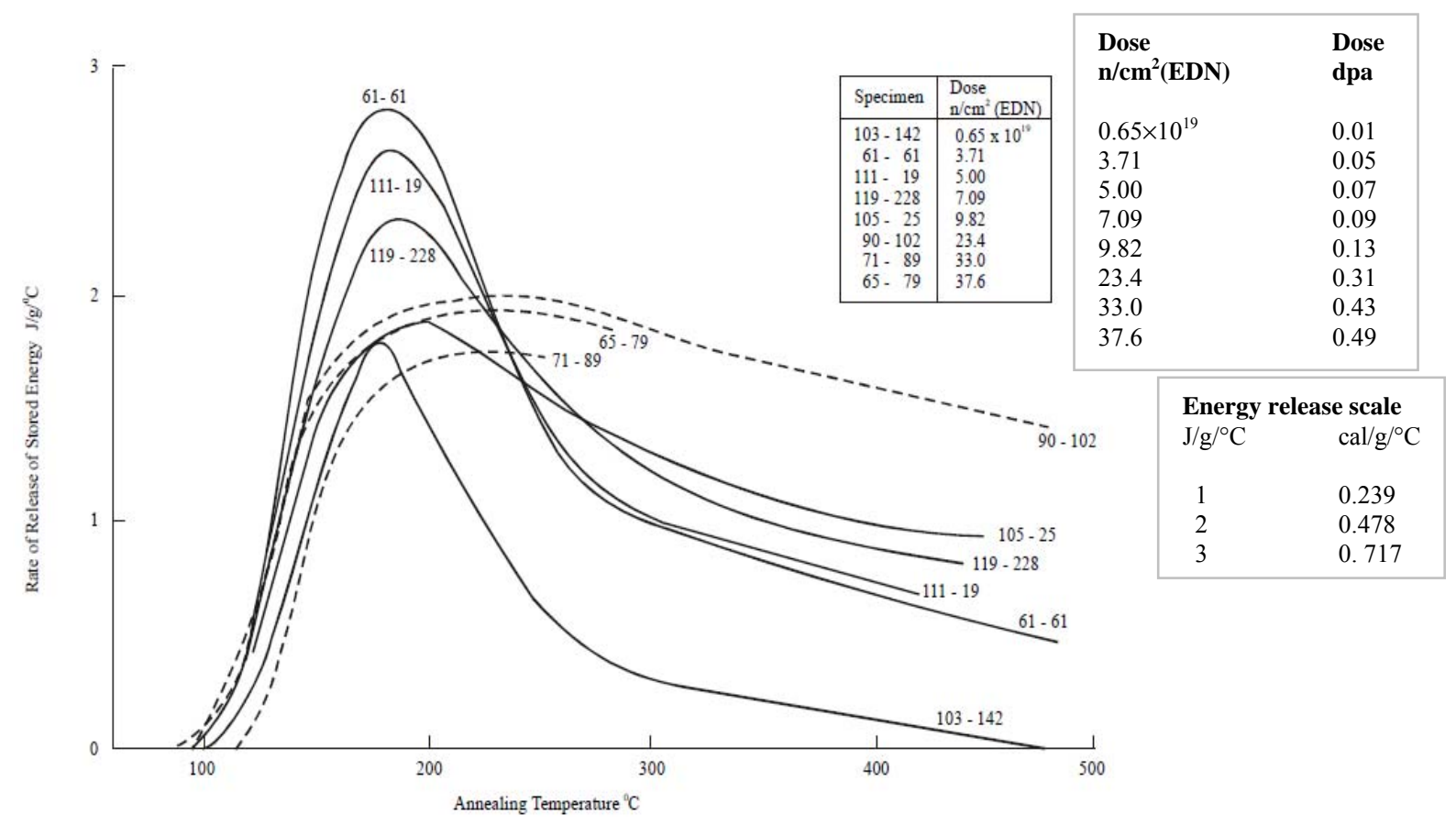

Figure 15. Stored energy release curves for CSF graphite irradiated at $\sim 30{ }^{\circ} \mathrm{C}$ in the Hanford $\mathrm{K}$ reactor cooled test hole. ${ }^{65}$

The effect of irradiation dose (from about 0.48 to $2.70 \mathrm{dpa}$ ) at an irradiation temperature slightly higher than room temperature $\left(150{ }^{\circ} \mathrm{C}\right.$ ) was reported by Bell et al..$^{32}$ and is shown in Figure 16 (specimens irradiated at either the Calder Hall reactor or the material testing reactors DIDO and PLUTO). It is observed that no peak is as well defined as those of the previously reported samples irradiated at near-room temperature, and that the onset of the release of stored energy is shifted to higher temperature. More important, the maximum release rate achieved for these samples is below the specific heat of unirradiated graphite. 


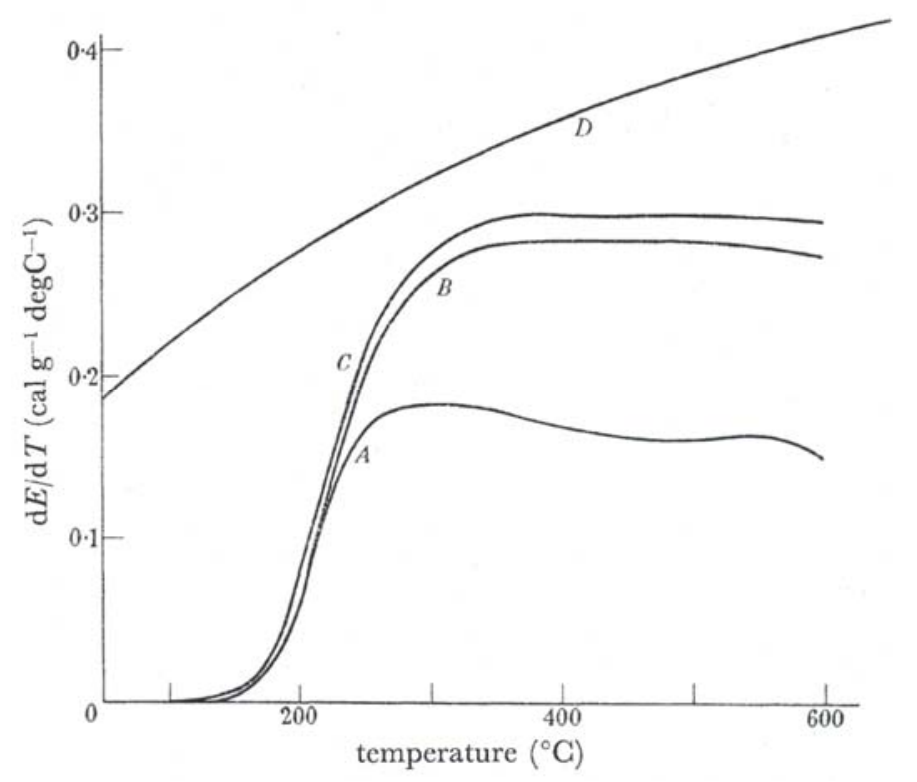

\begin{tabular}{lr|} 
Sample & Dose MWd/AT (dpa) \\
A & $2000(0.48)$ \\
B & $7735(1.84)$ \\
C & $11320(2.70)$ \\
& \\
D is the specific heat of unirradiated \\
graphite
\end{tabular}

Figure 16. Rate of release of stored energy in specimens irradiated at $150{ }^{\circ} \mathrm{C} .{ }^{32}$

\subsubsection{Effects of irradiation temperature}

Data on the effect of irradiation temperature for graphite samples irradiated at similar or equivalent doses have been reported by Woods et al., ${ }^{63}$ Cottrell et al., ${ }^{57}$ Bell et al., ${ }^{32}$ and Rappeneau ${ }^{66}$ (Figure 17 to Figure 22).

Although the maximum irradiation temperature reported in these sets of data is $300{ }^{\circ} \mathrm{C}$ and the irradiation doses are different for each case, a general trend can be observed in all cases - that is, the energy release decreases significantly (to almost undetectable limits) as the irradiation temperature increases. Again, we need to emphasize that a direct comparison of the magnitude of the energy release rates from various sources should be avoided, as mentioned earlier, because the measurements are sensitive to the experimental details; however, a comparison of the trends of the results should be valid. 


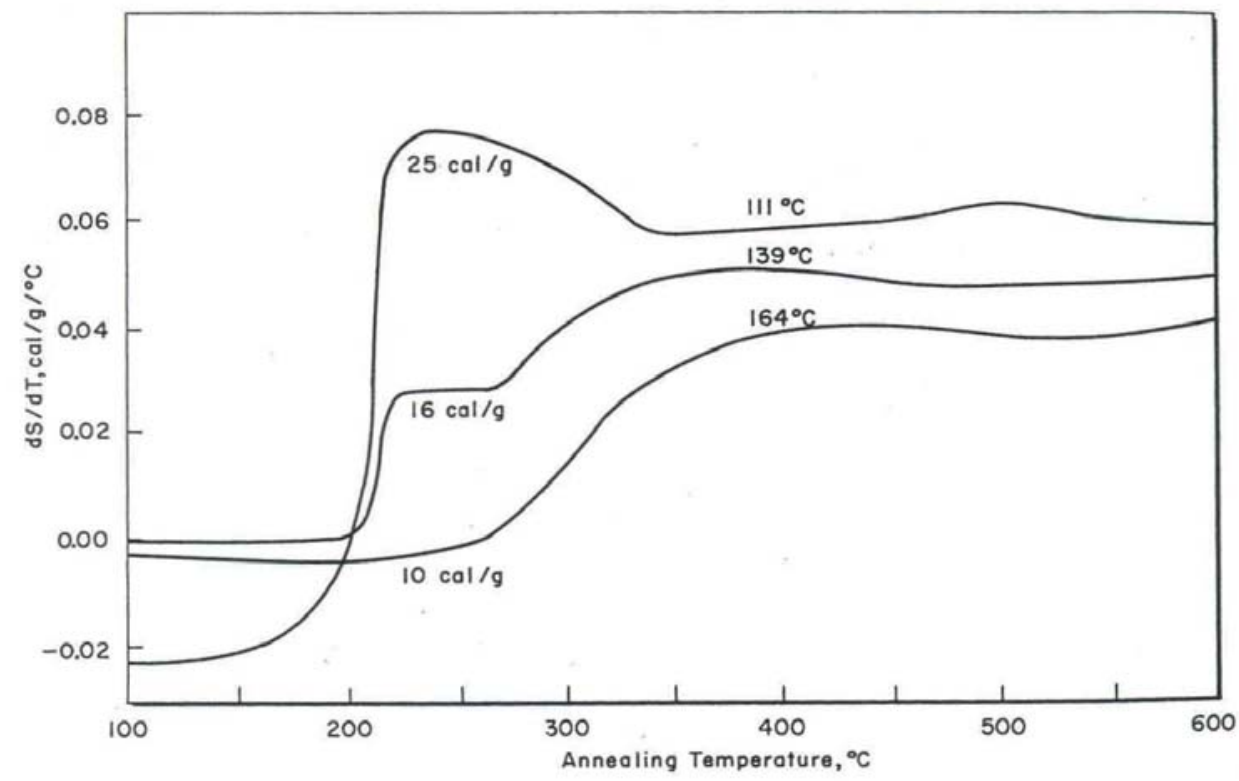

Figure 17. Stored energy release curves of CSF graphite exposed to $193 \mathrm{MWd} / A T(\sim 0.03 \mathrm{dpa})$. Numbers under the curves give the stored energy release to $600{ }^{\circ} \mathrm{C} .{ }^{63}$

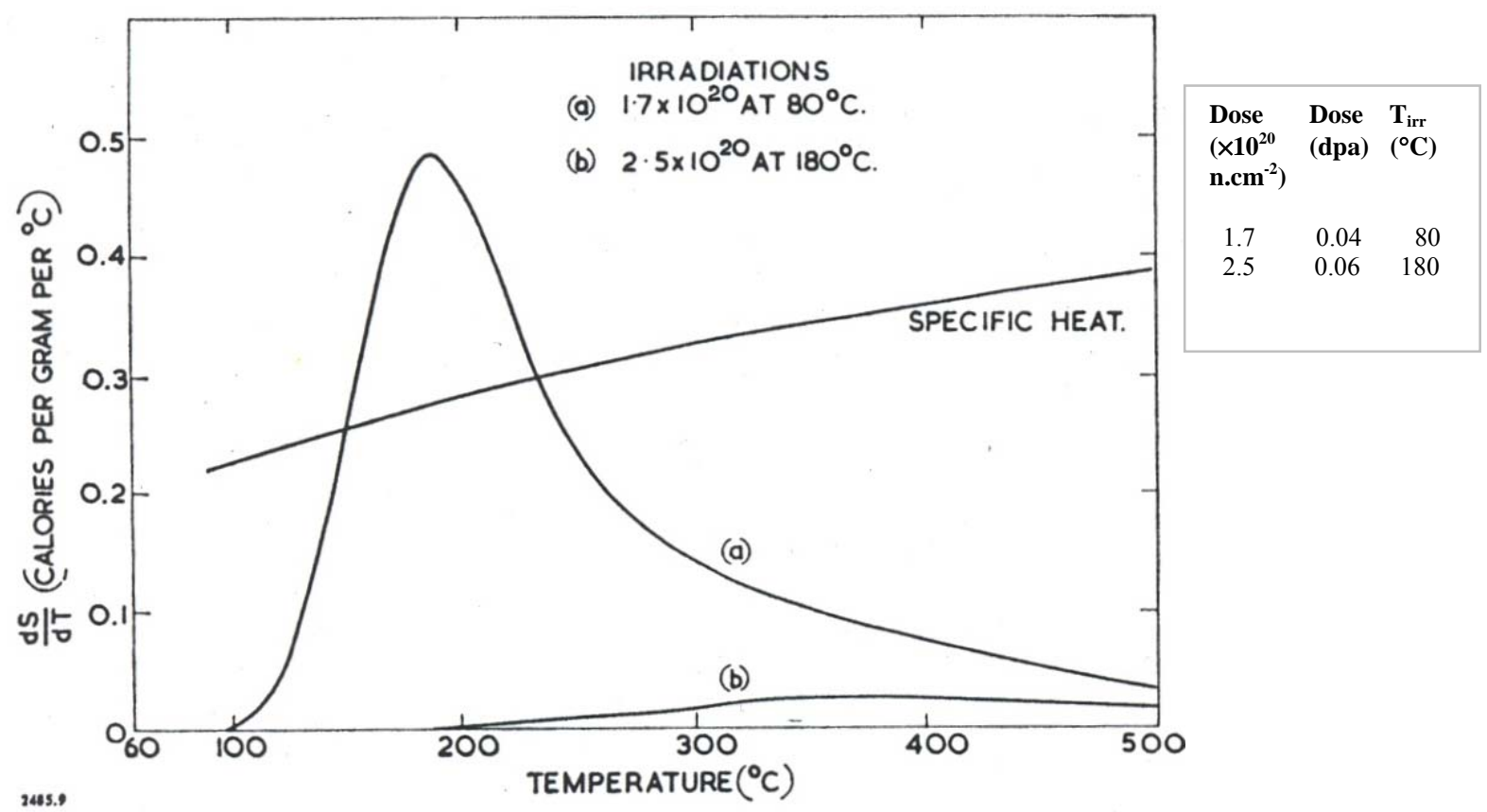

Figure 18. Rates of release of stored energy (measured by linear rise method) for graphites irradiated at 80 and $180{ }^{\circ} \mathrm{C}^{57}$ 


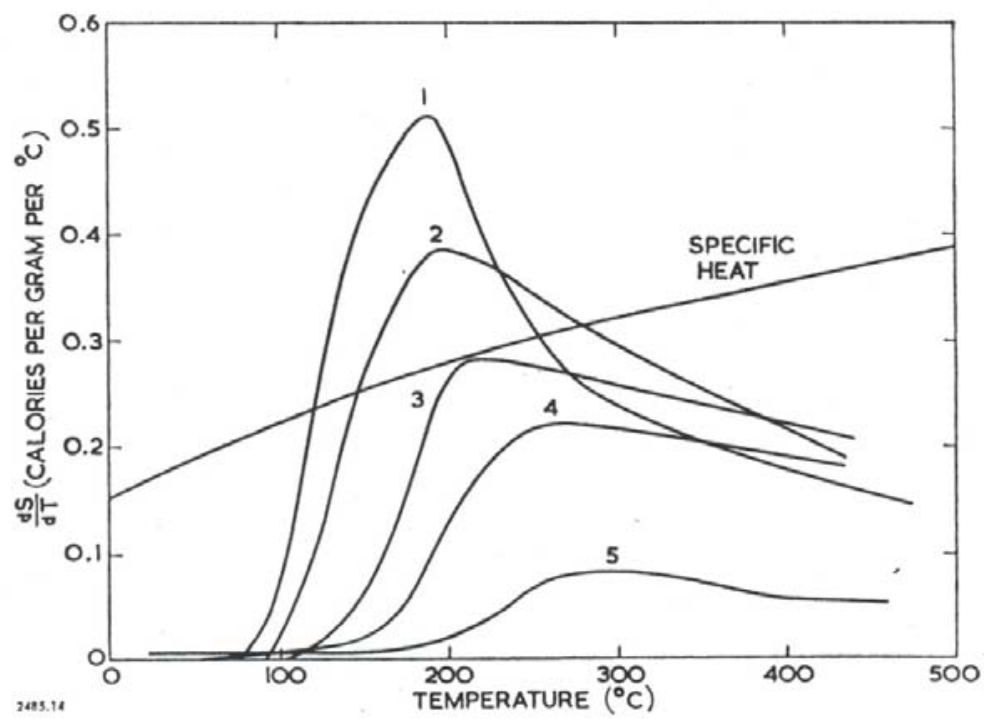

\begin{tabular}{|ccc|}
\hline Sample & $\begin{array}{c}\text { Relative } \\
\text { neutron dose }\end{array}$ & $\begin{array}{c}\text { Estimated } \mathbf{T}_{\text {irr }} \\
\left({ }^{\circ} \mathbf{C}\right)\end{array}$ \\
1 & 0.39 & 30 \\
2 & 0.81 & 50 \\
3 & 1.00 & 80 \\
4 & 0.95 & 105 \\
5 & 0.51 & 145 \\
& & \\
& & \\
\hline
\end{tabular}

Figure 19. Rates of release of stored energy (measured by linear rise method) for graphites irradiated at temperatures from 30 to $145^{\circ} \mathrm{C}^{57}$

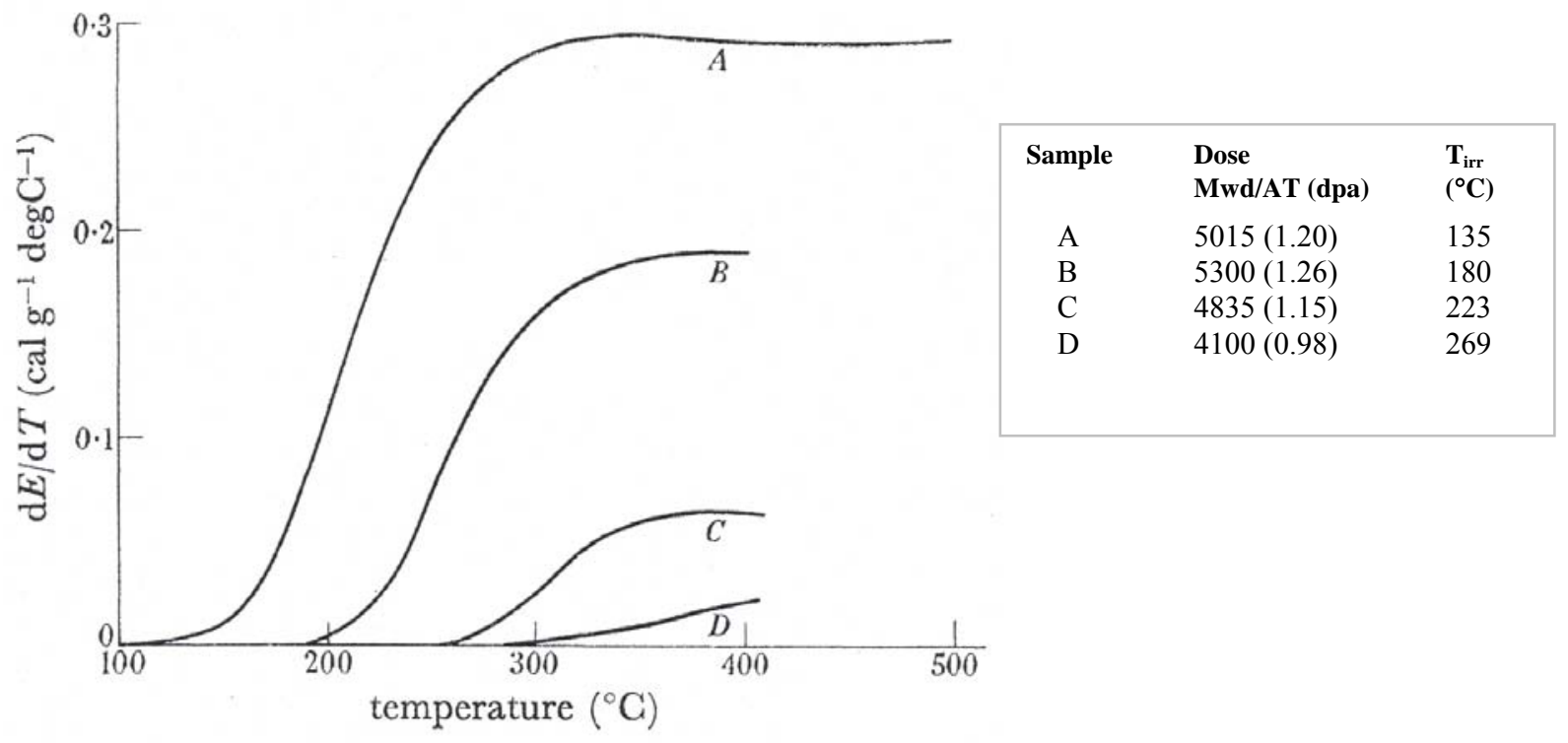

Figure 20. The effect of irradiation temperature (from 135 to $269^{\circ} \mathrm{C}$ ) on the rate of release of stored energy at equivalent irradiation dose. ${ }^{32}$ 


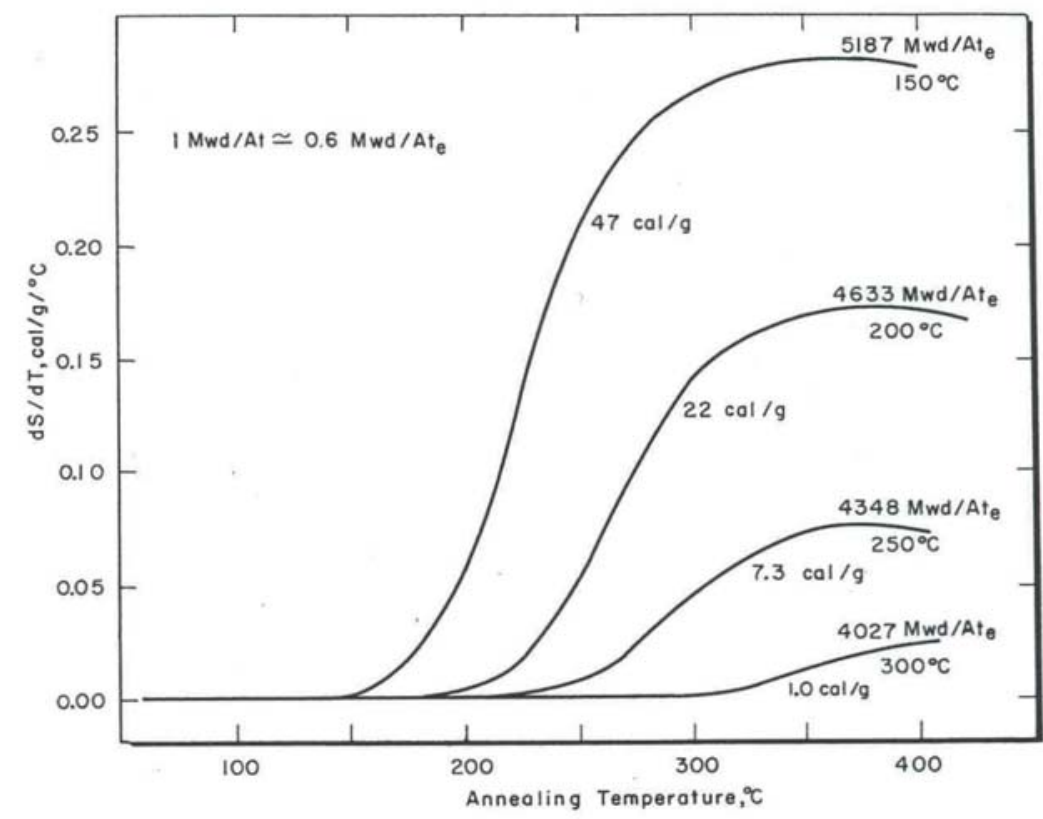

\begin{tabular}{|ll|}
\hline $\begin{array}{l}\text { Dose } \\
\text { MWd/ATe }\end{array}$ & $\begin{array}{l}\text { Dose } \\
\text { dpa }\end{array}$ \\
5187 & 0.74 \\
4633 & 0.66 \\
4348 & 0.62 \\
4027 & 0.58 \\
& \\
& \\
\hline
\end{tabular}

Figure 21. The effect of irradiation temperature on stored energy release curves for exposures around 0.66 dpa. Numbers under the curves give the stored energy released to $400{ }^{\circ} \mathrm{C} .{ }^{49}$

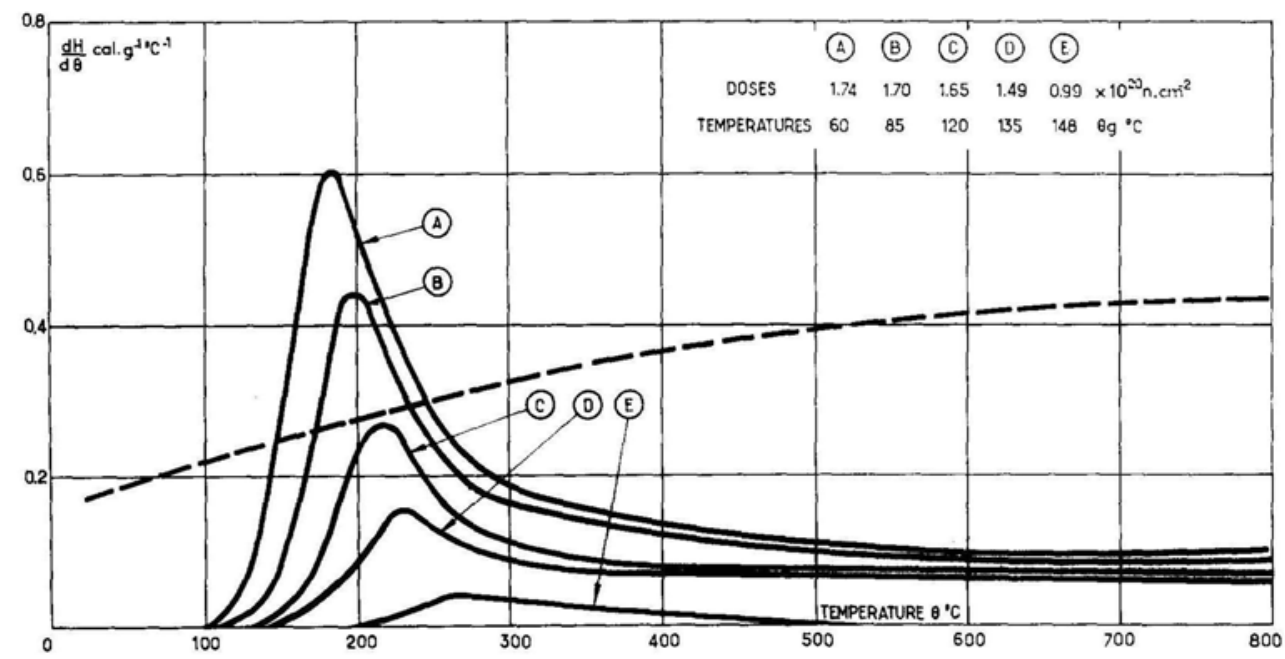

\begin{tabular}{|c|c|}
\hline 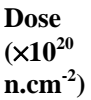 & $\begin{array}{l}\text { Dose } \\
\text { (dpa) }\end{array}$ \\
\hline 1.74 & 0.04 \\
\hline 1.70 & 0.04 \\
\hline 1.65 & 0.04 \\
\hline 1.49 & 0.03 \\
\hline 0.99 & 0.02 \\
\hline
\end{tabular}

Figure 22. The effect of irradiation temperature on release of stored energy for graphites irradiated in the $G 1$ reactor. ${ }^{66}$

Some data for irradiation temperatures above $300{ }^{\circ} \mathrm{C}$ are shown in Figure 23, which shows measurements of energy release rate following irradiations at 350 and $390{ }^{\circ} \mathrm{C}$. The first thing to notice is the absence of a well-defined "release peak," along with a very low magnitude of the released energy 
$\left(<0.08 \mathrm{cal} / \mathrm{g} /{ }^{\circ} \mathrm{C}\right)$. Additionally, the temperature at which the release becomes detectable increases with the irradiation temperature - in this case, very close to the irradiation temperature of the graphite. ${ }^{67,12}$

A few studies ${ }^{68,69,70,56}$ can be found on the behavior of graphite irradiated at higher temperatures (from 850 up to $\sim 1500 \mathrm{C}^{\circ}$ ); however, these studies deal mainly with dimensional changes and changes to the crystallite dimensions. Nightingale et al. ${ }^{56}$ did measure the total stored energy of a graphite sample irradiated at $750{ }^{\circ} \mathrm{C}$ and found it to be only $9 \mathrm{cal} / \mathrm{g}$, significantly lower than the energy content of those graphites irradiated at lower temperatures. The study did not evaluate the release rate of the stored energy.

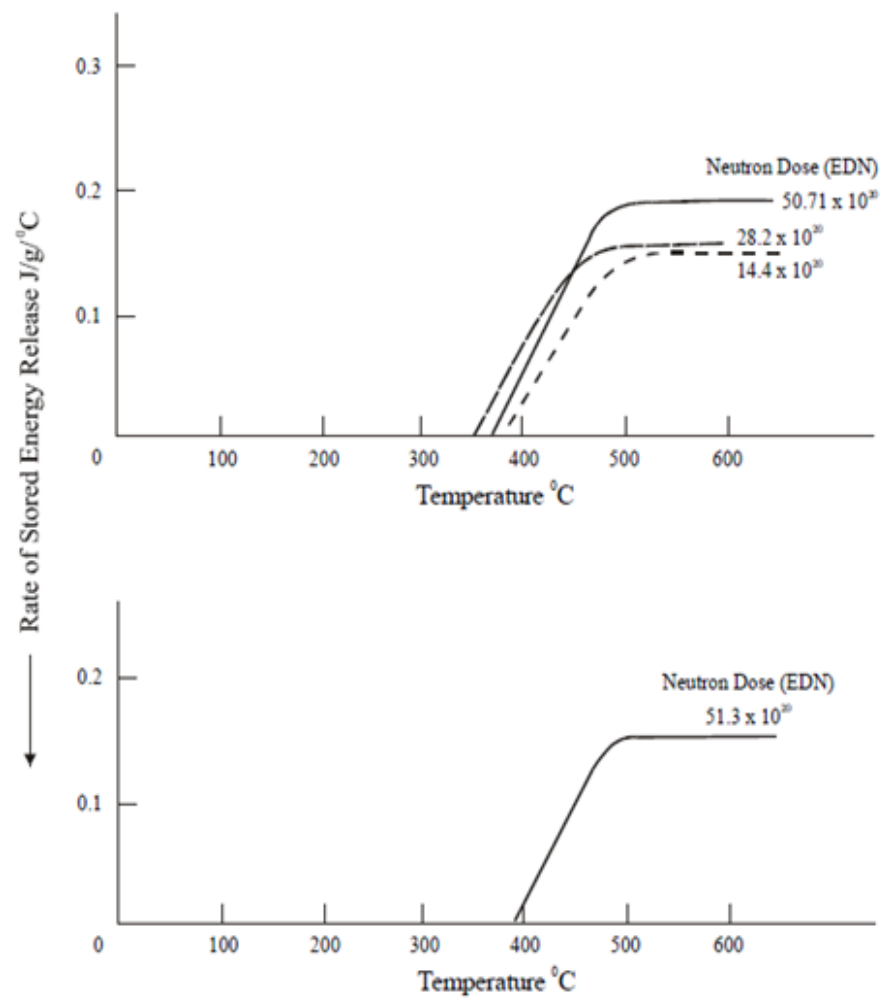

\begin{tabular}{|ll|}
\hline $\begin{array}{l}\text { Dose } \\
\times \mathbf{1 0}^{\mathbf{2 0}} \mathbf{E D N}\end{array}$ & $\begin{array}{l}\text { Dose } \\
\text { dpa }\end{array}$ \\
50.71 & 6.64 \\
28.2 & 3.69 \\
14.4 & 1.89 \\
& \\
$\mathrm{~T}_{\text {irr }}=350^{\circ} \mathrm{C}$ & \\
\hline
\end{tabular}

\begin{tabular}{|lc|}
\hline \multicolumn{2}{|l|}{ Energy release scale } \\
$\mathbf{J} / \mathbf{g} /{ }^{\circ} \mathbf{C}$ & $\mathbf{c a l} / \mathbf{g} /{ }^{\circ} \mathbf{C}$ \\
& \\
0.1 & 0.024 \\
0.2 & 0.048 \\
0.3 & 0.072 \\
\hline
\end{tabular}

\begin{tabular}{ll}
$\begin{array}{l}\text { Dose } \\
\times \mathbf{1 0}^{\mathbf{2 0}} \mathbf{E D N}\end{array}$ & $\begin{array}{l}\text { Dose } \\
\text { dpa }\end{array}$ \\
51.3 & 6.72 \\
$\mathrm{~T}_{\text {irr }}=390^{\circ} \mathrm{C}$ & \\
\hline
\end{tabular}

Figure 23. Release rate curves for graphite irradiated at $350{ }^{\circ} \mathrm{C}$ (top) and $390{ }^{\circ} \mathrm{C}$ (bottom). ${ }^{12}$

Rappeneau ${ }^{66}$ compared his results to those of Neubert and Lees, ${ }^{61}$ Nightingale et al., ${ }^{56}$ and Simmons ${ }^{21}$ and plotted the stored energy as a function of irradiation temperature (see Figure 24) for graphites that received a low irradiation dose of $\sim 2 \times 10^{20} \mathrm{n} / \mathrm{cm}^{2}(\sim 0.04 \mathrm{dpa})$. Data was obtained by one of two methods: (1) integration of the DTA curve to a temperature of $800^{\circ} \mathrm{C}, \mathrm{H}(\theta) 800$; or (2) difference between the heat of combustion of irradiated and unirradiated graphite samples, $\mathrm{H}_{\mathrm{t}}$.

For the low irradiation dose, the difference between the $\mathrm{H}(\theta) 800$ and $\mathrm{H}_{\mathrm{t}}$ is a maximum of $15-20 \mathrm{cal} / \mathrm{g},{ }^{66}$ which is fairly small. Considering this difference and the fact that there are various uncertainties related to the estimation of the irradiation dose and temperature in each of the reactors, and errors related to the energy the measurements themselves, the correlation of the various results is remarkable. The data points are all grouped in a single curve (Figure 24), where a rapid decrease of the stored energy with increasing irradiation temperature is observed, corresponding with the gradual disappearance of the release peak. 


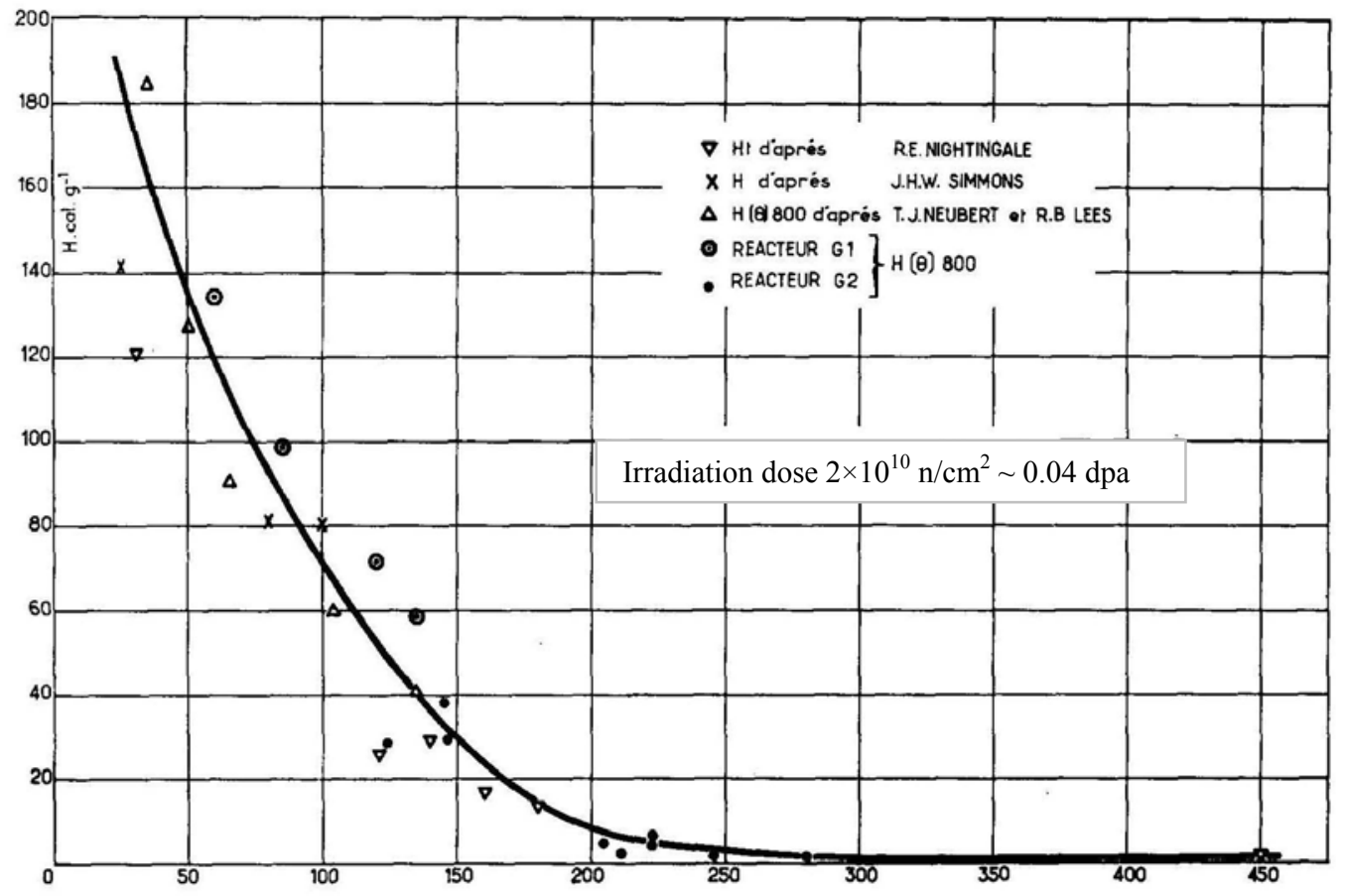

Figure 24. Effect of the irradiation temperature on the stored energy of graphite irradiated at a dose of $\sim 0.04 \mathrm{dpa}^{66}$

Kelly et al. ${ }^{71}$ worked out a model function of equivalent dose and Calder equivalent temperature for pile grade A graphite $\S$ and concluded that the stored energy saturates at temperatures between 100 and $300{ }^{\circ} \mathrm{C}$ (Figure 25).

$\S$ In the Kelly et al. ${ }^{71}$ paper, the details of the model are not very clear. 


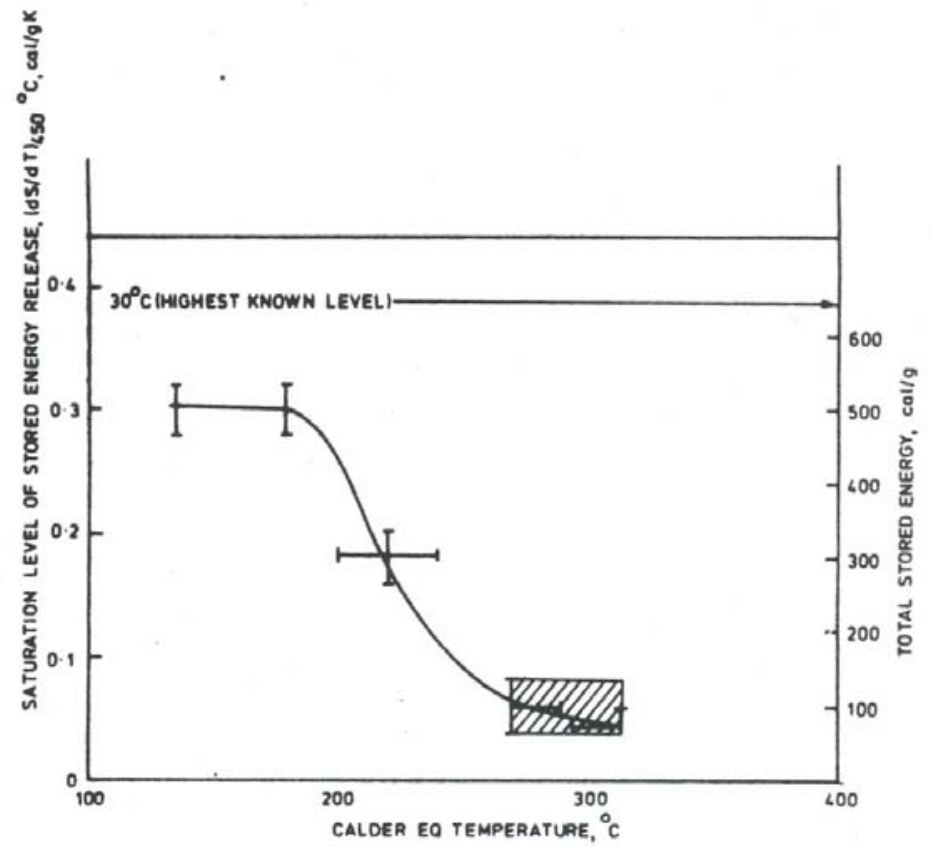

Figure 25. Predicted levels of saturation of stored energy. ${ }^{71}$

\subsubsection{Effects of the degree of graphitization}

Irradiation-induced expansion is substantially reduced in noncrystalline carbons during roomtemperature irradiation, and therefore it is expected that poorly graphitized carbons would be less susceptible to the buildup of stored energy. The effects of irradiation at room temperature on the release curves of carbon powders with various degrees of crystallinity are shown in Figure 26 . The $200{ }^{\circ} \mathrm{C}$ peak vanishes, and the stored energy released up to $600{ }^{\circ} \mathrm{C}$ lessens as the degree of crystallinity is reduced. It should be noted that carbon black and polymer carbon are extreme examples of noncrystalline carbons. 


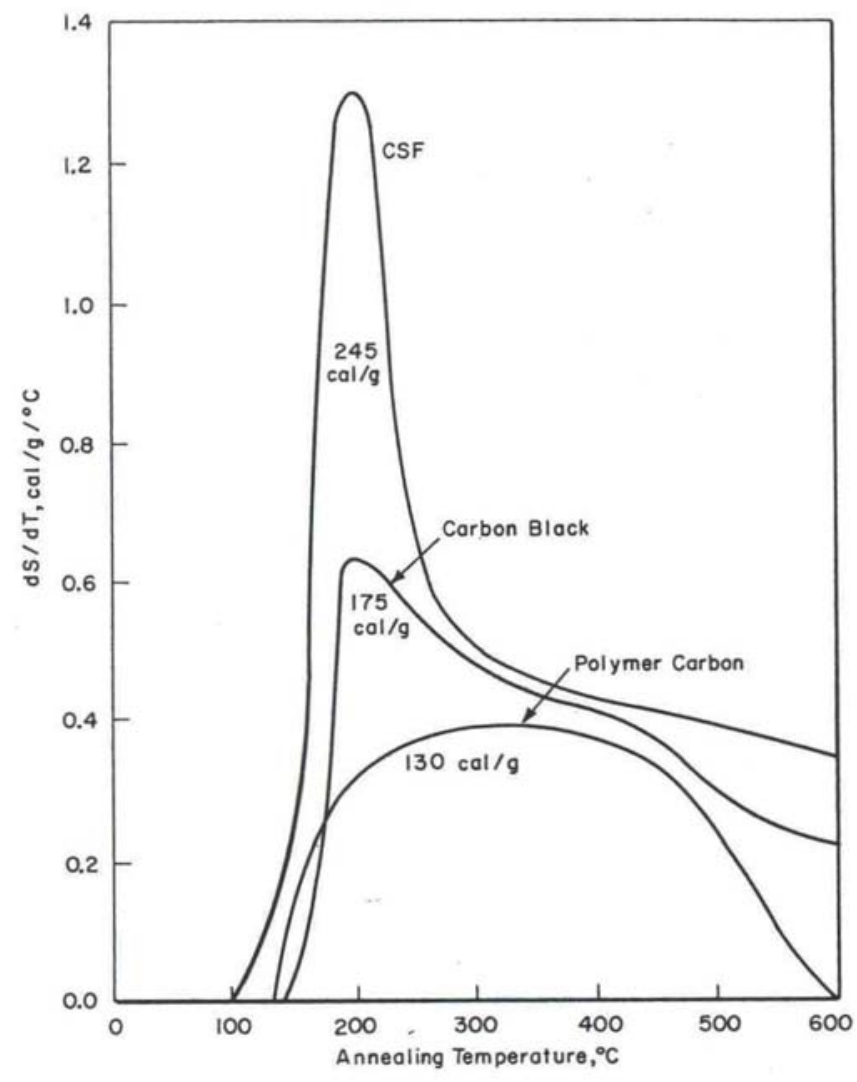

Figure 26. Stored energy in special carbons (exposure, $530 \mathrm{MWd} / \mathrm{AT}$ or $0.05 \mathrm{dpa}$ ). CSF, carbon black, and polymer carbon have decreasing degrees of crystallinity. The stored energy released to $600{ }^{\circ} \mathrm{C}$ is given by the numbers under the curves. ${ }^{49}$ 


\subsubsection{Release curves at high annealing temperatures}

Experimental data summarized in the previous section showed that the accumulation of total stored energy as a function of fast neutron dose tends to saturation and reduces in magnitude with increased irradiation temperature. In addition, after the $200^{\circ} \mathrm{C}$ peak, the rate of release of stored energy decreases, falling below the specific heat, at irradiation temperatures above $100^{\circ} \mathrm{C}$ as a function of neutron dose. However, the maximum graphite irradiation temperature for the data presented is $400{ }^{\circ} \mathrm{C}$, and the annealing behavior has been studied in general for temperatures up to about $500-600{ }^{\circ} \mathrm{C}$. It is of interest too to determine if residual stored energy remains in the irradiated graphite after annealing at these temperatures.

Kinchin ${ }^{62}$ presented data on the total stored energy (determined by heats of combustion) and the energy released up to about $400{ }^{\circ} \mathrm{C}$ as a function of dose $(<\sim 0.03 \mathrm{dpa})$ for irradiation at $30^{\circ} \mathrm{C}$ (Figure 27). The data shows that annealing temperatures $>400{ }^{\circ} \mathrm{C}$ are required to release the stored energy accumulated in graphites irradiated at room temperature and doses $>1.0 \mathrm{n} / \mathrm{cm}^{2}(0.02)$. Analysis by Hennig and Hove ${ }^{72}$ also showed that for room temperature irradiations, stored energy in lightly damaged graphites anneals considerably at about $200{ }^{\circ} \mathrm{C}$; however, for more heavily irradiated graphite, a progressively smaller fraction of the damage anneals near $200^{\circ} \mathrm{C}$ and a larger fraction requires much higher temperature for annealing.

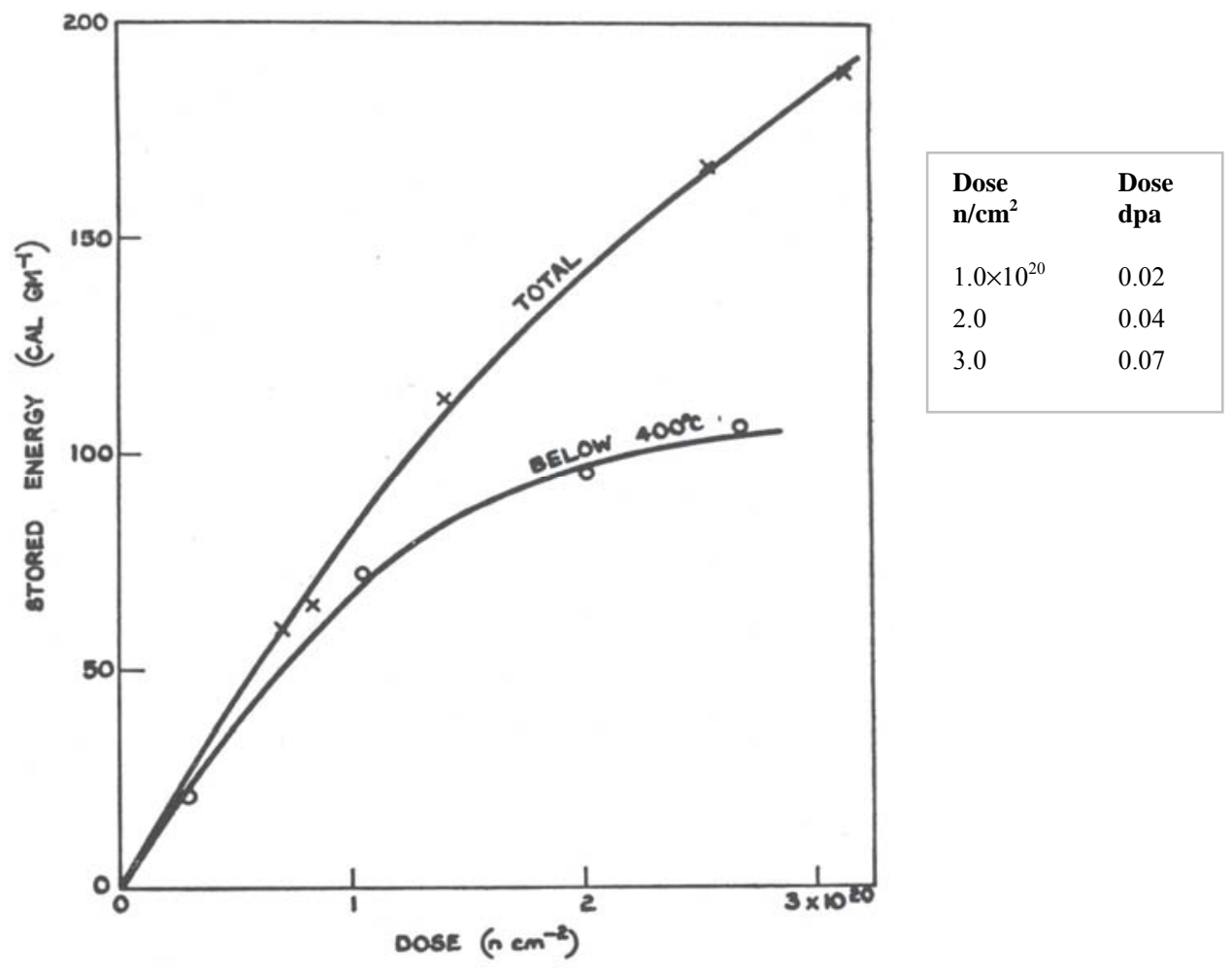
$30{ }^{\circ} \mathrm{C}^{62}$

Figure 27. Total stored energy and energy release below about $400{ }^{\circ} \mathrm{C}$; irradiation temperature

Similarly, Woods et al. ${ }^{63}$ showed the total stored energy in irradiated graphite as a function of dose and the stored energy that remains after prolonged annealing at $1000{ }^{\circ} \mathrm{C}$ for irradiations at $30^{\circ} \mathrm{C}$ (Figure 28). The difference (shown as a dotted line in Figure 28) is the amount of stored energy that was released during the annealing. One should notice that, as shown earlier (see Figure 11), the stored energy effects are large: 
$500 \mathrm{cal} / \mathrm{g}$ of stored energy represents the energy required to raise the temperature of a gram of graphite more than $1200{ }^{\circ} \mathrm{C}$. The second observation is that all of the stored energy accumulated during brief irradiations can be released by annealing at a temperature of $1000^{\circ} \mathrm{C}$, but essentially none of the incremental amounts of stored energy accumulated after exposures greater than $13 \times 10^{20} \mathrm{n} / \mathrm{cm}^{2}(\sim 0.3 \mathrm{dpa})$ can be released by annealing at a temperature of $1000^{\circ} \mathrm{C}$.

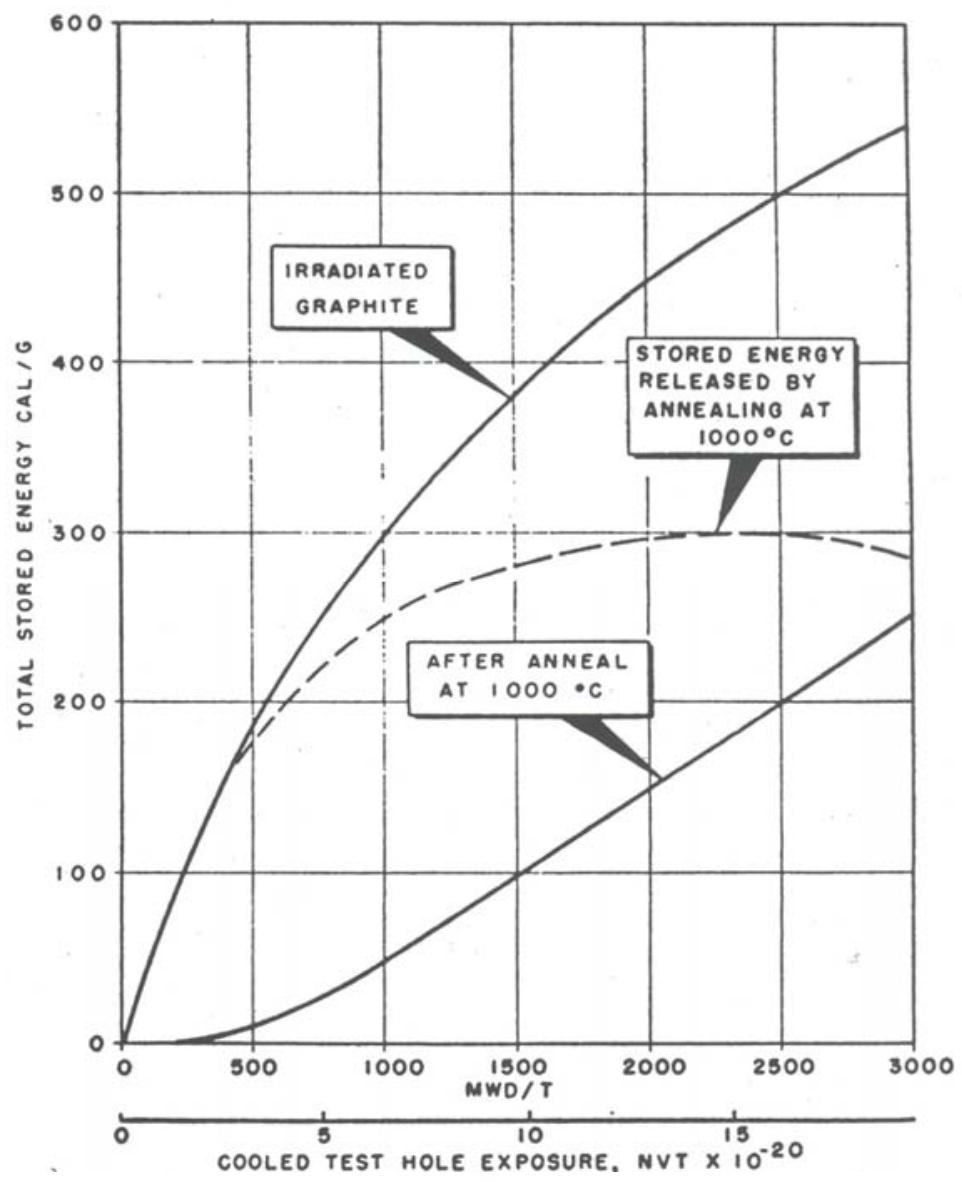

$\begin{array}{ll}\begin{array}{l}\text { Dose } \\ \text { MWD/AT }\end{array} & \begin{array}{l}\text { Dose } \\ \text { dpa }\end{array} \\ 500 & 0.07 \\ 1000 & 0.14 \\ 1500 & 0.21 \\ 2000 & 0.29 \\ 2500 & 0.36 \\ 3000 & 0.43 \\ & \\ \mathbf{T}_{\text {irr }}=\mathbf{3 0}^{\circ} \mathbf{C} & \end{array}$

Figure 28. Buildup of total stored energy in graphite irradiated at $30^{\circ} \mathrm{C}$ and residual stored energy after annealing at $1000^{\circ} \mathrm{C}^{63}$

Powell et al. ${ }^{73}$ also showed that there is remaining stored energy (in the range of 35 up to $\sim 50 \mathrm{cal} / \mathrm{g}$ ) even after annealing at $1000{ }^{\circ} \mathrm{C}$ in graphites taken from the $\mathrm{BNL}$ reactor at the end of the pile anneal (Figure 29). The measurements were made by complete combustion (calorimetry) at the National Bureau of Standards. 


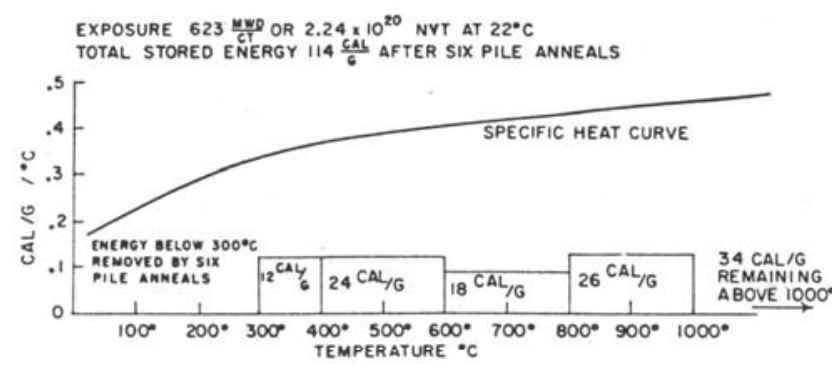

Dose : 623 MWD/AT 0.09 (dpa)

Tirr: $22^{\circ} \mathrm{C}$

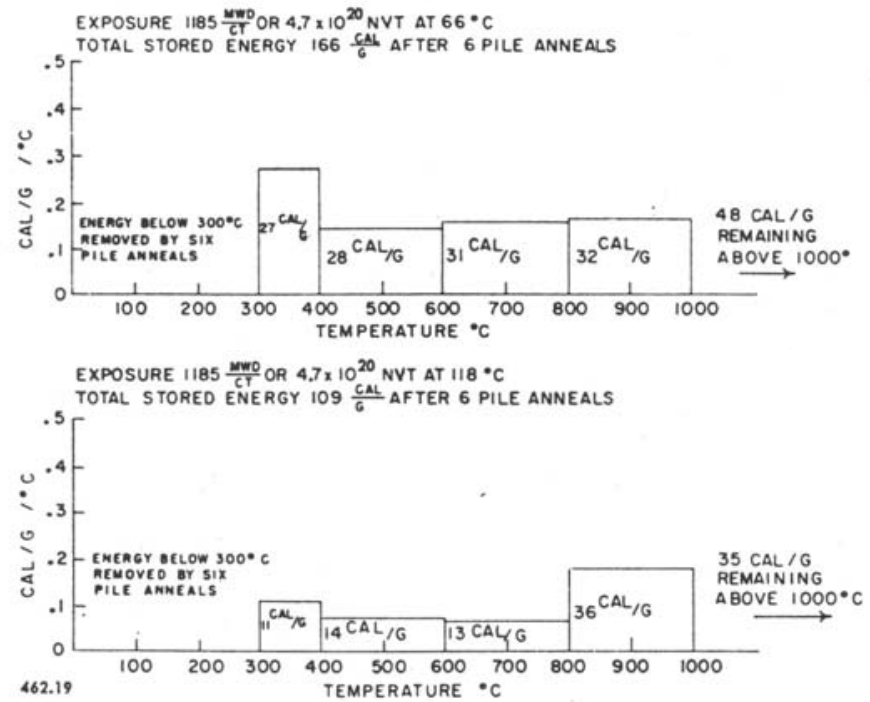

Dose : 1185 MWD/AT 0.17 (dpa)

Tirr: $66^{\circ} \mathrm{C}$

Dose : 1185 MWD/AT 0.17 (dpa)

$\mathbf{T}_{\text {irr }}: 118^{\circ} \mathrm{C}$

Figure 29. Release curves measured by complete combustion (calorimetry) showing residual stored energy even after annealing at $1000{ }^{\circ} \mathrm{C} .{ }^{73}$

The evidence shown, that unreleased stored energy remains in irradiated graphite even after annealing at $1000{ }^{\circ} \mathrm{C}$, leads to the question, what temperatures are required to release all of the stored energy and in what manner would this release occur, leading to the prediction of an additional release peak at higher temperatures. Some literature data ${ }^{74}$ claim that, in addition to the rate of release peak at $200{ }^{\circ} \mathrm{C}$, there is another peak in the rate of release curve at around $1200{ }^{\circ} \mathrm{C}$ for graphites irradiated at lower temperatures. However, UK researchers consider that the heat released at this temperature would be insignificant as compared with the heat generated by thermally oxidizing graphite at $120{ }^{\circ} \mathrm{C}$, assuming, of course, that sufficient oxygen could be made available to the graphite internal porosity, which is unlikely at such a high temperature. The heat of combustion of graphite is $3.26 \times 10^{4} \mathrm{~J} / \mathrm{g}$, and the highest level of stored energy ever measured is $2.7 \times 10^{3} \mathrm{~J} / \mathrm{g}$.

The behavior of irradiated graphite at high annealing temperatures (stored energy release curves) is difficult to evaluate experimentally at high temperatures, and very little data have been reported above $500{ }^{\circ} \mathrm{C}$. Nightingale ${ }^{49}$ refers to data from a classified report by Ballinger, in which he measured the release curve to $800{ }^{\circ} \mathrm{C}$ for a sample exposed at approximately $30{ }^{\circ} \mathrm{C}$ for $650 \mathrm{MWd} / \mathrm{AT}(0.06 \mathrm{dpa}) .{ }^{*}$ In this case the curve contained a broad minimum between 400 and $600{ }^{\circ} \mathrm{C}$, followed by an increase at higher temperatures. However, the stored energy release did not exceed the specific heat in the high temperature region.

\footnotetext{
* These results were mentioned by Nightingale in his book; however, the corresponding graph was not shown.
} 
Nightingale et al. ${ }^{56}$ reported on the stored energy annealed in three broad temperature ranges, for TSBG graphite irradiated at $30^{\circ} \mathrm{C}$ and doses of up to $0.71 \mathrm{dpa}$, as shown in Table 1 . The stored energy released in the $\sim 5000 \mathrm{MWD} / \mathrm{AT}(0.72 \mathrm{dpa})$ sample in each of the three temperature ranges approached the value of the specific heat integrated over the temperature interval (Figure 30). ${ }^{49}$ This implies that a self-sustained energy release might be started at $100-200{ }^{\circ} \mathrm{C}$, which would cause a spontaneous temperature increase to temperatures on the order of $1000{ }^{\circ} \mathrm{C} .{ }^{56}$ The exact temperature rise would depend on the detailed form of the stored energy release curve and the rate of heat removal. However, it is clear that this would represent a very hazardous situation if significant quantities of graphite moderator were in such condition.

From Table 1 it is also observed that as the radiation damage becomes more severe, a larger fraction of the stored energy anneals at the higher temperatures; however, most of the stored energy is annealed at temperatures $\sim 1800^{\circ} \mathrm{C}$, and only energy levels in the range $5-10 \mathrm{cal} / \mathrm{g}$ remain.

Table 1. Stored energy annealing ${ }^{56}$

\begin{tabular}{|c|c|c|c|c|}
\hline \multirow{2}{*}{$\begin{array}{l}\text { Exposure at } 30^{\circ} \mathrm{C} \\
{[\mathrm{MWD} / \mathrm{AT}(\mathrm{dpa})]}\end{array}$} & \multirow{2}{*}{$\begin{array}{c}\text { Total stored } \\
\text { energy } \\
(\mathrm{cal} / \mathrm{g})\end{array}$} & \multicolumn{3}{|c|}{ Stored energy anneal in 3 hours (cal/g) } \\
\hline & & Up to $800{ }^{\circ} \mathrm{C}$ & $\begin{array}{c}\text { Between } 800 \text { and } \\
1300^{\circ} \mathrm{C}\end{array}$ & $\begin{array}{c}\text { Between } 1300 \text { and } \\
1800^{\circ} \mathrm{C}\end{array}$ \\
\hline$\sim 600(0.09)$ & 210 & 160 & 35 & 5 \\
\hline$\sim 2000(0.29)$ & 425 & 280 & 100 & 40 \\
\hline$\sim 5000(0.72)$ & 630 & 275 & 170 & 175 \\
\hline
\end{tabular}




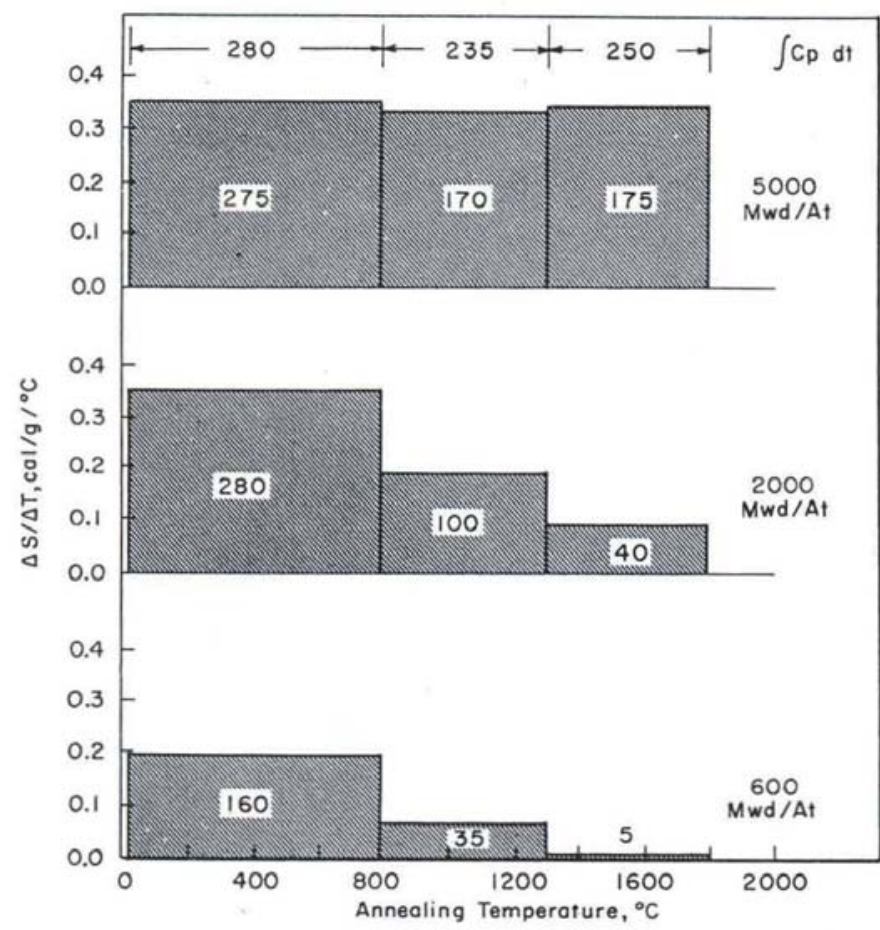

\begin{tabular}{|ll|}
\hline $\begin{array}{l}\text { Dose } \\
\text { MWD/AT }\end{array}$ & $\begin{array}{l}\text { Dose } \\
\text { dpa }\end{array}$ \\
5000 & 0.72 \\
2000 & 0.29 \\
600 & 0.09 \\
& \\
$\mathbf{T}_{\text {irr }}=\mathbf{3 0}^{\circ} \mathbf{C}$ & \\
\hline
\end{tabular}

Figure 30. Stored energy released from TSGBF graphite irradiated at $30^{\circ} \mathrm{C}$. The numbers inside the areas give the stored energy (in cal/g) released in the corresponding temperature range. ${ }^{* *}$ The specific heat integrated over each temperature range is given at the top of the figure. ${ }^{49}$

The apparent heat content $H\left(T_{1}, T_{2}\right)$ between $T_{1}$ and $T_{2}$, defined by

$$
H\left(T_{1}, T_{2}\right)=\int_{T_{1}}^{T_{2}} C_{p} d T-\int_{T_{1}}^{T_{2}} \frac{d S}{d T} d T
$$

will be negative if the stored energy is sufficient for the graphite to self-heat between $T_{1}$ and $T_{2}$; if the stored energy is insufficient for the graphite to self-heat, the amount of energy required to raise the temperature from $T_{1}$ to $T_{2}$ is given by $H\left(T_{1}, T_{2}\right)$. For the samples exposed at 2000 and $5000 \mathrm{MWd} / \mathrm{AT}(0.29$ and $0.72 \mathrm{dpa})$, $H(25,800) \cong 0$. Above $800{ }^{\circ} \mathrm{C}, H\left(800, T_{2}\right)$ is greater than zero for these samples, but it is appreciably less than the value for unirradiated graphite. It appears that the stored energy builds up to a maximum of about $280 \mathrm{cal} / \mathrm{g}$ in the 25 to $800^{\circ} \mathrm{C}$ range.

Furthermore, Woods et al. ${ }^{63}$ also reported results for anneals up to $2000{ }^{\circ} \mathrm{C}$ (Figure 31 ). The slope of the curve in the figure is the stored energy released per unit change in annealing temperature. According to Woods, " ... for these samples the average stored energy release is about $0.22 \mathrm{cal} / \mathrm{g} \cdot{ }^{\circ} \mathrm{C}$ over the range from 100 to $1100{ }^{\circ} \mathrm{C}$. The release then increases to about $0.6 \mathrm{cal} / \mathrm{g} \cdot{ }^{\circ} \mathrm{C}$, and subsides to a value of about $0.1 \mathrm{cal} / \mathrm{g} \cdot{ }^{\circ} \mathrm{C}$ at annealing temperatures above $1500{ }^{\circ} \mathrm{C} . "$ However, Rappeneau et al. ${ }^{74}$ in his paper from 1966 reproduced

\footnotetext{
** The values of total stored energy (in the shaded area of the figure) are obtained by calorimetry of sample after annealing at each temperature $T_{1}$ and $T_{2}$ and then calculating the difference in stored energy between $T_{l}$ and $T_{2}$. The $\Delta S / \Delta T$ is computed as an average of the stored energy over the given temperature range.
} 
Woods's data and overlapped his calculated release rate, as shown in Figure 32. The Rappeneau et al. calculation of the release rate shows a peak at $200{ }^{\circ} \mathrm{C}$ with an intensity of $\sim 0.6 \mathrm{cal} / \mathrm{g} \cdot{ }^{\circ} \mathrm{C}$ and a second peak at about $1400{ }^{\circ} \mathrm{C}$ with an intensity of $\sim 0.9 \mathrm{cal} / \mathrm{g} \cdot{ }^{\circ} \mathrm{C}$, much higher values than those reported by Woods in his original paper. Our own analysis of the experimental data indicated that the release peak at $\sim 200{ }^{\circ} \mathrm{C}$ would have a magnitude of $\sim 0.4 \mathrm{cal} / \mathrm{g} \cdot{ }^{\circ} \mathrm{C}$ and the release peak at $1400{ }^{\circ} \mathrm{C}$ would be $\sim 0.67 \mathrm{cal} / \mathrm{g} \cdot{ }^{\circ} \mathrm{C}$, in closer agreement with the Woods' original values.

It is important to note here that Figure 32 (Figure 3 in Rappeneau's paper) has not only been referenced incorrectly, given that the original experimental data came from Woods et al., but also used improperly as evidence of the potential magnitude of the stored energy release peak at high anneal temperatures.

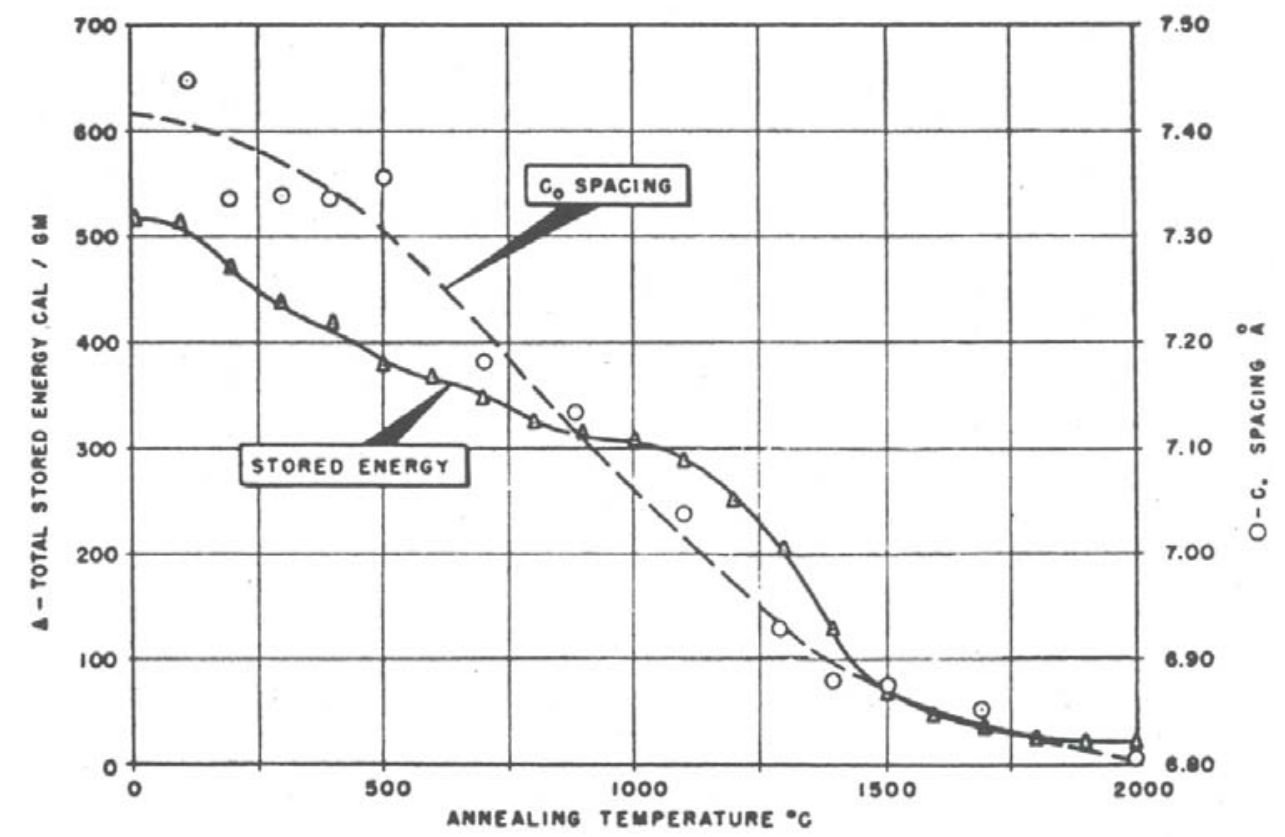

Figure 31. High temperature annealing of stored energy for graphite irradiated at $30{ }^{\circ} \mathrm{C} .{ }^{63}$ 


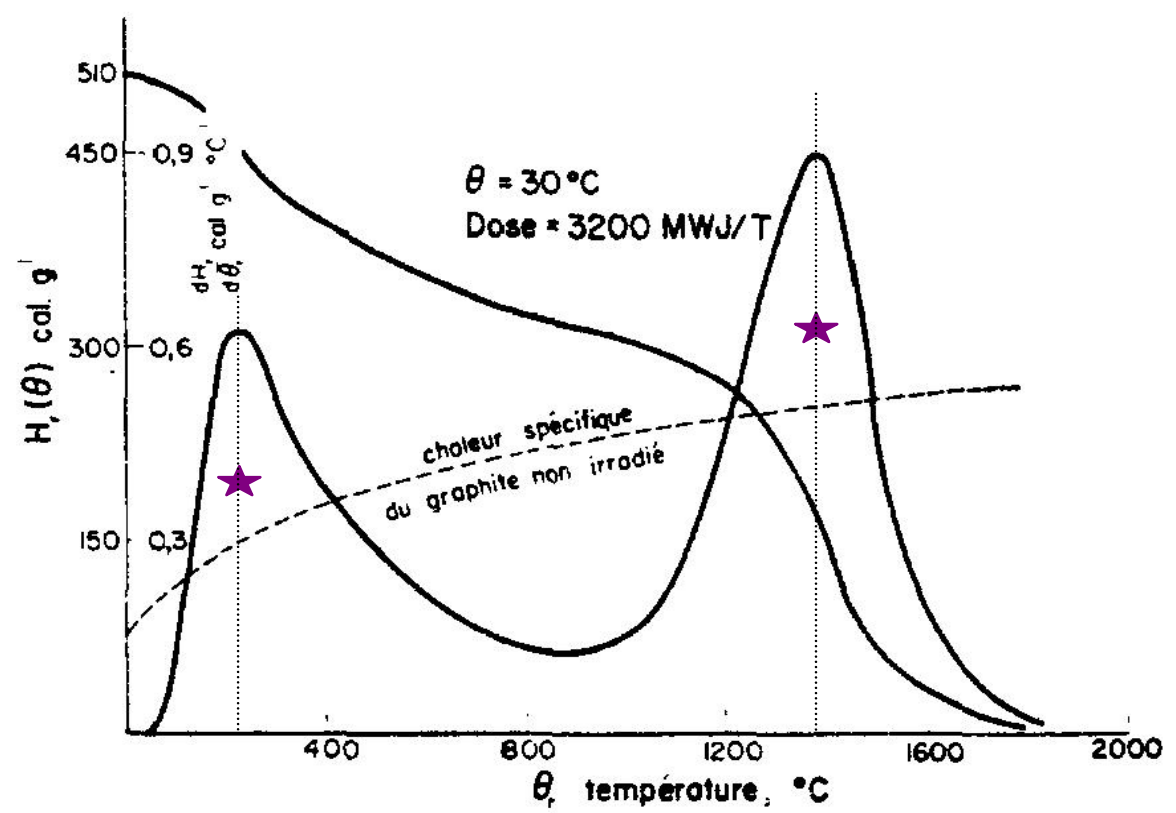

Figure 32. Stored energy release behavior for graphite irradiated at $30^{\circ} \mathrm{C}$ and a dose of $3200 \mathrm{MWd} / \mathrm{AT}$ $(0.27 \mathrm{dpa})$, compared with unirradiated graphite $C_{p}$ behavior. ${ }^{74}$ Note: the stars represent the peak values calculated by the authors, which are in closer agreement to those reported by Woods. ${ }^{63}$

Rappeneau et al. ${ }^{74}$ also reported on their own measurements at higher temperatures using a custom-built differential thermal analysis (DTA) instrument and graphite samples irradiated in the reactors BR.2 (CEN. Mol, Belgium), HFR (Petten, Holland), and G.1 and G.2 (Marcoule, France) at doses between 1000 and $5000 \mathrm{MWd} / \mathrm{AT}(0.09$ and $0.43 \mathrm{dpa})$ and at irradiation temperatures between 30 and $250{ }^{\circ} \mathrm{C}$.

The results in Figure 33 for graphites irradiated in the BR.2 reactor show the systematic presence of a release peak of internal energy at temperatures around $1500{ }^{\circ} \mathrm{C}$ for the sample irradiated at the lowest temperatures of $70{ }^{\circ} \mathrm{C}$, and at $1750{ }^{\circ} \mathrm{C}$ for samples irradiated at the highest temperatures of 170 and $190{ }^{\circ} \mathrm{C}$. The exact position of this peak depends on the irradiation conditions.

The majority of the samples studied by Rappeneau were annealed up to $800^{\circ} \mathrm{C}$ prior to measuring the energy release using his DTA instrument. However, one sample was studied from ambient temperature up to $1900{ }^{\circ} \mathrm{C}$, and in this case the commonly observed peak at about $200{ }^{\circ} \mathrm{C}$ was observed (Figure 33). The behavior leading to the peak is unusual and may be due to the rather high heating rate applied $\left(10^{\circ} \mathrm{C} / \mathrm{min}\right)$. He also observed that the release peak at annealing temperature higher than $\sim 1500{ }^{\circ} \mathrm{C}$ did not appear at doses lower than $1200 \mathrm{MWd} / \mathrm{AT}(0.10 \mathrm{dpa})$. Rappeneau also noted that the results represented in Figure 33 have only a qualitative value. At the time of these tests, it was not possible to measure quantitatively the stored energy because of experimental difficulties that were not yet solved. Therefore, the differential enthalpy $\left(\mathrm{dH} / \mathrm{d} \theta_{\mathrm{R}}\right)$ is affected by proportionality coefficient $\mathrm{k}$. Rappeneau mentioned plans for additional tests to confirm these results; however, we could not find published results of this effort. 


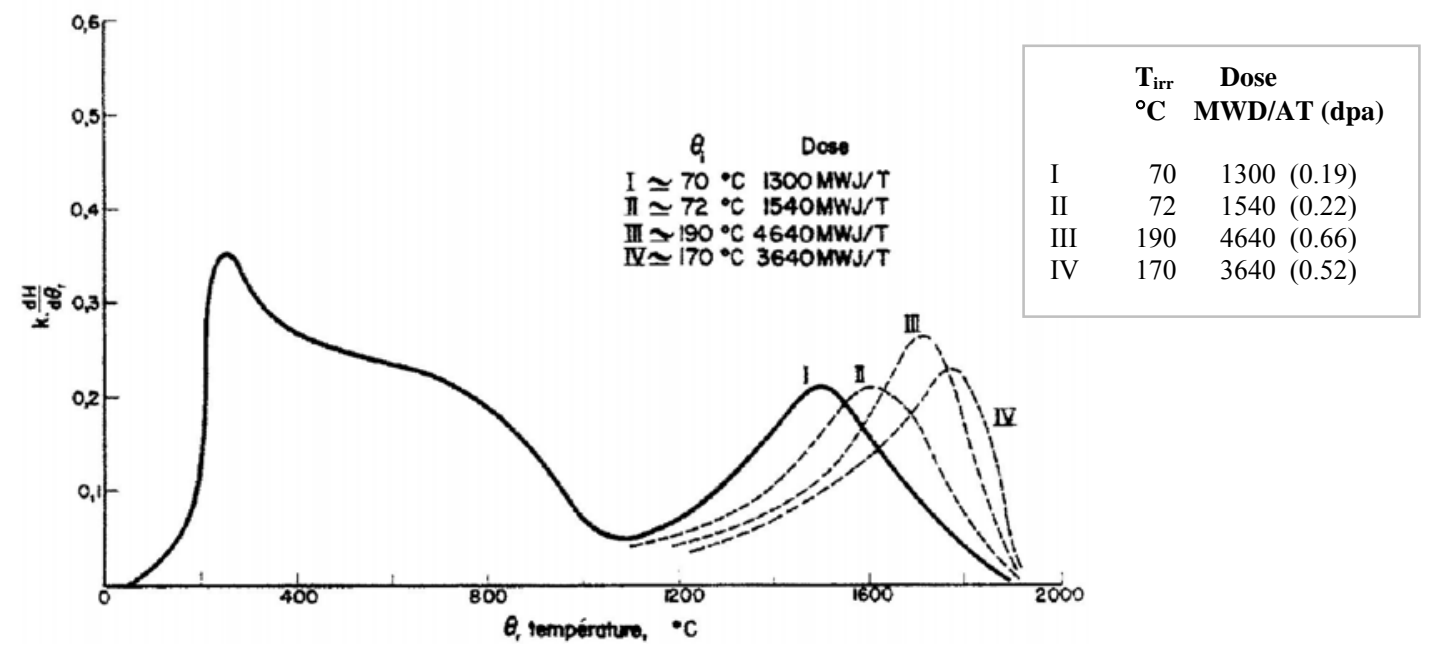

Figure 33. Energy release curves for samples irradiated at the BR. 2 reactor. ${ }^{74}$

Figure 34 shows the high temperature release peak from graphite samples irradiated in the G.1 reactor. The graphite samples were taken from the reactor by "coring" (boring) reactor G.1. This reactor operated at low temperatures $\left(30-170^{\circ} \mathrm{C}\right)$, and it had already undergone annealing operations at maximum temperatures of about $300{ }^{\circ} \mathrm{C}$ to release the energy stored by graphite at low temperatures in an attempt to reduce the dimensional variations of the pile. Of the four samples studied, two were annealed up to $800{ }^{\circ} \mathrm{C}$ prior to measuring the release energy by DTA. Again, a release peak with the maximum temperature of $1250^{\circ} \mathrm{C}$ was observed for samples previously annealed at $800{ }^{\circ} \mathrm{C}$, or at $1400{ }^{\circ} \mathrm{C}$ for samples that were not annealed. The position of the peak's maximum appears at lower temperatures than for the samples irradiated in reactor BR.2 (Figure 33), which agrees with the lower irradiation temperature and underlines the influence of irradiation temperature on the position of the release peak. It was also observed that the lower doses of irradiation received by graphite from pile G.1 led to a release peak of lower amplitude. In addition, annealing at $800{ }^{\circ} \mathrm{C}$ prior to testing could have had a small influence on the shape and position of the maximum of the release peak; however, such behavior has not been confirmed by further testing. 


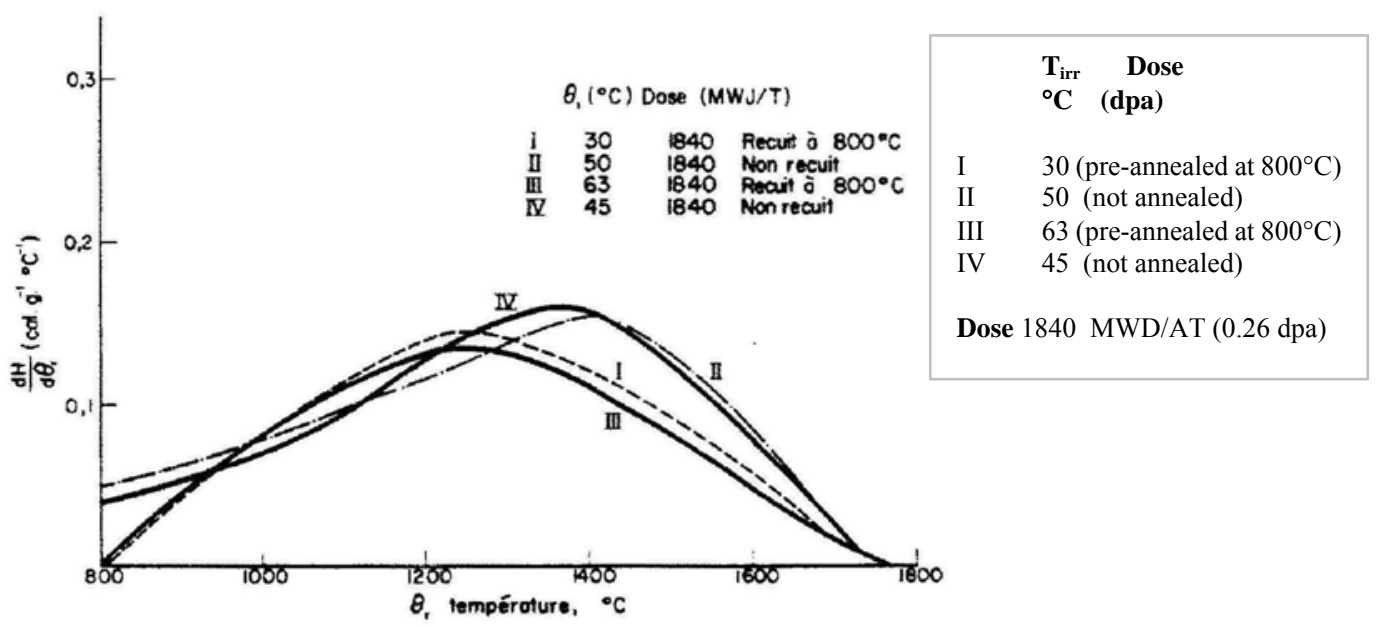

Figure 34. Release curves for samples irradiated in the G. reactor. $^{74}$

Rappeneau also studied the effect of the degree of graphitization on the release peak at high temperatures. The results showed that the samples, which were graphitized well, have a release peak with the maximum at a temperature of $1400{ }^{\circ} \mathrm{C}$ (Figure 35). Considering the conditions of irradiation (dose and temperature), these results confirm previous results. On the contrary, the samples not fully graphitized (sample I in Figure 35) showed, under the same irradiation conditions, a release peak for which the maximum at $1200^{\circ} \mathrm{C}$ is much higher. If this result can be confirmed, then graphite that has not been completely graphitized should have a release peak that exceeds the specific heat of unirradiated graphite $\mathrm{C}_{\mathrm{g}}$, because the value of $\mathrm{C}_{\mathrm{p}}$ is $0.4 \mathrm{cal} / \mathrm{g} \cdot{ }^{\circ} \mathrm{C}$ at $1200^{\circ} \mathrm{C}$. This trend, however, is opposite to that reported by Nightingale ${ }^{49}$ for the release peak at $200^{\circ} \mathrm{C}$ (Figure 26), where the intensity of the peak decreased as the degree of crystallinity (or graphitization) decreased.

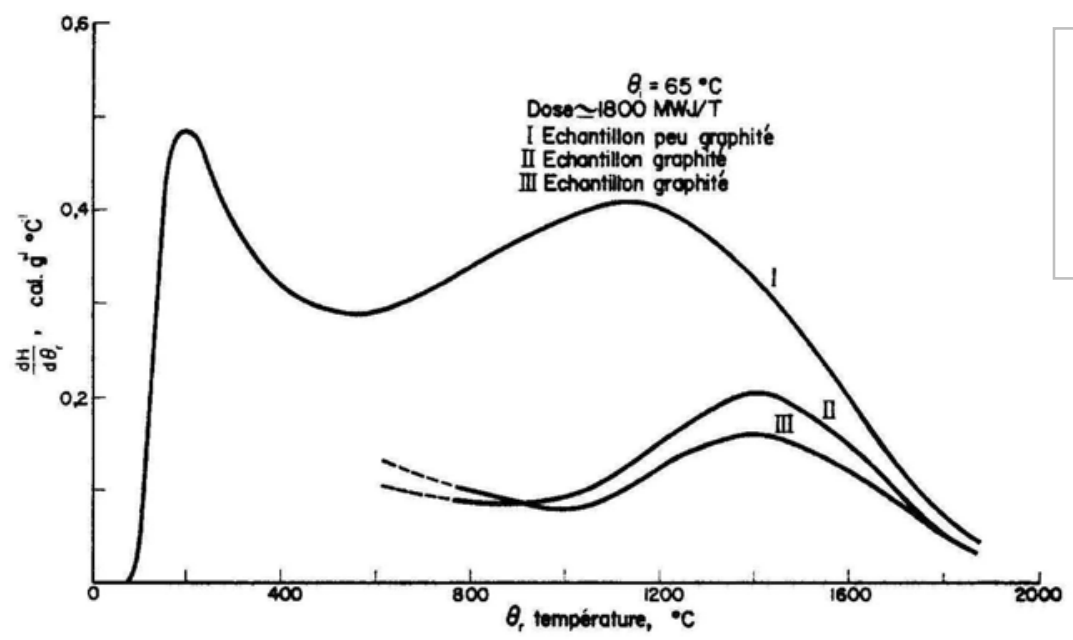

Figure 35. Release curves for graphite samples of various degrees of graphitization, irradiated in the G. 2 reactor. ${ }^{74}$ 
Rappeneau also mentioned preliminary results for graphite samples irradiated at temperatures of about $250{ }^{\circ} \mathrm{C}$ and doses between 2000 and $3000 \mathrm{MWd} / \mathrm{AT}$ ( 0.17 and $0.26 \mathrm{dpa}$ ). The preliminary thermal analysis data appear to show the presence of a peak of release of very weak amplitude because the irradiation damage for graphite is weak, at $250{ }^{\circ} \mathrm{C}$, indicating that much higher irradiation doses would be required to observe an important release peak. Rappeaneau noted that results showing a release of stored energy in the temperature range between 1000 and $1500{ }^{\circ} \mathrm{C}$ need further detailed evaluation. ${ }^{*}$

* Although Rappeneau indicates that work was continuing in order to optimize measurements at temperatures above $1000{ }^{\circ} \mathrm{C}$, we were unable to find additional published work in this area from his group. 


\section{Implications of the Wigner Energy Content}

The stored energy in graphite is due to lattice strain-stress introduced due to irradiation damage, and excludes the elastic strain energy due to localized deformation by the applied load. Stored energy has two important practical effects. First, following irradiations at temperatures below $\sim 150{ }^{\circ} \mathrm{C}$, it is possible to reach a state in which a small temperature rise can be followed by a much larger rise due to the sudden release of stored energy. Graphite irradiated at $\sim 30^{\circ} \mathrm{C}$, for instance, and then heated to $70{ }^{\circ} \mathrm{C}$ can rise rapidly in temperature to $\sim 400{ }^{\circ} \mathrm{C}$, which is approximately that required for thermal oxidation in the presence of oxygen. Second, in the case of graphite irradiated at higher temperatures, the presence of stored energy reduces the heat capacity and hence affects the progress of any transient temperature condition. In other words, the presence of stored energy can be responsible for, or seriously modify, the progression of a graphite reactor accident. ${ }^{12}$ Therefore, monitoring of the stored energy in graphite reactors is a routine practice when the operating temperature is low, because of the effects it has on the thermal capacity of the moderator in accident situations.

The early air-cooled graphite-moderated reactors, which had low irradiation temperature, accumulated large amounts of stored energy. A number of reactors controlled stored energy by regular controlled anneals. The first reactors to be annealed were those at Windscale and BEPO in the United Kingdom. The method used was to shut off the coolant flow and then operate at low power in order to raise the graphite temperatures to $\sim 100{ }^{\circ} \mathrm{C}$. Afterward, the power was cut off and the temperature allowed to rise due to the stored energy release, which then spread through the reactor core. The reactor graphite temperatures rose rapidly to levels between $300{ }^{\circ} \mathrm{C}$ and $400{ }^{\circ} \mathrm{C}$. For this technique to work, it was necessary to choose the duration of the anneal carefully so that there would be enough energy to produce successful propagation but not so much as to produce excessive temperature rise. The amount of nuclear heating applied needed careful control. Eventually, annealing became regarded as a potentially dangerous operation in air-cooled reactors because of the graphite-air reaction, which was enhanced by irradiation damage. In 1957 one of the two Windscale Production Piles ${ }^{75}$ caught fire during an annealing operation. As a result, the annealing process was reviewed and improved methods devised. The fire was due to uranium fuel burning, and subsequent analysis showed that very little graphite was lost due to oxidative weight loss. ${ }^{77}$ Dickson et al. ${ }^{59}$ describe an improved technique used on the BEPO reactor in which a flow of preheated air at $140{ }^{\circ} \mathrm{C}$ to the reactor was maintained throughout the anneal, permitting quasiadiabatic annealing conditions. Similar techniques were applied in France and the United States. ${ }^{48}$

On September 3, 1986, NRC published in the Federal Register (51 FR 3134, 1986) a notice of receipt of a petition for rule making filed by The Committee to Bridge the Gap to consider the subject of graphite fires in U.S. research nuclear reactors. Following this, NRC sponsored research at the Brookhaven National Laboratory (BNL) to initiate a reevaluation of graphite burning and stored energy information. The objective of this evaluation was to develop an analysis of the potential role of stored energy releases in initiating or contributing to graphite burning scenarios in research reactors, as well as an analysis of graphite ignition and self-sustained combustion in the event of a loss-of-coolant accident. The results were reported by BNL (NUREG/CR 7981). ${ }^{3}$

Prior to a detailed analysis of the Windscale accident, the British mistakenly assumed that the accident might have been initiated by a stored energy release that took place during the annealing of the reactor. Subsequent work by both the BNL team and the British showed that this was not true and that the accident was triggered by a uranium fire ${ }^{75,76}$; similar conclusions were drawn by the analysis done at ORNL by Wichner and Ball. ${ }^{77}$ 
The BNL report presented a review and summary of the Windscale and Chernobyl accidents, and it concluded that for the Chernobyl event, there is no evidence that stored energy releases played a role in either initiating or contributing to this accident. An improperly controlled process of annealing the graphite pile at Windscale with nuclear heat damaged the fuel elements, which initiated the uranium fuel to burn. Stored energy releases did not initiate or contribute to this accident either. The conclusions from these analyses are that the potential to initiate or maintain a graphite weight loss due to oxidation is essentially independent of the stored energy in the graphite, and is dependent on other factors that are unique to each research reactor and to Fort St. Vrain. To have self-sustained rapid graphite oxidation in any of these reactors, certain necessary conditions of geometry, temperature, oxygen supply, reaction product removal, and favorable heat balance must be maintained. There is no new evidence associated with either the Windscale accident or the Chernobyl accident, which indicates a credible potential for an accident due to graphite in any of the reactors considered in the BNL review. ${ }^{3}$

Stored energy can be released if the graphite is heated above its irradiation temperature $\left(50{ }^{\circ} \mathrm{C}\right.$ above is typical to achieve a significant release rate), although a temperature in excess of $2000^{\circ} \mathrm{C}$ is required before all the energy can be released. The restoration of the dislocations of carbon atoms can be observed over a wide temperature range from above room temperature up to $1500{ }^{\circ} \mathrm{C} .{ }^{78}$ The release of this energy can be triggered by any heat source. 


\section{Stored Energy and HTGR}

The basic feasibility of using graphite for the core components planned for the NGNP has been demonstrated in former HTGRs (e.g., DRAGON, Peach Bottom, AVR, THTR, and FSVR). These reactor designs represent two design categories: the pebble bed reactor (PBR) and the prismatic modular reactor (PMR). Current commercial examples of potential NGNP candidates are the SC-MHR from General Atomics and the HTR concept (ANTARES) from AREVA. Furthermore, the Japanese High-Temperature Engineering Test Reactor (HTTR) and the Chinese HTR are demonstrating the feasibility of the reactor components and materials needed for NGNP (HTTR reached a maximum coolant outlet temperature of $950{ }^{\circ} \mathrm{C}$ in April 2004, and again an extended operation at this temperature in March 2010). This cumulative experience has, in large part, formed our understanding of graphite's response within an HTGR environment.

Normal operating conditions have been formulated from reactor models based on both PBR and PMR designs. Normal steady-state temperatures and fluxes (dose) based on a $725^{\circ} \mathrm{C}$ coolant outlet for both reactors are summarized in Table 2. The range of expected dose is rather large and needs further refinement as designs mature since higher dose rates will lead to a need for greater testing and longer irradiation programs. Recent conceptual design information from the NGNP project indicates that nominal helium temperatures at the reactor inlet will be $260{ }^{\circ} \mathrm{C}$ and $250{ }^{\circ} \mathrm{C}$ for the prismatic block and pebble bed NGNP design options, respectively, ${ }^{9,8}$ and that maximum normal operating temperatures of the inlet helium at the top of the prismatic block core should not exceed $350{ }^{\circ} \mathrm{C} .{ }^{79} \mathrm{Fuel}$ and reflector blocks at locations near the top of the core may thus be irradiated at temperatures as low as $250{ }^{\circ} \mathrm{C}$.

Table 2. Reactor operating conditions ${ }^{15,9,8}$

\begin{tabular}{|l|l|l|}
\hline Parameter & PMR & PBR \\
\hline $\begin{array}{l}\text { Temperature (normal operations) } \\
\text { Reflector blocks }\end{array}$ & $250-1000^{\circ} \mathrm{C}$ & $250-1000{ }^{\circ} \mathrm{C}$ \\
Fuel centerline & $250-1100^{\circ} \mathrm{C}$ & $250{ }^{\circ} \mathrm{C}-1000{ }^{\circ} \mathrm{C}$ \\
\hline $\begin{array}{l}\text { Peak fast fluence }(>0.1 \mathrm{MeV}) \\
\quad \text { Reflector }\end{array}$ & $1.7-12.2 \times 10^{20} \mathrm{n} / \mathrm{cm}^{2}$ & $1.6-12.2 \times 10^{20} \mathrm{n} / \mathrm{cm}^{2}$ \\
Dose $\left(0.78 \times 10^{21} \mathrm{n} / \mathrm{cm}^{2}=1 \mathrm{dpa}\right)$ & $0.19-0.85 \mathrm{dpa} / \mathrm{FPY}$ & $0.18-0.85 \mathrm{dpa} / \mathrm{FPY}$ \\
\hline
\end{tabular}

$\mathrm{FPY}=$ full power year

The available published data on release of stored energy in irradiated graphite indicate that the amount of stored energy decreases with increasing irradiation temperature. However, such measurements and data are not available in open literature, on graphite irradiated at temperatures and/or doses relevant to NGNP reactor operation. Figure 36 shows the context for relating this phenomenon to normal operating conditions in both a PMR and a PBR core with respect to the irradiation conditions of graphite samples, which have been the subject of studies and tests of stored energy release. As it is observed, there is insufficient data on the behavior of stored energy for graphites irradiated under conditions relevant to the NGNP reactors. 


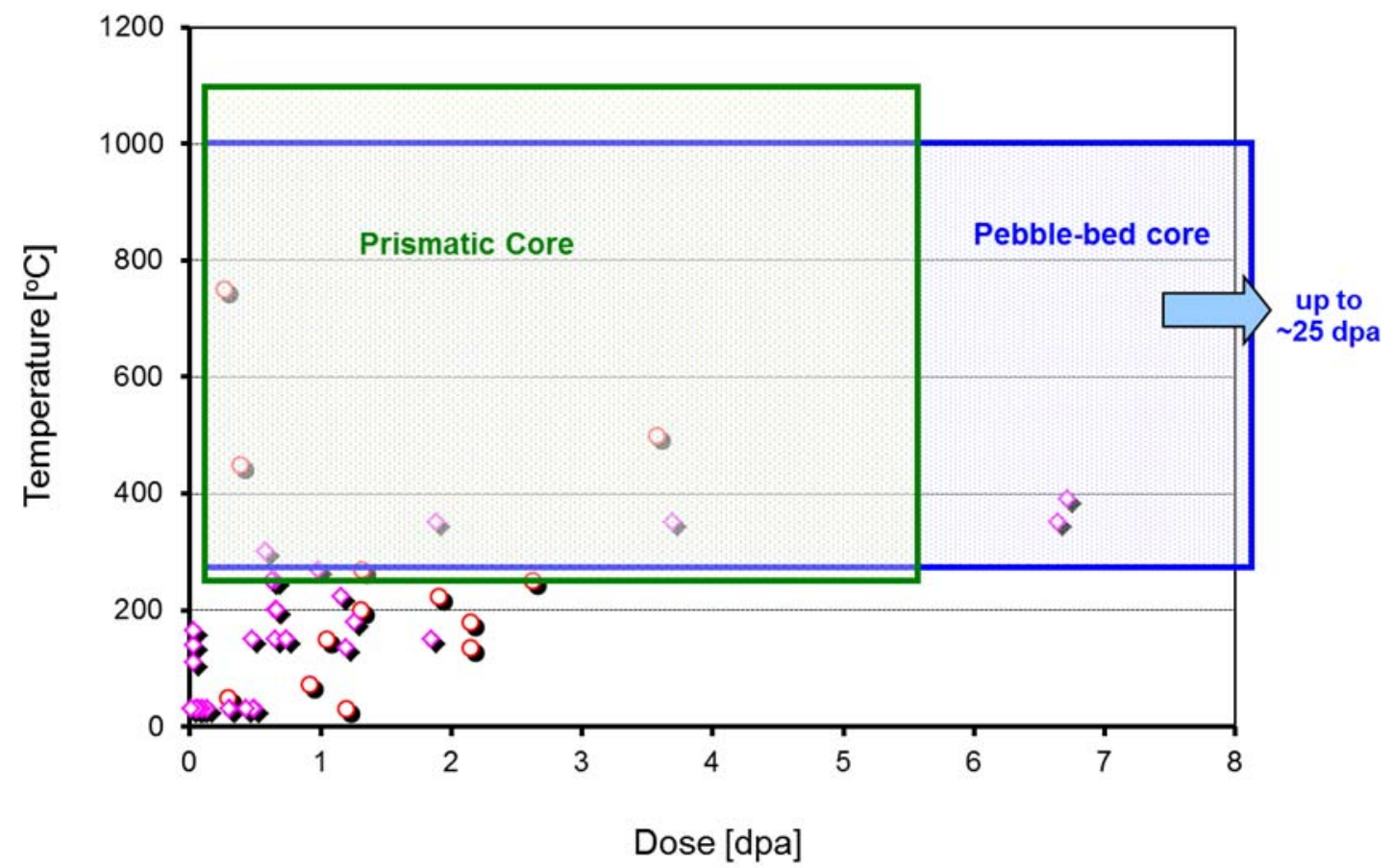

Figure 36. Irradiation conditions, dose and temperature, of graphites for which stored energy behavior has been characterized (circles: measurements of total stored energy; diamonds: measurements of release rate); shaded rectangles envelop the operating conditions for both prismatic and pebble-bed type reactors, being considered for the NGNP.

While the phenomenon of stored energy release is well documented for graphite irradiated at low temperatures (i.e., $T_{\text {irr }}<200{ }^{\circ} \mathrm{C}$ ), there are few data for the release of stored energy from graphites irradiated at higher temperatures, particularly those relevant to HTR operations (i.e., $T_{\text {irr }} \sim 250-1050{ }^{\circ} \mathrm{C}$ ). The work of Woods $^{63}$ and Rappeneau ${ }^{74}$ shows that stored energy accumulates at low irradiation temperatures $\left(T_{\text {irr }}<\right.$ $200{ }^{\circ} \mathrm{C}$ ) and releases progressively with increasing annealing temperature to $T_{\text {ann }} \sim 2000{ }^{\circ} \mathrm{C}$. There is a substantial release rate peak at an annealing temperature of $\sim 200^{\circ} \mathrm{C}$ and another at $T_{\text {ann }} \sim 1400{ }^{\circ} \mathrm{C}$. However, the magnitude of the $\sim 1400{ }^{\circ} \mathrm{C}$ peak appears to reduce with increasing irradiation temperature, and increases with neutron dose at a given irradiation temperature. There are no data for the rate of release of stored energy at high temperature $\left(T_{\text {ann }}>1000{ }^{\circ} \mathrm{C}\right)$ for graphites irradiated at HTR-relevant temperatures $\left(T_{\text {irr }} \sim 250-\right.$ $\left.1050^{\circ} \mathrm{C}\right)$.

It is well known that irradiation damage structures in graphite are larger and more complex when produced at higher irradiation temperatures. ${ }^{17}$ Thus the energy required to initiate annealing of these defects would be expected to be relatively large since such defects are typically stable. Moreover, Nightingale ${ }^{49}$ showed that the total stored energy in irradiated graphite saturates with increasing irradiation temperature. Nightingale ${ }^{49}$ showed (Figure 11) that at $T_{\text {irr }} \sim 450{ }^{\circ} \mathrm{C}$ the total stored energy was $<15 \mathrm{cal} / \mathrm{g}$ at a dose of $4500 \mathrm{MWD} / \mathrm{AT}$ ( $0.39 \mathrm{dpa}$ ) and increases very slowly with neutron dose. If a high temperature stored energy release peak exists for graphites irradiated at higher temperatures $\left(T_{\mathrm{irr}}>250^{\circ} \mathrm{C}\right)$, it would be very relevant in terms of the temperatures attained during HTR accident scenarios. During a loss-of-coolant or core conduction cool-down event, the graphite may reach temperatures approaching $1600{ }^{\circ} \mathrm{C}$, more than sufficient to release any energy that may be stored in the graphite as a result of irradiation at temperatures $>250{ }^{\circ} \mathrm{C}$ (normal HTR operating conditions). If such a release of energy occurred, would the effect of the specific heat 
of the graphite be significant? If the energy release occurred during an air-ingress accident, the amount of heat released probably would be small in comparison to the heat liberated by the exothermic air oxidation of graphite.

The stored energy data discussed here suggests that only small amounts of stored energy can accumulate at HTR-relevant operating temperatures and that if this energy were released at higher annealing temperatures, the rate of release probably would be small. However, there is no experimental data for stored energy release rate at high temperatures from graphite irradiated at HTR-relevant temperatures $\left(T_{\text {irr }} \sim 250\right.$ $1100^{\circ} \mathrm{C}$ ). Thus acquiring a series of experimental measurements appears prudent. 


\section{Summary}

A comprehensive review of the subject of stored energy in irradiated graphite was conducted. The following observations can be made based on the published data on measurements of stored energy and release rate of stored energy of irradiated graphite:

- The majority of the experimental data available on studies of stored energy and release of stored energy date back to the 1950 s and 1960s.

- The total stored energy in irradiated graphite, for a given irradiation temperature, increases with irradiation dose and appears to reach a saturation level with increasing irradiation dose. The rate accumulation of stored energy, as well as the saturation level, decreases with increasing irradiation temperature. Actual experimental data to support the trend is available for temperatures up to $450{ }^{\circ} \mathrm{C}$ and irradiation doses $<2 \mathrm{dpa}$.

- The release of stored energy exhibits a characteristic peak at around $200{ }^{\circ} \mathrm{C}$ for samples irradiated at low temperature; the peak will shift to higher temperatures and the magnitude of the release will diminish significantly as the irradiation temperature increases.

- There is some evidence of residual stored energy on samples annealed at temperatures up to $\sim 1000{ }^{\circ} \mathrm{C}$, indicating that higher temperatures are required to release the stored energy. Additional evidence was found, for graphite irradiated at a low temperature, that a second release peak is possible at temperatures between 1200 and $1500^{\circ} \mathrm{C}$.

In general terms, the results discussed here suggest that only small amounts of stored energy would accumulate in graphites irradiated at temperatures relevant to the operating conditions of HTGRs $\left(T_{\text {irr }} \sim 250\right.$ $1100{ }^{\circ} \mathrm{C}$ ) and that the rate of release of any stored energy would be small. However, due to the lack of experimental data for high temperature stored energy release from graphite irradiated at HTGR-relevant temperatures, it is recommended that a series of experimental measurements be pursued to close this knowledge gap. 


\section{Appendix A. Conversion Factors for Irradiation Dose}

The following conversion factors for irradiation dose were used throughout the document to consolidate various dose units into dpa. ${ }^{80}$

\begin{tabular}{|lc|}
\hline \multicolumn{1}{|c|}{ Units } & $\begin{array}{c}\text { Multiplier to convert } \\
\text { to dpa }\end{array}$ \\
\hline $\mathrm{n} / \mathrm{cm}^{2}[\mathrm{E}>50 \mathrm{keV}]$ & $6.8 \times 10^{-22}$ \\
$\mathrm{n} / \mathrm{cm}^{2}[\mathrm{E}>0.1 \mathrm{MeV}]$ & $7.3 \times 10^{-22}$ \\
$\mathrm{n} / \mathrm{cm}^{2}[\mathrm{E}>0.18 \mathrm{MeV}]$ & $8.9 \times 10^{-22}$ \\
$\mathrm{n} / \mathrm{cm}^{2}[\mathrm{E}>1.0 \mathrm{MeV}]$ & $14.5 \times 10^{-22}$ \\
$\mathrm{n} / \mathrm{cm}^{2}[\mathrm{EDN}]$ & $13.1 \times 10^{-22}$ \\
Calder Equivalent Dose, MWd/ATe* & $1.43 \times 10^{-4}$ \\
$*$ Assumes ${ }^{49} 1 \mathrm{MWd} / \mathrm{AT}($ Hanford $)=0.6 \mathrm{MWd} /$ Ate $(\mathrm{Calder})$
\end{tabular}




\section{References}

${ }^{1}$ N. C. Gallego, T. D. Burchell, and M. Srinivasan, Milestone Report on the Workshop on Nuclear Graphite Research, ORNL/NRC/LTR-09/03, Oak Ridge National Laboratory, September 2009.

${ }^{2}$ D. A. Powers, Trip Report-Travel by D. A. Powers to Attend the High-Temperature Gas-Cooled Reactor Safety and Research Issues Workshop, Rockville, Md., October 10-12, 2001, ADAMS Accession Number ML020450645.

${ }^{3}$ D. G. Schweitzer, D. H. Gurinsky, E. Kaplan, and C. Sastre, A Safety Assessment of the Use of Graphite in Nuclear Reactors Licensed by the U.S. NRC, NUREG/CR-4981, BNL-NUREG-52092, September 1987.

${ }^{4}$ Next Generation Nuclear Plant, http://www.nextgenerationnuclearplant.com/

${ }^{5}$ W. R. Corwin et al., Generation IV Reactors Integrated Materials Technology Program Plan: Focus on Very High Temperature Reactors Materials, ORNL/TM-2008/129, Oak Ridge National Laboratory, 2008.

${ }^{6}$ W. Windes, T. Burchell, and R. Bratton, Graphite Technology Development Plan, INL/EXT-07-13165, September 2007.

7 "PBMR postponed," World Nuclear News, September 11, 2009, http://www.world-nuclear-news.org/NN-PBMR_postponed-1109092.html

${ }^{8}$ L. Lommers (AREVA), "Pebble Bed Technology Update," presented at VHTR R\&D FY11 Technical Review Meeting, April 26, 2011.

${ }^{9}$ J. Saurwein (General Atomics), "Prismatic HTGR Conceptual Design for the NGNP Project," presented at VHTR R\&D FY11 Technical Review Meeting, April 26, 2011.

${ }^{10}$ The Status of Graphite Development for Gas Cooled Reactors, Proceedings of a Specialists Meeting Held in Tokai-mura, Japan, 9-12 September 1991, IAEA-TECDOC-690, ISSN 1011-4289, printed by the IAEA in Austria, February 1993.

${ }^{11}$ Graphite Moderator Lifecycle Behaviour, Proceedings of a Specialists Meeting held in Bath, United Kingdom, 24-27 September 1995, IAEA-TECDOC-901, ISSN 1011-4289, printed by the IAEA in Austria, August 1996.

${ }^{12}$ B. J. Marsden (Editor), Irradiation Damage in Graphite Due to Fast Neutrons in Fission and Fusion Systems, IAEA_TECDOC-1154, September 2000

${ }^{13}$ HTTR in Japan, http://httr.jaea.go.jp/eng/index.html

${ }^{14}$ HTR-10 in China, http://www.inet.tsinghua.edu.cn/english2/academics.htm 
${ }^{15}$ Graphite Technology Development Plan, Document PLN-2497, Revision 1, Project 23747, Idaho National Laboratory, October 4, 2010.

${ }^{16}$ G. B. Engle and B. T. Kelly, "Radiation damage of graphite in fission and fusion reactor systems," J. Nucl. Mater. 122\&123, 122-129 (1984).

${ }^{17}$ B. T. Kelly, Physics of Graphite, Applied Science Publishers, London, 1981.

${ }^{18}$ G. B. Engle and W. P. Eatherly, "Irradiation behavior of graphite at high temperatures," High Temp. High Press. 4, 119-158 (1972).

${ }^{19}$ R. J. Price, "High-temperature neutron irradiation of highly oriented carbons and graphites," Carbon 12, 159-169 (1974).

${ }^{20}$ T. D. Burchell and L. L. Snead, "The effect of neutron irradiation damage on the properties of grade NBG10 graphite," J. Nucl. Mater. 371, 18-27 (2007).

${ }^{21}$ J. W. H. Simmons, Radiation Damage in Graphite, Pergamon Press, Oxford, UK, 1965.

22 J. E. Brocklehurst and B. T. Kelly, "Analysis of the dimensional changes and structural changes in polycrystalline graphite under fast neutron irradiation," Carbon 31, 155-178 (1993).

${ }^{23}$ B. T. Kelly and T. D. Burchell, "Structure-related property changes in polycrystalline graphite under neutron irradiation," Carbon 32, 499-505 (1994).

${ }^{24}$ M. O. Tucker, A. P. G. Rose, and T. D. Burchell, "The fracture of polygranular graphites," Carbon 24, 581-602 (1986).

${ }^{25}$ T. D. Burchell, “A microstructurally based fracture model for polygranular graphites," Carbon 34, 297-316 (1996).

${ }^{26}$ T. D. Burchell and W. P. Eatherly, "The effects of radiation damage on the properties of GraphNOL N3M," J. Nucl. Mater. 170-181, 205-208 (1991).

${ }^{27}$ T. D. Burchell, "Thermal properties and nuclear energy applications," in Graphite and Precursors, ed. P. Delhaès, Gordon \& Breach Science Publishers, The Netherlands, 2001.

${ }^{28}$ T. D. Burchell, "Radiation damage in carbon materials," in Physical Processes of the Interaction of Fusion Plasmas with Solids, ed. W. O. Hofer and J. Roth, Academic Press, San Diego, USA, 1996.

${ }^{29}$ T. D. Burchell, "Radiation effects in graphite and carbon-based materials," MRS Bulletin XXII, 29-35 (1997).

${ }^{30}$ R. Taylor, B. T. Kelly, and K. E. Gilchrist, "The thermal conductivity of fast neutron irradiated graphite," J. Phys. Chem. Solids 30, 2251-2267 (1969). 
${ }^{31}$ L. L. Snead and T. D. Burchell, "Thermal conductivity degradation of graphite due to neutron irradiation at low temperature," J. Nucl. Mater. 224, 222-229 (1995).

${ }^{32}$ J. C. Bell, H. Bridge, A. H. Cottrell, G. B. Greenough, W. N. Reynolds, and J. H. W. Simmons, "Stored energy in the graphite of power-producing reactor," Philos. Trans. Roy. Soc. London Ser. A Math. Phys. Sci. 254(1043), 361-395 (1962).

${ }^{33}$ B. T. Kelly, "Nuclear reactor moderator materials," in Materials Science and Technology A Comprehensive Treatment: Vol. 10A, Nuclear Materials, ed. R. W. Cahn, P. Haasen, and E. J. Kramer, Wiley VCH, Weinheim, 1994.

${ }^{34}$ T. D. Burchell, "Nuclear Graphite," Chapter 4.10 in Comprehensive Nuclear materials, Rudy Konings, Editor, Elsevier, 2012.

${ }^{35}$ P. A. Thrower and R. M. Meyer, "Review article: point defects and self diffusion in graphite," Phys. Status Solidi (a) 47, 11-37 (1978).

${ }^{36}$ F. Banhart, "Irradiation effects in carbon nanostructures," Rep. Prog. Phys. 62, 1181-1221 (1999).

${ }^{37}$ R. H. Telling and M. I. Heggie, "Radiation defects in graphite," Philosoph. Magazine 87, 4797-4846 (2007).

${ }^{38}$ B. D. Hehr, A. I. Hawari, and V. H. Gillette, "Molecular dynamic simulations of graphite at high temperatures," Nucl. Technol. 160, 251-256 (2007).

${ }^{39}$ K. Nakai, C. Kinoshita, and A. Matsunaga, "A study of amorphization and microstructural evolution of graphite under electron or ion irradiation," Ultramicroscopy 39, 361-368 (1991).

${ }^{40}$ P. R. Wallace, "Configuration of interstitial atoms in irradiated graphite," Solid State Commun. 4, 521-524 (1966).

${ }^{41}$ G. M. Jenkins, "Deformation mechanisms in carbon," Chem. Phys. Carbon 11, 189-242 (1973).

${ }^{42}$ K. Urita, K. Suenaga, T. Sugai, H. Shinohara, and S. Iijima, "In Situ Observation of Thermal Relaxation of Interstitial-Vacancy Pair Defects in a Graphite Gap," Phys. Rev. Lett. 94, 155502 (2005).

${ }^{43}$ T. Tanabe, "Radiation damage of graphite - degradation of material parameters and defect structures," Physica Scripta T64, 7-16 (1996).

${ }^{44}$ J. Koike and D. F. Pedraza, "Dimensional changes in highly oriented pyrolytic graphite due to electronirradiation,” J. Mater. Res. 9, 1899-1907 (1994).

${ }^{45}$ G. M. Jenkins, "Basal plane distortion in pyrolytic carbon," Carbon 7, 9-14 (1969).

${ }^{46}$ P. J. Ouseph, "Observation of Prismatic Dislocation Loops in Graphite,” Phys. Stat. Sol. (a) 169, 25-32 (1998). 
${ }^{47}$ S. Amelinckx, P. Dellavignette, and M. Heerschap, "Dislocations and stacking faults in graphite," Chem. Phys. Carbon 1, 1-71 (1965).

${ }^{48}$ J. H. W. Simmons, Radiation Damage in Graphite, Pergamon Press, 1965.

${ }^{49}$ R. E. Nightingale, Nuclear Graphite, Academic Press, 1962.

${ }^{50}$ E. J. Prosen and F. D. Rossini, "Some experimental data on the heats of combustion of benzoic acid and carbon (graphite)," J. Res. Nat. Bur. Stand. 33, 439-446 (1944).

${ }^{51}$ G. F. Jackson and D. Cordall, The Windscale Bomb Calorimeter, British report IG-189 (RD/W), 1959.

${ }^{52}$ E. J. Prosen and D. R. Valent, The Energy Content of Irradiated Graphite Samples, reports NBS-D-101 to NBS-D-110, 1951.

${ }^{53}$ W. A. Fraser and E. J. Prosen, Heats of Combustion of Irradiated Graphite and Diamond Samples, report NBS-D-111, 1952.

${ }^{54}$ L. A. Quaterman and W. L. Primak, The Heat of Reaction of Irradiated Graphite with Potassium, report ANL-4749, U.S. Atomic Energy Commission, 1952.

${ }^{55}$ J. J. Newgard, “Simple semiempirical model for neutron induced stored energy in graphite," J. Appl. Phys. 30, 1449-1451 (1959).

${ }^{56}$ R. E. Nightingale, J. M. Davidson, and W. A. Snyder, "Damage to graphite irradiated up to $1000^{\circ}$ C," p. 295 in Proceedings of the Second United Nations International Conference on Peaceful Uses of Atomic Energy, Geneva, 1958, vol. 7, United Nations, New York, 1959.

${ }^{57}$ A. H. Cottrell, J. C. Bell, G. B. Greenough, W. M. Lomer, and J. H. W. Simmons, "Theory of annealing kinetics applied to the release of stored energy from irradiated graphite in air-cooled reactors," pp. 315-327 in Proceedings of the Second United Nations International Conference on Peaceful Uses of Atomic Energy, Geneva, 1958, vol. 7, United Nations, New York, 1959.

${ }^{58}$ M. S. Wechsler, R. R. Coltman, R. H. Kernohan, and M. C. Wittels, "Use of a radiation calorimeter in measurement of stored energy in irradiated graphite," J. Appl. Phys. 30, 42-45 (1959).

${ }^{59}$ J. L. Dickson, G. H. Kinchin, R. F. Jackson, W. M. Lomer, and J. H. W. Simmons, "BEPO Wigner energy release," pp. 250-281 in Proceedings of the Second United Nations International Conference on Peaceful Uses of Atomic Energy, Geneva, 1958, vol. 7, United Nations, New York, 1959.

${ }^{60}$ C. Sykes, "Methods for investigating thermal changes occurring during transformations in a solid solution," Proc. Roy. Soc. A148 (1935).

${ }^{61}$ T. J. Neubert and R. B. Lees, "Stored energy in neutron-bombarded graphite," Nucl. Sci. Eng. 2(6), 748767 (1957). 
${ }^{62}$ G. H. Kinchin, "Effects of irradiation on graphite," pp. 472-478 in 1955 International Conference on the Peaceful Uses of Atomic Energy, vol. 7, United Nations, New York, 1956.

${ }^{63}$ W. K. Woods, L. P. Bupp, and J. F. Fletcher, "Irradiation damage to artificial graphite," pp. 455-471 in 1955 International Conference on the Peaceful Uses of Atomic Energy, vol. 7, United Nations, New York, 1956.

${ }^{64}$ A. T. D. Butland and R. J. Maddison, "The specific heat of graphite: and evaluation of measurements," J. Nucl. Mater. 49, 45 (1973/74).

${ }^{65}$ H. Bridge, B. T. Kelly, and B. S. Gray, "Stored energy and dimensional changes in reactor graphite,” p. 289 in Proceedings of the Fifth Conference on Carbon, vol. 1, Pergamon Press, 1961.

${ }^{66}$ J. Rappeneau, "Energie emmagasinee par le graphite irradie. Effets de la temperature d'irradiation," J. Nucl. Mat. 6(1), 107-118 (1962).

${ }^{67} \mathrm{H}$. Bridge and D. Mottershead, "A relation between irradiation temperature, flux intensity and starttemperature for stored energy release in irradiated graphite," J. Nucl. Mater. 20, 281 (1966).

${ }^{68}$ R. J. Price, "High-temperature neutron irradiation of highly oriented carbons and graphites," Carbon 12, 159-169 (1974).

${ }^{69}$ J. C. Bokros, G. L. Guthrie, and D. W. Stevens, "Irradiation-induced dimensional changes in imperfect graphite crystals," Carbon 9, 349-353 (1971).

${ }^{70}$ B. T. Kelly and J. E. Brocklehurst, "High dose fast neutron irradiation of highly oriented pyrolytic graphite," Carbon 9, 783-789 (1971).

${ }^{71}$ B. T. Kelly, J. E. Brocklehurst, and K. E. Gilchrist, "Stored energy in irradiated graphite," Extended Abstracts of the $14^{\text {th }}$ Biennial Conference on Carbon, University Park, PA, June 25-29, 1979.

${ }^{72}$ G. R. Hennig and J. E. Hove, "Interpretation of radiation damage to graphite," pp. 666-675 in 1955 International Conference on the Peaceful Uses of Atomic Energy, vol. 7, United Nations, New York, 1956.

${ }^{73}$ R. W. Powell, R. A. Meyer and R. G. Bourdeau, "Control of radiation effects in a graphite reactor structure," pp. 282-294 in 1958 Proceedings of the Second United Nations International Conference on Peaceful Uses of Atomic Energy, Geneva, 1958, vol. 7, United Nations, New York, 1959.

${ }^{74}$ J. Rappeneau, J. L. Taupin, and J. Grehier, "Energy released at high temperature by irradiated graphite," Carbon 4(1), 115-124 (1966).

${ }^{75}$ Sir William Penney, B. F. J. Schonland, J. M. Kay, and J. Diamond, “Accident at Windscale No. 1 Pile on $10^{\text {th }}$ October 1957," presented to Parliament by the Prime Minister by command of Her Majesty, London, November 1957. 
${ }^{76}$ R. Wakeford, “The Windscale reactor accident—50 years on," J. Radiol. Prot. 27, 211-215 (2007).

${ }^{77}$ R. P. Wichner and S. J. Ball, Potential Damage to Gas-Cooled Graphite Reactors Due to Severe Accidents, ORNL/TM-13661, Oak Ridge National Laboratory, 1999.

${ }^{78}$ W. Botzem and J. Worner, "Inert annealing of irradiated graphite by inductive heating," pp. 92-104 in Proceedings of IAEC Technical Committee Meeting on Nuclear Graphite Waste Management (TCMManchester99), held Oct. 18-20, 1999, in Manchester, United Kingdom, International Atomic Energy Agency, 2001.

79 General Atomics, "Prismatic HTGR Core Design Description," Module 5a, presented at HTGR Technology Course for the U.S. Nuclear Regulatory Commission, May 24-27, 2010.

${ }^{80}$ T. D. Burchell (Editor), Carbon Materials for Advanced Technologies, Pergamon Press, 1999. 